\title{
THE EMPIRICAL CAPM: ESTIMATION AND IMPLICATIONS FOR THE REGULATORY COST OF CAPITAL
}

by

Wei Zhang

\author{
A thesis \\ submitted to the Victoria University of Wellington \\ in fulfilment of the \\ requirements for the degree of \\ Master of Commerce and Administration \\ in Finance \\ Victoria University of Wellington \\ 2008
}




\begin{abstract}
In calculating the cost of capital for regulated businesses, the New Zealand Commerce Commission uses the Capital Asset Pricing Model to estimate the cost of the equity component of capital, a procedure that involves assuming particular values for unobservable key parameters. This thesis proposes, instead, to estimate these parameters from market data. The principal result is that estimates of these parameters differ significantly from the values assumed by the Commerce Commission. Applying these estimates to two recent cases involving the electricity line and gas pipeline businesses, the estimated costs of capital for the entities involved are 3.5\% to $5.5 \%$ more than those obtained by the Commission, but the associated confidence intervals are wider. One implication of these findings is that the Commissions approach systematically understates the uncertainty surrounding cost of capital estimates.
\end{abstract}




\section{Acknowledgement}

I am greatly indebted to my supervisors Prof Glenn Boyle and Prof Graeme Guthrie for their consistent guiding and encouraging throughout the entire master year.

I thank Ian Smith from Investment Research Group Ltd for providing the New Zealand stock price database, and thank Charlotte Clements and Melanie Mills from the library of the Victoria University of Wellington for facilitating the transferring of the database. 


\section{Contents}

1 Introduction 1

2 Review and Methodology 10

2.1 A review on the methodology for estimating the empirical form of the CAPM . . . . . . . . . . . 10

2.1.1 The FM method using the estimated stock betas as the independent variable (FM SB) . . . . . . . . 12

2.1.2 The FM method using the estimated portfolio betas as the independent variable (FM PB) . . . . . . . . . 12

2.2 Methodology in detail . . . . . . . . . . . . . 15

2.2.1 A detailed description of the implementation of the FM method using stock betas as the independent variable ..................... 15

2.2.2 A detailed description of the implementation of the FM method using portfolio betas as the independent variable ..................... 18 
CONTENTS

3 Data for estimating the empirical CAPM 22

3.1 Stock return data . . . . . . . . . . . . . . 22

3.2 Proxies for the market portfolio and the risk free rate . . . 26

3.3 Market capitalization data . . . . . . . . . . . . 32

4 Estimation Results $\quad 35$

4.1 Estimation results: the FM method with the stock betas (SB) as the independent variable $(\mathrm{FM} \mathrm{SB}) \ldots \ldots . \ldots 35$

4.2 Estimation results: the FM method with the portfolio betas (PB) as the independent variable (FM PB) . . . . . . . . 48

4.2.1 The baseline case result: monthly data with the OLS beta-estimation method . . . . . . . . . . . 48

4.2.2 Robust check I: monthly data with the SW beta-estimation method ................... 56

4.2.3 Robust check II: the FM method with portfolio betas as the independent variable with the weekly data . . 65

4.3 A discussion on all estimation results $\ldots \ldots \ldots 73$

5 The implication of the empirical CAPM $\quad 77$

5.1 Estimating the WACC using the empirical CAPM . . . . . 77

5.2 Two case studies . . . . . . . . . . . . . . . . . . . . 79

6 Conclusion $\quad 92$

$\begin{array}{llr}7 & \text { Appendix } & 94\end{array}$ 


\section{List of Figures}

3.1 NZSE-40, NZX-50 and NZX All Index from 1990 to 2006 . . 27

3.2 The 10-year government bond yield and the approximate monthly capital gain returns on the bond from 1990 to 2006 at the monthly frequency . . . . . . . . . . . . . 30

4.1 The Histogram of $\hat{\gamma}_{i, t}$ estimated where the OLS method is used to estimate stock betas . . . . . . . . . . . . 39

4.2 The plot of the empirical and theoretical CAPM - FM SB: OLS and SW . . . . . . . . . . . . . . . . 47

4.3 The Histogram of $\hat{\gamma}_{i, t}-$ FM PB: OLS+OLS . . . . . . . . . 50

4.4 The plot of the empirical and theoretical CAPM - FM PB:

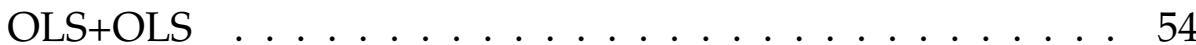

4.5 The plot of the empirical and theoretical forms of the CAPM - FM PB: SW+SW and SW+OLS . . . . . . . . . . . . . . . . 64

4.6 The plot of the empirical and theoretical CAPM - a summary (weekly data) . . . . . . . . . . . . . 72 
5.1 The distribution of the WACC calculated using the theoretical and empirical CAPM . . . . . . . . . . . . . . . . . 89

7.1 The Histogram of $\hat{\gamma}_{i, t}$ estimated where the SW method is used to estimate stock betas . . . . . . . . . . . . . . 96

7.2 The plot of the empirical and theoretical forms of the CAPM - a summary (with an alternative risk free rate) . . . . . . . . 102

7.3 The distribution of the WACC calculated using the theoretical and empirical CAPM (with an alternative risk free rate) 107 


\section{List of Tables}

2.1 An illustration of the work mechanism of the FM method using stock betas as the independent variable . . . . . . . . 17

2.2 An illustration of how to calculated portfolio returns . . . . 19

2.3 An illustration of the data panel for estimating $\gamma_{i, t} \ldots \ldots 21$

3.1 The Number of stocks with returns available at each month from Jan-1990 to Dec-2006 . . . . . . . . . . . . . . . 23

3.2 Thin trading problem illustration from 1990 to 2006 . . . . . 25

3.3 Summary statistics of proxies for $R_{m}$ and $R_{f} \ldots \ldots$. . . . 31

3.4 Market capitalization data: large companies dominate the New Zealand Stock Exchange . . . . . . . . . . . . . . 34

4.1 Stock betas estimated using the OLS method with monthly

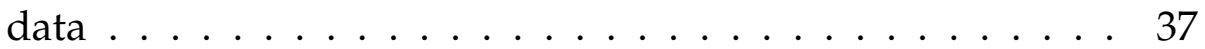

4.2 The summary of $\gamma_{i}^{\star}-$ FM SB: OLS and SW . . . . . . . . . . 41 
4.3 The 95\% confidence interval of the estimated annual taxadjusted excess returns for two special securities: $\beta=0$ and 1 - FM SB: OLS and SW . . . . . . . . . . . . . . . 44

4.4 The summary of portfolio betas estimated using the OLS method ......................... 49

4.5 The summary of $\gamma_{i}^{\star}$ - FM PB: OLS+OLS . . . . . . . . . 51

4.6 The 95\% confidence interval of the estimated annual taxadjusted excess returns for two special securities: $\beta=0$ and 1 - FM PB: OLS+OLS . . . . . . . . . . . . . . . . . 53

4.7 The summary of $\gamma_{i}^{\star}-$ FM SB: OLS and SW; FM PB: OLS+OLS, $\mathrm{SW}+\mathrm{SW}$ and $\mathrm{SW}+\mathrm{OLS} \ldots \ldots \ldots \ldots$

4.8 The 95\% confidence interval of the estimated annual taxadjusted excess returns for two special securities: $\beta=0$ and 1 - a summary . . . . . . . . . . . . . . 61

4.9 The summary of $\gamma_{i}^{\star}-$ FM PB: OLS+OLS, SW+SW and SW+OLS (weekly data) . . . . . . . . . . . . . . . . 68

4.10 The 95\% confidence interval of estimated annual tax-adjusted excess returns for two special securities: $\beta=0$ and $1-\mathrm{a}$ summary (weekly data) . . . . . . . . . . . 70

4.11 The summary of all methodologies and data used for estimating the empirical CAPM . . . . . . . . . . . 74

5.1 The summary of the annual cost of equity and its standard errors esitmated using the empirical CAPM . . . . . . . . 81

5.2 The WACC and its 95\% confidence interval for the electricity line business estimated using the empirical CAPM . . . . 84 
5.3 The probability of the underestimation of the Commission's WACC: case study $1 \ldots \ldots \ldots \ldots$

5.4 The WACC and its 95\% confidence interval for gas pipeline businesses estimated using the empirical CAPM . . . . . . 87

5.5 The probability of the underestimation of the Commission's WACC: case study $2 \ldots \ldots \ldots$. . . . . . . . . . 90

7.1 Stock betas estimated using the SW method with monthly

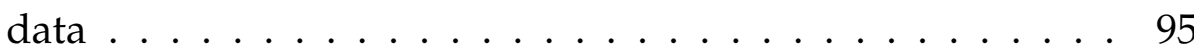

7.2 The summary of portfolio betas estimated using the combination of the SW and OLS method . . . . . . . . . . 97

7.3 Stock betas estimated using the OLS and SW methods with weekly data . . . . . . . . . . . . . . . . 98

7.4 The summary of portfolio betas estimated using combinations of the SW and OLS methods with weekly data . . . . . 99

7.5 The summary of $\gamma_{i}^{\star}-$ FM SB: OLS and SW; FM PB: OLS+OLS, SW+SW and SW+OLS (with the alternative risk free rate) . 100

7.6 The 95\% confidence interval of the estimated annual taxadjusted excess returns for two special securities: $\beta=0$ and 1 - a summary (with the alternative risk free rate) . . . . . . . 101

7.7 The WACC of electricity line businesses and gas pipeline businesses estimated using the empirical CAPM - a summary (with an alternative risk free rate) . . . . . . . . . 105

7.8 The probability of the underestimation of the Commission's WACC for both studies - a summary (with alternative risk free rate $\ldots \ldots \ldots \ldots \ldots \ldots$ 


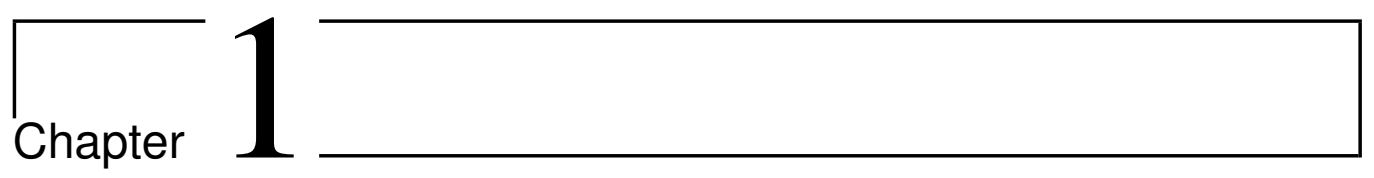

\section{Introduction}

The New Zealand Commerce Commission (the Commission) is a competition regulatory agency, whose main duty is to promote a competitive market environment for businesses, so that consumers can benefit from lower prices, better quality products and a greater range of choices. One of the Commission's ways of achieving this goal is to impose controls over the supply of specified goods and services. Under Commerce Act 1986, the "specified goods and services" refer to electricity lines and gas pipelines, while under Dairy Industry Restructuring Act 2001 and Telecommunications Act 2001, they refer to raw milk and telecommunication services.

The cost of capital is one of the key parameters that the Commission uses to impose the control on regulated firms and industries. For electricity line businesses, the cost of capital is used as a screening mechanism identifier for businesses' future performance and a tool for assessing returns (Commerce Commission (2005a)). For gas pipeline businesses and telecommunication service providers, it assists with the calculation of the authorised 
prices and revenues. For raw milk provider(s) such as Fonterra, it is used as a discount rate to determine the company's share price and, the supply and pricing of the raw milk.

The Commission regards firms' cost of capital as an important multifunctional decision making tool for regulating businesses. Setting an appropriate cost of capital for regulated businesses is closely related to the development of the New Zealand economy. If the cost of capital is set too high for a business, it is very likely that this business will attract excess funds, which may reduce investments for other types of businesses, hence, results an unevenly developed economy. Moreover, as the cost of capital is an important price setting parameter, a high value will increase the price of products, and consequently harms consumers. On the other hand, if the cost of capital is set too low, the reverse may happen. A low allocated cost of capital will discourage investments, which may lead to the capital shortage in the long-run. The supply side may shrink due to the capital shortage. With the demand side remaining, the price will increase and consumers will be worse off.

Given the importance of the role played by the cost of capital, the Commission has released a draft guideline which specifically explains the method of its calculation (Commerce Commission (2005a)). The "capital", according to the guideline, refers to the financial resources invested in a business or a project with a delayed payback and there are two formats, which are the debt capital and the equity capital. In order to incorporate the cost of both capitals to determine the overall cost of capital for a firm, the Commission uses the weighted average cost of capital (WACC), and it is for- 
mulated as

$$
\mathrm{WACC}=R_{e}(1-L)+R_{d}\left(1-T_{c}\right) L,
$$

where

$L$ is the financial leverage ratio

$R_{d}$ is the cost of debt

$R_{e}$ is the cost of equity capital

$T_{c}$ is the corporate tax rate

There are two types of components in (1.1) - observable components and unobservable ones. The observable ones are the financial leverage ratio, the corporate tax rate and the cost of debt ${ }^{1}$. The cost of equity is, on the other hand, unobservable, for whose estimation the Commission uses the capital asset pricing model (CAPM). The original version of the model is developed by Sharpe (1964) and Lintner (1965), which is formulated as

$$
E\left(R_{e}\right)=R_{f}+\beta_{e}\left[E\left(R_{m}\right)-R_{f}\right],
$$

where

$\beta_{e}$ is the equity beta

$R_{f}$ is the risk free rate

$E\left(R_{m}\right)$ is the expect return on the market portfolio

\footnotetext{
${ }^{1}$ Strictly speaking, the cost of debt is not directly observable, i.e, it is the expected rate of return (which is unobservable), not the promised rate of return on bonds (which is what is used in practice). However, the difference between the two is likely to be small given normal default probabilities.
} 
To better suit the tax regime in New Zealand, the Commission adopts a simplified tax adjusted version of CAPM, known as the "Brennan-Lally model", based on Brennan (1970) and developed by Lally (1992) and Cliffe and Marsden $(1992)^{2}$, which is presented as

$$
E\left(R_{e}\right)=R_{f}\left(1-T_{I}\right)+\beta_{e}\left[E\left(R_{m}\right)-R_{f}\left(1-T_{I}\right)\right]
$$

where $T_{I}$ is the average (across equity investors) of their marginal tax rates on ordinary income while other components remain.

In essence, the "Brennan-Lally model" employs all the standard CAPM assumptions - such as one-period mean-variance investors having rational expectations, - but takes account of personal tax rates that differ across both investors and sources of income, and adjusts for the effect of any imputation credits attached to dividends. Most importantly, both models assert that the company beta is the only risk that is priced.

The Commission calculates the WACC in a straightforward way. First, it observes, approximates or estimates the parameters appearing in (1.1) $R_{f}, \beta_{e}, T_{I}$, and the market risk premium. Second, it substitutes these estimates into (1.3) to yield the estimated cost of equity. Thirdly, it substitutes this cost of equity together with other relevant variables into (1.1) in order to arrive at an estimate of the cost of capital ${ }^{3}$. Although a standard error

\footnotetext{
${ }^{2}$ This simplified version assumes that dividends are fully imputed and investors have the ability to fully utilise them; the average investor faces a marginal tax rate on interest (currently of 33\%); and that capital gains are not taxed. The model also assumes that domestic equity markets are closed to foreign investors

${ }^{3}$ For example, in the Commission's report on estimating the WACC for electricity line businesses (Commerce Commission (2005b)), the relevant parameter values are $R_{f}=$
} 
for this estimate is reported, this only attempts to take into account of possible errors in the input variables and ignores the potential for specfication error in the model used to estimate the cost of equity.

In estimating the cost of equity, the Commission uses a "strict" version of the CAPM. That is, it assumes not only that beta is the only priced risk and that the relationship between beta and expected return is linear, but also that the intercept of this relationship is equal to the riskfree rate of interest (or zero if the expected return variable is expressed in excess terms) and the slope equal to the market risk premium. Clearly, any or all of these assumptions may be violated in practice.

Many studies have directly tested the "strict" CAPM (e.g., Black et al. (1972), Fama and MacBeth (1973), Banz (1981), BASU (1983), Fama and French (1992), Kan and Zhang (1999) and Bryant and Eleswarapu (1997)). Testing the CAPM involves estimating the regression model

$$
\tilde{R}_{i}=\gamma_{0}+\gamma_{1} \hat{\beta}_{i}+e_{i}
$$

where

$$
\tilde{R}_{i}=R_{i}-R_{f} \text { is the excess return of security } i
$$

$6.3 \%, M R P_{\text {tax-adjusted }}=7 \%, \beta_{e}=0.67, T_{I}=33 \%, T_{c}=33 \%, L=40 \%$ and $k_{d}=7.3 \%$. By applying (1.3), the cost of equity is calculated as

$$
\hat{k}_{e}=6.3 \%(1-33 \%)+0.67 \times 7 \%=8.9 \%
$$

The cost of capital is then computed applying (1.1)

$$
\widehat{\mathrm{WACC}}=8.9 \%(1-40 \%)+7.3 \%(1-33 \%) 40 \%=7.29 \%
$$


$\hat{\beta}_{i}$ is the estimated beta of security $i$

and testing the following hypotheses:

$H_{0}: \gamma_{0}=0$

$H_{0}: \gamma_{1}=E\left(R_{m}\right)-R_{f}$

These hypotheses have been consistently rejected. Black et al. (1972) and Fama and MacBeth (1973) found no significantly positive empirical relationship between systematic risks and returns. Fama and French (1992) went further and found that returns are unrelated to beta once other firmspecific features, such as size and market-to-book, are controlled for. Using New Zealand data, Bryant and Eleswarapu (1997) obtain similar results. Overall, both hypotheses above appear to be systematically violated. There are several possible reasons for the rejection of the null hypothesises. It could be due to the failure of the CAPM itself for some of the unrealistic assumptions (e.g., perfectly efficient capital market, existence of risk free rate and investors homogeneous and rational expectations) are unable to stand up in a real world situation. It also could be that the CAPM may not be testable. As Roll (1977) pointed out, given the true market portfolio is not observable, tests on the CAPM are actually assessing whether the proxy for the market portfolio is mean-variance efficient or not.

Whatever the exact reason or reasons for the failure of the strict form of the CAPM to hold empirically, its rejection must cast some doubt on its usefulness for cost of capital calculations. In this thesis, I investigate this issue in the following way: rather than impose the requirements that $\gamma_{0}=0$ and $\gamma_{1}=E\left(R_{m}\right)-R_{f}$, I instead estimate $\gamma_{0}$ and $\gamma_{1}$ from market data, thus 
obtaining an "empirical" form of the CAPM (the terminology I use to distinguish my approach from the theoretical, or "strict", form). That is, I estimate:

$$
\tilde{R}_{i}=\gamma_{0}^{\star}+\gamma_{1}^{\star} \beta_{i},
$$

where, in order to maintain comparability with the Commission

$$
\tilde{R}_{i}=R_{i}-\left(1-T_{I}\right) R_{f}
$$

$\gamma_{0}^{\star}$ and $\gamma_{1}^{\star}$ are the respective market estimates of $\gamma_{0}$ and $\gamma_{1}$. I then use this empirical form to obtain a cost of equity estimate (and subsequently a WACC) and compare this with the corresponding estimate obtained from the strict form. That is, I calculate

$$
\begin{gathered}
\hat{R}_{e}=\left(1-T_{I}\right) R_{f}+\gamma_{0}^{\star}+\gamma_{1}^{\star} \beta_{e} \\
\widehat{\mathrm{WACC}}=\hat{R}_{e}(1-L)+R_{d}\left(1-T_{c}\right) L
\end{gathered}
$$

When calculating the $\widehat{\mathrm{WACC}}$, I assume all components except for $\hat{R}_{e}$ can be estimated without error. The reason of doing so is for better examination of the effect solely arising from the use of the "empirical" form of the CAPM.

Note that this approach is not fundamentally different to that followed by the Commission, but is instead simply an alternative, and more general, way of estimating parameters that the insights of the CAPM suggest are important. For example, the Commission sets $\gamma_{1}$ equal to the market risk premium and then proceeds to estimate this latter variable from historical data; my approach essentially cuts out the intermediate step - I estimate $\gamma_{1}$ directly from data without first requiring it to be equal to the market risk 
premium. Of course, if $\gamma_{0}^{\star}=0$ and $\gamma_{1}^{\star}=E\left(R_{m}\right)-R_{f}\left(1-T_{I}\right)$, the empirical CAPM collapses to its theoretical "Brennan-Lally" version, but not otherwise.

Using the empirical CAPM provides an alternative mean of estimating the cost of capital and its standard error. Even if the CAPM actually holds, applying the empirical model does not contradict with the Commission's approach which has to estimate parameter values regardless. Moreover, it proposes a conventional econometric way of calculating the standard error of the cost of equity. The WACC of regulated businesses calculated using this approach will reflect the rate of return required by the market since the market price on systematic risks is estimated instead of being appointed.

The contents in this thesis are organised as follows. Chapter 2 reviews methods for estimating the empirical CAPM, followed by detailed descriptions of how these methods are implemented. Chapter 3 describes the dataset used, which are daily stock price data, the NZX All (ordinary shares) Index as a proxy for the market portfolio, the 10 year government bond yield from Reserve Bank of New Zealand as a proxy for the risk free rate and the market capitalization data; the duration for all data is from Jan-1990 to Dec-2006.

Chapter 4 presents all estimation results of the empirical CAPM from different methods. Chapter 5 applies the estimated empirical model to recalculating the cost of capital for two Commission's reports - Commerce Commission (2005b) and Commerce Commission (2007). By assuming all components in the WACC formula (1.1) can be estimated without errors 
except for the cost of equity, I find that the cost of capital reported from the Commission's studies for electricity line and gas pipeline businesses are underestimated by approximately 3.5\% and 5.5\% respectively, and the probabilities of such underestimation are, considerably high, $95 \%$ and $90 \%$ respectively. The last chapter concludes key findings and suggests that using the CAPM based WACC to calculate firms' cost of capital should be a starting point and a bench mark, but not the final answer for decision makers. 


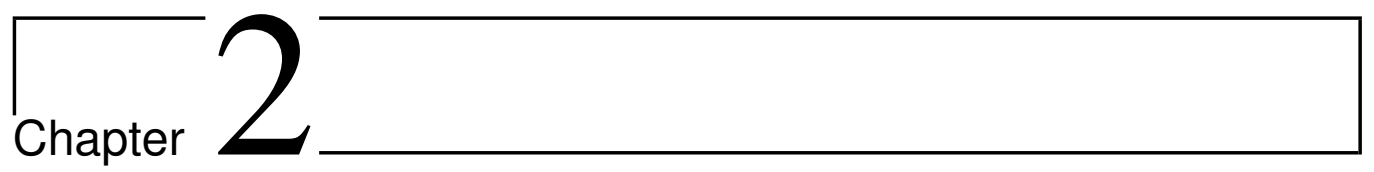

\section{Review and Methodology}

\subsection{A review on the methodology for estimating the empirical form of the CAPM}

The cross-sectional regression developed by Fama and MacBeth (1973) has become a standard approach for dealing with financial panel data, which is adopted in this paper to estimate the empirical form of the CAPM (1.5). The fundamental idea of their method is to regress returns on the corresponding systematic risks for each cross section, then aggregate estimates for all periods. The regression model at the time period $t$ of $N$ securities is

$$
\tilde{R}_{t}=\gamma_{0, t}+\gamma_{1, t} \beta+e_{t}
$$

where

$\tilde{R}_{t}$ is the $(N \times 1)$ vector of tax-adjusted excess returns at period $t$

$\beta$ is the $(N \times 1)$ vector of systematic risks 
There are two steps to execute the Fama-MacBeth (FM, hereafter) method. The first step is, given $T$ periods of data, to use the ordinary least square (OLS) method to estimate (2.1) for each $t$ from 1 to $T$, which will yield $T$ estimates of $\gamma_{i, t}$. The second step is to aggregate them to yield the intercept and slope coefficients of the empirical form of the CAPM. That is

$$
\gamma_{i}^{\star}=\frac{1}{T} \sum_{t=1}^{T} \hat{\gamma}_{i, t}
$$

The variance is given by

$$
\hat{\sigma}^{2}\left(\gamma_{i}^{\star}\right)=\frac{1}{T(T-1)} \sum_{t=1}^{T}\left(\hat{\gamma}_{i, t}-\gamma_{i}^{\star}\right)^{2}
$$

Finally, the empirical form of the CAPM can be expressed as

$$
\tilde{R}_{i}=\gamma_{0}^{\star}+\gamma_{1}^{\star} \beta_{i},
$$

where $\tilde{R}_{i}$ is the estimated tax-adjusted excess return for security $i$ and $\beta_{i}$ is the systematic risk. Assuming the systematic risk can be estimated without error, the standard error of $\tilde{R}_{i}$ can be calculated by

$$
\hat{\sigma}\left(\tilde{R}_{i}\right)=\sqrt{\hat{\sigma}^{2}\left(\gamma_{0}^{\star}\right)+\beta_{i}^{2} \hat{\sigma}^{2}\left(\gamma_{1}^{\star}\right)+2 \beta_{i} \operatorname{cov}\left(\gamma_{0}^{\star}, \gamma_{1}^{\star}\right)},
$$

where $\operatorname{cov} v\left(\gamma_{0}^{\star}, \gamma_{1}^{\star}\right)=\frac{\operatorname{cov}\left(\hat{\gamma}_{0, t}, \hat{\gamma}_{1, t}\right)}{T}$.

An unavoidable problem of the FM method is that the independent variable, systematic risks, in (2.1) is not observable, which has to be estimated. One approach is to use the estimated stock betas as the independent variable. However, the estimated stock betas are likely to possess large estimation errors. For example, the thin trading problem will bias the OLS estimators of the stock betas downwards (Scholes and Williams (1977)). 
To minimize errors in beta estimates, the method adopted by Fama and MacBeth (1973) is applied. They grouped stocks into portfolios in order to increase the precision of beta estimates. As they pointed out, given an estimated portfolio beta can be expressed as a weighted sum of estimated stock betas, as long as the errors in stock beta estimates are less than perfectly positively correlated, portfolio betas can be more precisely estimated than stock betas.

\subsubsection{The FM method using the estimated stock betas as the independent variable (FM SB)}

Using stock betas as the independent variable to estimate $\gamma_{i}^{\star}$ involves three steps. The first step is to estimate stock betas. The second step is to use the OLS method on (2.1) to produce time series estimates of $\gamma_{i, t}$. The last step is to calculate the intercept and slope coefficients, and their variances of the empirical CAPM using (2.2) and (2.3) respectively. Since implementing the FM method with stock betas as the independent variable can be seen as a subset of the FM with portfolio betas, any technological discussion is left to the next section.

\subsubsection{The FM method using the estimated portfolio betas as the independent variable (FM PB)}

In practise, the implementation of the FM method (where portfolio betas are the independent variable) can be divided into three parts: the first part is to estimate the systematic risk of individual stocks; group corresponding stocks into a certain number of portfolios based on the rank of stock 
betas and calculate portfolio returns by averaging stock returns in each portfolio. The second part is to estimate the systematic risk of portfolios by regressing their returns, calculated in the first part, on returns of the market portfolio. The last part is to regress portfolio returns on the estimated portfolio betas to estimate $\gamma_{i, t}$ (2.1), then $\gamma_{i}^{\star}$ (2.2). There are several difficulties to be overcome.

\section{How to form portfolios to prevent the loss of information}

There is inevitable loss of information when using portfolios instead of individual stocks in estimating the empirical CAPM. To reduce the information loss, Fama and MacBeth (1973) proposed to form portfolios on the basis of ranked values of estimated stock betas. By doing so, the dispersion of estimated portfolio betas are maximized.

\section{Which method to estimate stock betas}

Another problem is which method should be used to estimate stock betas so that one can obtain the precise rank and form appropriate portfolios. There are two candidates capable of this job.

The OLS method is the most well-known and the most frequently used method to estimate stock and portfolio betas (among others, Black et al. (1972), Fama and MacBeth (1973) and Fama and French (1992)). Bartholdy and Riding (1994) reported that there is no significant efficiency gain in estimating betas using other methods, than using the OLS method regardless of data frequency. Hence, the OLS method is adopted to estimate stock as a baseline case. 
In a contrast view, as most stocks in the New Zealand Stock Market are traded very infrequently, the OLS estimator of stock betas tends to be biased downwards (Scholes and Williams (1977)). To obtain unbiased estimators, Scholes and Williams (1977) proposed an alternative beta estimation model - the SW model. By assuming non-trading periods for a security are distributed independently and identically over time, Scholes and Williams derived a relationship between the true beta and the measured beta $^{1}$

$$
\beta^{s}=\beta-\left(\beta^{-s}+\beta^{+s}-2 \beta \rho_{m}^{s}\right)
$$

where

${ }^{s}$ stands for anything that is related to the measured returns

$\beta$ is the true beta

$$
\begin{aligned}
& \beta^{s} \equiv \frac{\operatorname{cov}\left(R_{t}^{s}, R_{m, t}^{s}\right)}{\operatorname{var}\left(R_{m, t}^{s}\right)} \\
& \beta^{-s} \equiv \frac{\operatorname{cov}\left(R_{t}^{s}, R_{m, t-1}^{s}\right)}{\operatorname{var}\left(R_{m, t-1}^{s}\right)} \\
& \beta^{+s} \equiv \frac{\operatorname{cov}\left(R_{t}^{s}, R_{m, t+1}^{s}\right)}{\operatorname{var}\left(R_{m, t+1}^{s}\right)} \\
& \rho_{m}^{s} \equiv \frac{\operatorname{cov}\left(R_{m, t}^{s}, R_{m, t-1}^{s}\right)}{\operatorname{var}\left(R_{m, t-1}^{s}\right)}
\end{aligned}
$$

After rearranging (2.6), the estimated true beta, $\hat{\beta}_{S W}$, can be presented as

$$
\hat{\beta}_{S W}=\frac{\hat{\beta}_{i,-1}+\hat{\beta}_{i}+\hat{\beta}_{i,+1}}{1+2 \hat{\rho}_{m}},
$$

\footnotetext{
${ }^{1}$ In practise, prices for (infrequently traded) securities are recorded only at distant random intervals. Hence, returns measured over any fixed sequence of periods are mere proxies for the true returns. The true beta, therefore, refers to the one derived from the true returns whereas the measured beta refers to the one from the proxy of the true returns.
} 
where

$$
\begin{aligned}
& \hat{\beta}_{i,-1} \text { is estimated by } \frac{\operatorname{cov} v\left(R_{i}, R_{m, t-1}\right)}{\operatorname{va} r\left(R_{m, t-1}\right)} \\
& \hat{\beta}_{i,+1} \text { is estimated by } \frac{\operatorname{cov} v\left(R_{i}, R_{m, t+1}\right)}{\operatorname{var}\left(R_{m, t+1}\right)} \\
& \hat{\beta}_{i} \text { is estimated by } \frac{\operatorname{cov}\left(R_{i}, R_{m}\right)}{v \hat{a} r\left(R_{m}\right)} \\
& \hat{\rho}_{m} \text { is estimated by } \frac{\operatorname{cov}\left(R_{m, t}, R_{m, t-1}\right)}{\operatorname{var}\left(R_{m, t-1}\right)}
\end{aligned}
$$

Bartholdy et al. (1996) has reviewed several beta-estimation methods dealing with thin trading problems ${ }^{2}$. As reported, the SW model performed over other methods. Therefore, the SW model is applied as a robustness check.

\subsection{Methodology in detail}

\subsubsection{A detailed description of the implementation of the FM method using stock betas as the independent vari- able}

The implementation of the FM method using stock betas as the independent variable involves three steps. The first step is to estimate stock betas,

\footnotetext{
${ }^{2}$ Among others, two methods were reported to perform outstandingly, which are Scholes-William model by Scholes and Williams (1977) and Aggregate Coefficient model by Dimson (1979). However, the later method has been seriously questioned by Cohen et al. (1983) and Fowler and Rorke (1983). Especially, Fowler and Rorke (1983) has shown that Aggregate Coefficient method is incorrect and the correct version is identical to the model propose by Scholes and Williams (1977).
} 
the second step is to estimate $\gamma_{i, t}$ using the OLS method, and the last step is to calculate $\gamma_{i}^{\star}$ and $\hat{\sigma}^{2}\left(\gamma_{i}^{\star}\right)$. With monthly data (from Jan-90 to Dec-06), the OLS and SW method are adopted to estimate stock betas.

The preliminary step is to estimate stock betas. Fama and MacBeth (1973) used 5 years of monthly data because of their large dataset (from 1926 to 1968, 43 years of monthly data). As only 17 years of monthly (Jan-90 to Dec-06) stock returns are available for this study, I have chosen to use 3 years of data to estimate stock betas instead. More specifically, for the first 3-year period (Jan-90 to Dec-92), stocks with returns available in at least in the latest two years (Jan-91 to Dec-92) and all returns available in next year (Jan-93 to Dec-93), are selected. Then, stock betas are estimated by regressing all available stock returns in the period Jan-90 to Dec-92 on market portfolio returns.

The reasons for selecting stocks in such ways are two-fold. The first condition that stocks must have at least the latest two year returns available, guarantees that there are enough observations to consistently estimate stock betas. The second condition that stocks must have all returns available in next year is to make sure that the cross-sectional regressions (2.1) can be performed.

The second step is to perform the cross-sectional regression (2.1). For each month from Jan-93 to Dec-93, I use the OLS method to regress tax-adjusted stock returns on their estimated betas. That is there are 12 regressions performed from

$$
\tilde{R}_{\mathrm{Jan}-93}=\gamma_{0, \mathrm{Jan}-93}+\gamma_{1, \mathrm{Jan}-93} \hat{\beta}+e_{\mathrm{Jan}-93}
$$


to

$$
\tilde{R}_{\text {Dec-93 }}=\gamma_{0, \text { Dec-93 }}+\gamma_{1, \text { Dec }-93} \hat{\beta}+e_{\text {Dec-93 }}
$$

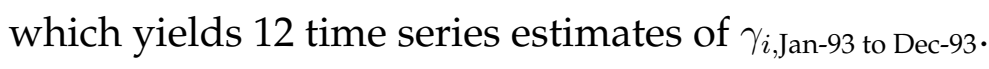

The first step and the second step are then repeated on data with the period interval being moved forward for one year until the last period interval Jan-2003 to Dec-2006. Table 2.1 illustrates the way of repeating the first and the second step for calculating $\hat{\gamma}_{i, t}$. In total, there will be 168 (14 years $\times 12$ months) time series estimates of $\gamma_{i, t}$ obtained respectively.

Finally, the intercept and slope coefficients of the empirical CAPM are cal-

\section{Table 2.1: An illustration of the work mechanism of the FM} method using stock betas as the independent variable

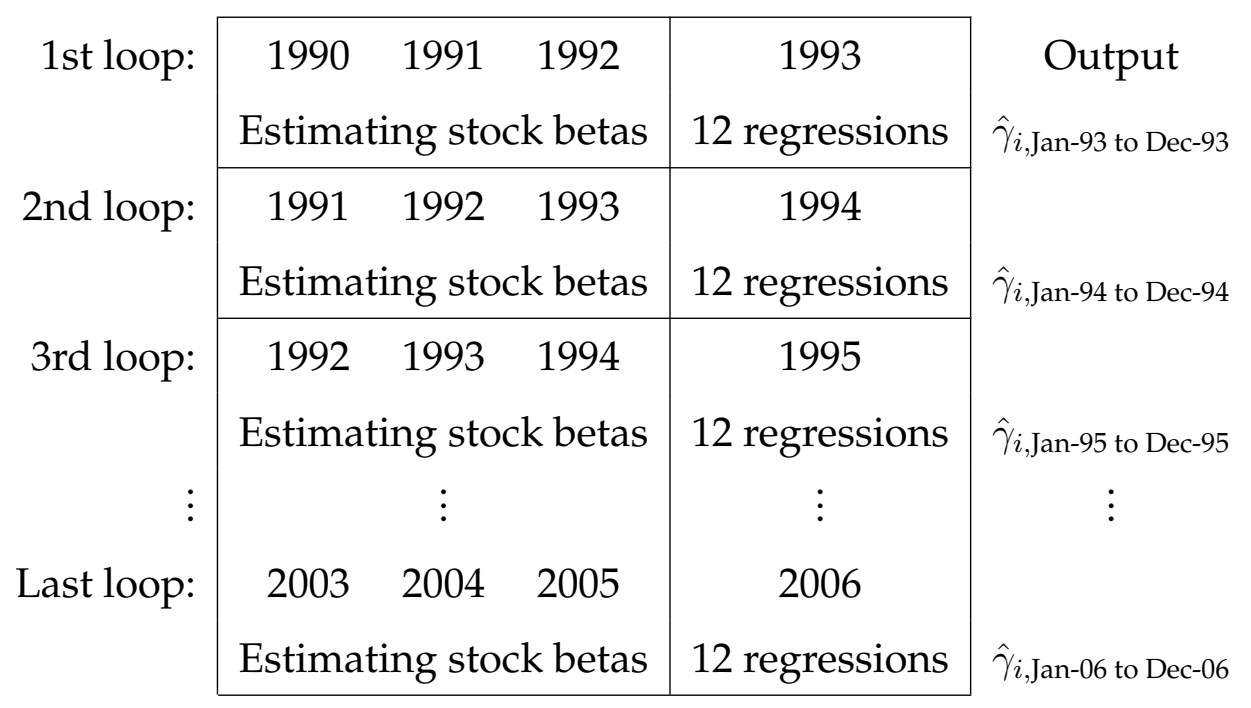

Note: There are 14 loops in total, executed to calculate $\gamma_{i, t}$ from Jan-93 to Dec-06. 
culated as:

$$
\gamma_{i}^{\star}=\frac{1}{168} \sum_{t=\operatorname{Jan}-93}^{\text {Dec-06 }} \hat{\gamma}_{i, t}
$$

The variance is calculated by:

$$
\hat{\sigma}^{2}\left(\gamma_{i}^{\star}\right)=\frac{1}{168(168-1)} \sum_{t=\operatorname{Jan}-93}^{\text {Dec-06 }}\left(\hat{\gamma}_{i, t}-\gamma_{i}^{\star}\right)^{2}
$$

\subsubsection{A detailed description of the implementation of the FM method using portfolio betas as the independent variable}

For the baseline case, the monthly data is used along with the OLS method to estimate stock and portfolio betas.

The preliminary step is to estimate stock betas. The details of estimation are exactly the same as ones outlined in previous contents (the FM method with stock betas).

The next step is to rank the estimated stock betas in an ascending order and group them into 10 portfolios, e.g. $10 \%$ of stocks with lowest beta are grouped into the first portfolio; another $10 \%$ with second lowest beta are grouped into the second portfolio, until the last $10 \%$ with the highest beta are grouped into the tenth portfolio. Then portfolio returns in the next period (Jan-93 to Dec-93) are computed by value-weighting stock returns, e.g., the return of the first portfolio at Jan- 93 is calculated by valueweighting stock returns in the first portfolio at Jan-93, and so forth until Dec-93.

By repeating the process above, except for moving one year forward, the 


\section{Table 2.2: An illustration of how to calculated portfolio re- turns}

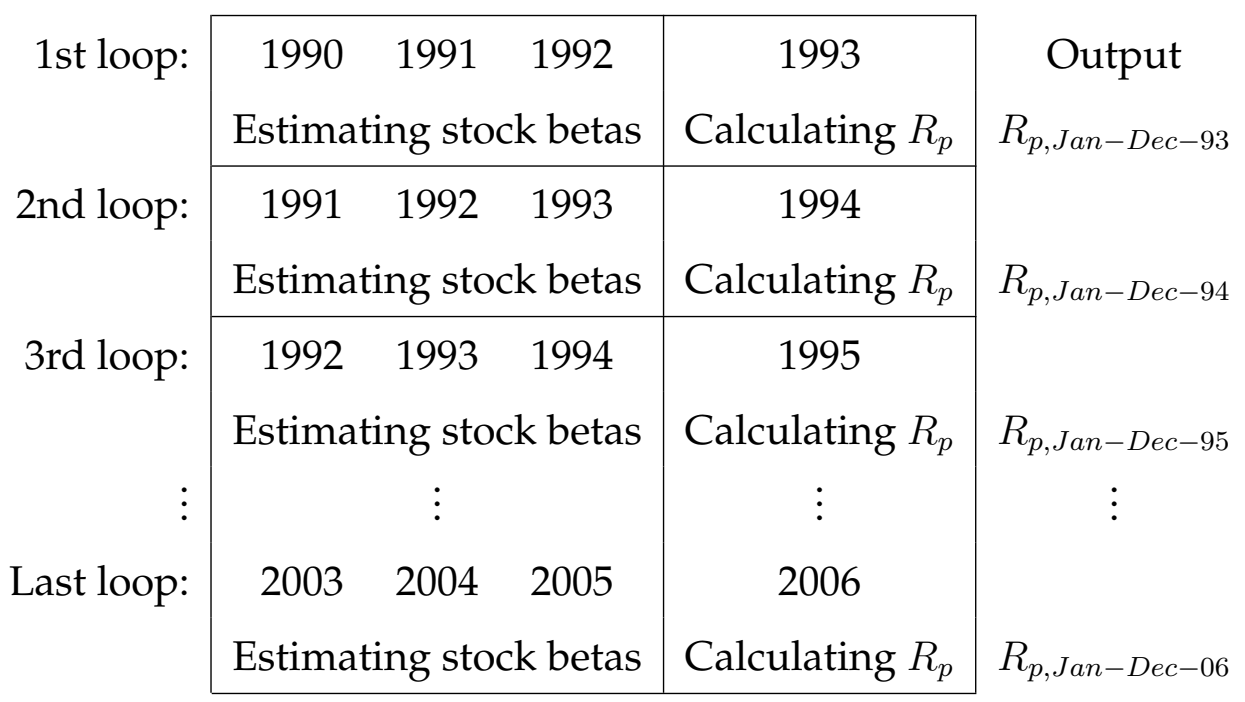

Note: There are 14 loops in total, executed to calculate 10 portfolio returns from Jan-93 to Dec-06

portfolio returns from Jan-94 to Dec-94 are computed. That is: for the period of Jan-91 to Dec-93, stocks with returns at least available from Jan-92 to Dec-93 and all returns available for Jan-94 to Dec-94 are selected; then using all available stock returns from Jan-91 to Dec-93 to estimate stock betas; 10 portfolios are formed and portfolio returns are calculated from Jan-94 to Dec-94 by value-weighting stock returns at the same period. By continuing to repeat these calculations, 10 portfolio returns from Jan-93 to Dec-06 are calculated. Table 2.2 offers an intuitive illustration of how portfolio returns are calculated for the entire period.

Next, 10 portfolio betas are estimated by using all portfolio returns from 
Jan-93 to Dec-06 for each portfolio. There are 10 time series regressions executed. For each regression, the OLS method is used to regress the portfolio returns from Jan-93 to Dec-06 on the market portfolio returns from the same period. 10 portfolio betas are estimated.

These portfolio betas are incorporated into the next step - estimating $\gamma_{i, t}$. However, they cannot be estimated by regressing portfolio returns on the estimated portfolio betas directly as this would give a single regression with just ten observations. On the other hand, Fama and MacBeth (1973) regressed stock returns on the portfolio betas. This alteration was also carried out by Bryant and Eleswarapu (1997).

More specifically, for each month from Jan-93 to Dec-06, stocks in each portfolio are assumed to have their betas equal to the portfolio beta. Table 2.3 illustrates this idea. There are two panels. The first is the stock beta panel. For each month from Jan-93 to Dec-06, all stocks used to form 10 portfolios are assumed to have their betas equal to corresponding portfolio betas. For example, as the table shows, stock $\mathrm{A}$ is in the fourth portfolio in 1993 so its beta is assumed to equal the fourth portfolio's beta during that year. As the composition of the 10 portfolios changes yearly, the beta may change for the same stock. For instance, stock A's beta is assumed to equal the third portfolio's beta in 1994. The second panel is the stock return data, which consists of all the corresponding stock returns for each month from Jan-93 to Dec-06. For each month, stock returns are regressed on the assumed stock betas (the portfolio betas) to estimate $\hat{\gamma}_{i, t}$. 


\section{Table 2.3: An illustration of the data panel for estimating $\gamma_{i, t}$}

\begin{tabular}{rcccc|cccc}
\hline & \multicolumn{4}{c}{$\beta$} & \multicolumn{5}{c}{ Excess Return } \\
\cline { 2 - 9 } Stock: & $\mathrm{A}$ & $\mathrm{B}$ & $\mathrm{C}$ & $\ldots$ & $\mathrm{A}$ & $\mathrm{B}$ & $\mathrm{C}$ & $\ldots$ \\
\hline Jan-93 & $\beta_{p 4}$ & $\beta_{p 2}$ & $\beta_{p 7}$ & $\ldots$ & $R_{\text {Jan-93 }}^{A}$ & $R_{\text {Jan-93 }}^{B}$ & $R_{\text {Jan-93 }}^{C}$ & $\ldots$ \\
$\vdots$ & $\vdots$ & $\vdots$ & $\vdots$ & $\vdots$ & $\vdots$ & $\vdots$ & $\vdots$ & \\
Dec-93 & $\beta_{p 4}$ & $\beta_{p 2}$ & $\beta_{p 7}$ & $\ldots$ & $R_{\text {Dec-93 }}^{A}$ & $R_{\text {Dec-93 }}^{B}$ & $R_{\text {Dec-93 }}^{C}$ & $\ldots$ \\
\hline Jan-94 & $\beta_{p 3}$ & $\beta_{p 5}$ & $\beta_{p 6}$ & $\ldots$ & $R_{\text {Jan-94 }}^{A}$ & $R_{\text {Jan-94 }}^{B}$ & $R_{\text {Jan-94 }}^{C}$ & $\cdots$ \\
$\vdots$ & $\vdots$ & $\vdots$ & $\vdots$ & $\vdots$ & $\vdots$ & $\vdots$ & $\vdots$ & \\
Dec-94 & $\beta_{p 3}$ & $\beta_{p 5}$ & $\beta_{p 6}$ & $\ldots$ & $R_{\text {Dec-94 }}^{A}$ & $R_{\text {Dec-94 }}^{B}$ & $R_{\text {Dec-94 }}^{C}$ & $\cdots$ \\
\hline$\vdots$ & $\vdots$ & $\vdots$ & $\vdots$ & $\vdots$ & $\vdots$ & $\vdots$ & $\vdots$ & \\
Jan-06 & $\beta_{p 3}$ & $\beta_{p 5}$ & $\beta_{p 8}$ & $\ldots$ & $R_{\text {Jan-06 }}^{A}$ & $R_{\text {Jan-06 }}^{B}$ & $R_{\text {Jan-06 }}^{C}$ & $\cdots$ \\
$\vdots$ & $\vdots$ & $\vdots$ & $\vdots$ & $\vdots$ & $\vdots$ & $\vdots$ & $\vdots$ & \\
Dec-06 & $\beta_{p 3}$ & $\beta_{p 5}$ & $\beta_{p 8}$ & $\ldots$ & $R_{\text {Dec-06 }}^{A}$ & $R_{\text {Dec-06 }}^{B}$ & $R_{\text {Dec-06 }}^{C}$ & $\cdots$ \\
\hline
\end{tabular}

Note: This table is provided simply to illustrate the full version of the FM method. For each year, there are not necessarily the same stocks in both panels. For example, the stock A may be delisted in 1994. If that is the case, it will no long be in the stock beta and return panel in 1994.

There are in total 168 regressions (14 years $\times 12$ months) performed from Jan-93 to Dec-06, which yield time series estimates of $\gamma_{i, t}$ from Jan-93 to Dec-06. Finally, the $\gamma_{i}^{\star}$ and their variances are calculated in the same way as discussed previously. 


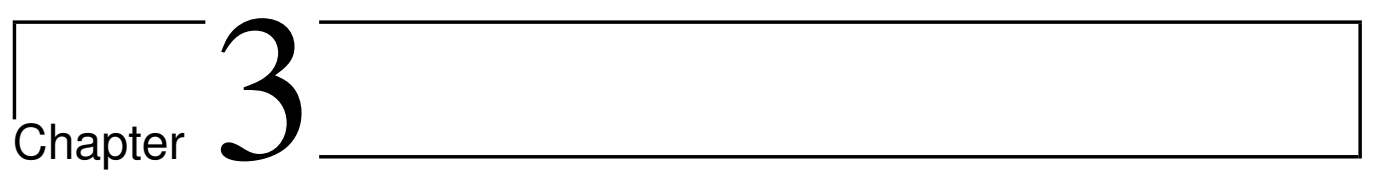

\section{Data for estimating the empirical}

\section{CAPM}

\subsection{Stock return data}

The stock price data has been provided by Investment Research Group Ltd (IRG Ltd) which is known as the IRG "Price Histories" Database. The IRG's stock database includes adjusted price data for all ordinary stocks (listed and delisted) from 3-Jan-1990 to 29-Dec-2006 on a daily basis. Daily stock returns are calculated by

$$
R_{i, t}=\frac{P_{i, t}-P_{i, t-1}+D_{i, t}}{P_{i, t-1}},
$$

where $D_{i, t}$ denotes for a dividend paid on a security $i$ at date $t$. Weekly and monthly stock returns are calculated by accumulating daily returns

$$
R_{i, T}=\prod_{t=1}^{N}\left(1+R_{i, t}\right)-1,
$$

where $N$ is the number of days in a week and a month respectively. 


\section{Table 3.1: The Number of stocks with returns available at each month from Jan-1990 to Dec-2006}

The number of stocks with returns available at each month is presented in this table, however, these numbers may not reflect the exact number of stocks listed in the New Zealand Stock Exchange at the corresponding time since there are a small number of stocks missing from the IRG database.

\begin{tabular}{rrrrrrrrrrrrr}
\hline & Jan & Feb & Mar & Apr & May & Jun & Jul & Aug & Sep & Oct & Nov & Dec \\
\hline 1990 & 27 & 74 & 80 & 81 & 82 & 83 & 83 & 86 & 86 & 86 & 86 & 86 \\
1991 & 86 & 86 & 86 & 86 & 86 & 86 & 87 & 89 & 89 & 89 & 89 & 89 \\
1992 & 90 & 90 & 90 & 90 & 92 & 95 & 96 & 97 & 98 & 99 & 102 & 102 \\
1993 & 102 & 102 & 102 & 102 & 102 & 103 & 104 & 105 & 106 & 110 & 116 & 116 \\
1994 & 122 & 122 & 122 & 125 & 126 & 127 & 128 & 131 & 131 & 131 & 133 & 134 \\
1995 & 137 & 137 & 137 & 137 & 137 & 138 & 138 & 138 & 138 & 138 & 138 & 137 \\
1996 & 137 & 137 & 135 & 138 & 135 & 133 & 133 & 133 & 132 & 132 & 132 & 131 \\
1997 & 132 & 131 & 131 & 132 & 132 & 133 & 134 & 135 & 136 & 136 & 136 & 136 \\
1998 & 139 & 138 & 137 & 137 & 137 & 136 & 139 & 142 & 142 & 142 & 142 & 141 \\
1999 & 141 & 142 & 141 & 141 & 141 & 140 & 141 & 139 & 136 & 136 & 137 & 137 \\
2000 & 135 & 135 & 135 & 137 & 140 & 141 & 142 & 139 & 139 & 139 & 139 & 144 \\
2001 & 148 & 146 & 146 & 146 & 146 & 146 & 144 & 142 & 140 & 141 & 139 & 138 \\
2002 & 139 & 139 & 139 & 138 & 139 & 140 & 140 & 141 & 139 & 138 & 136 & 135 \\
2003 & 137 & 137 & 138 & 137 & 137 & 138 & 137 & 138 & 137 & 139 & 140 & 143 \\
2004 & 144 & 144 & 144 & 146 & 146 & 146 & 148 & 151 & 150 & 152 & 153 & 154 \\
2005 & 157 & 157 & 156 & 155 & 154 & 150 & 148 & 149 & 149 & 147 & 147 & 147 \\
2006 & 147 & 147 & 144 & 143 & 143 & 142 & 141 & 141 & 138 & 138 & 139 & 138 \\
\hline
\end{tabular}


The New Zealand Stock Exchange is far smaller than many others, e.g., the New York Stock Exchange. Table 3.1 shows that the average number of stocks in more recent years (2004-2006) is approximately 140, and only roughly 90 in the early period (1990-1992). In Fama and MacBeth (1973), the stock data from the New York Stock Exchange was used. The number of stocks in 1926 was 710 while it grew to 1261 in 1968.

Thin trading is another feature of the New Zealand Stock Market, which is illustrated in Table 3.2. Each cell in the table represents the percentage of stocks that has been traded more than a given percentage of business days ( $>50 \%$, etc) in a given year (1990 to 2006). On average, only $51.4 \%$ of stocks from 1990 to 2006 has been traded on more than 50\% of trading days while no more than $3 \%$ of stocks has been traded on a rough daily basis (> 90\%). In other words, 50\% of stocks from 1990 to 2006 has been traded for no more than 3 days each week. 


\section{Table 3.2: Thin trading problem illustration from 1990 to 2006}

For each cell in this table, the number is calculated by dividing the number of stocks that have been traded on more than a certain percentage of business days by the total number of stocks in a given year. For example, $18.6 \%$ in the first row and the first column reads $18.6 \%$ of all stocks has been traded on more than $50 \%$ of business days in the year 1990 .

\begin{tabular}{rccccc}
\hline & \multicolumn{5}{c}{ Percentage of business days } \\
\cline { 2 - 6 } Year & $>50 \%$ & $>60 \%$ & $>70 \%$ & $>80 \%$ & $>90 \%$ \\
\hline 1990 & $18.6 \%$ & $14 \%$ & $9.3 \%$ & $7 \%$ & $2.3 \%$ \\
1991 & $20 \%$ & $15.6 \%$ & $12.2 \%$ & $6.7 \%$ & $0 \%$ \\
1992 & $49 \%$ & $39.2 \%$ & $23.5 \%$ & $5.9 \%$ & $0 \%$ \\
1993 & $64.8 \%$ & $54.1 \%$ & $39.3 \%$ & $10.7 \%$ & $3.3 \%$ \\
1994 & $57.7 \%$ & $40.1 \%$ & $23.4 \%$ & $8.8 \%$ & $3.6 \%$ \\
1995 & $42.6 \%$ & $27 \%$ & $14.2 \%$ & $5.7 \%$ & $1.4 \%$ \\
1996 & $47.7 \%$ & $32.2 \%$ & $18.1 \%$ & $7.4 \%$ & $2.7 \%$ \\
1997 & $54.5 \%$ & $38.6 \%$ & $26.9 \%$ & $10.3 \%$ & $4.1 \%$ \\
1998 & $52.7 \%$ & $37.8 \%$ & $26.4 \%$ & $12.8 \%$ & $6.8 \%$ \\
1999 & $45 \%$ & $33.8 \%$ & $13.9 \%$ & $4.6 \%$ & $0 \%$ \\
2000 & $54.1 \%$ & $38.2 \%$ & $17.8 \%$ & $4.5 \%$ & $1.3 \%$ \\
2001 & $62 \%$ & $43.7 \%$ & $32.9 \%$ & $15.2 \%$ & $4.4 \%$ \\
2002 & $56.1 \%$ & $42.6 \%$ & $30.4 \%$ & $15.5 \%$ & $2.7 \%$ \\
2003 & $61.5 \%$ & $43.9 \%$ & $29.7 \%$ & $18.2 \%$ & $4.7 \%$ \\
2004 & $63.2 \%$ & $49.1 \%$ & $28.8 \%$ & $16 \%$ & $4.3 \%$ \\
2005 & $66.5 \%$ & $51.6 \%$ & $32.9 \%$ & $19.3 \%$ & $3.1 \%$ \\
2006 & $58.6 \%$ & $48 \%$ & $33.6 \%$ & $22.4 \%$ & $5.3 \%$ \\
\hline Average & $51.4 \%$ & $38.2 \%$ & $24.3 \%$ & $11.2 \%$ & $2.9 \%$ \\
\hline
\end{tabular}




\subsection{Proxies for the market portfolio and the risk free rate}

This paper uses the NZX All Index ${ }^{1}$ as a proxy for the market portfolio. This index, according to New Zealand Exchange Limited, comprises all domestic equity securities listed on the New Zealand Stock Exchange Market (NZSX), and its constituents are weighted by free float market capitalisation, where "free float market capitalization" refers to the product of the number of shares available to public and the price of a share.

Using the NZX All Index as the proxy for the market portfolio is different from previous studies - Bryant and Eleswarapu (1997) chose the NZSE-40 Index as a proxy for the market portfolio. Reasons for using the NZX All Index are three-fold. First, it is the only index that covers the entire data period (1990 to 2006). The NZSE-40 Index ceased publishing in 2003 while the NZX-50 Index started to publish after 2002. Second, if a combined index of the NZSE-40 and NZX-50 could be used instead, a sudden change in the composition of this index (from 40 to 50 equity securities at a time point) can be problematic. Finally, the NZX All Index includes all equity securities. As Roll (1977) and Roll and Ross (1994) argued that a proxy for the market portfolio should be as comprehensive as possible. For example, Jagannathan and Wang (1996) includes the human capital along with stock data. Although the NZX All Index is far from being a comprehensive proxy for the market portfolio, it is at least not inferior to the NZSE-40, NZX-50 or any combination of them.

\footnotetext{
${ }^{1}$ For more information: http://www.nzx.com/market/price_by_index/ALL
} 
Figure 3.1: NZSE-40, NZX-50 and NZX All Index from 1990

\section{to 2006}

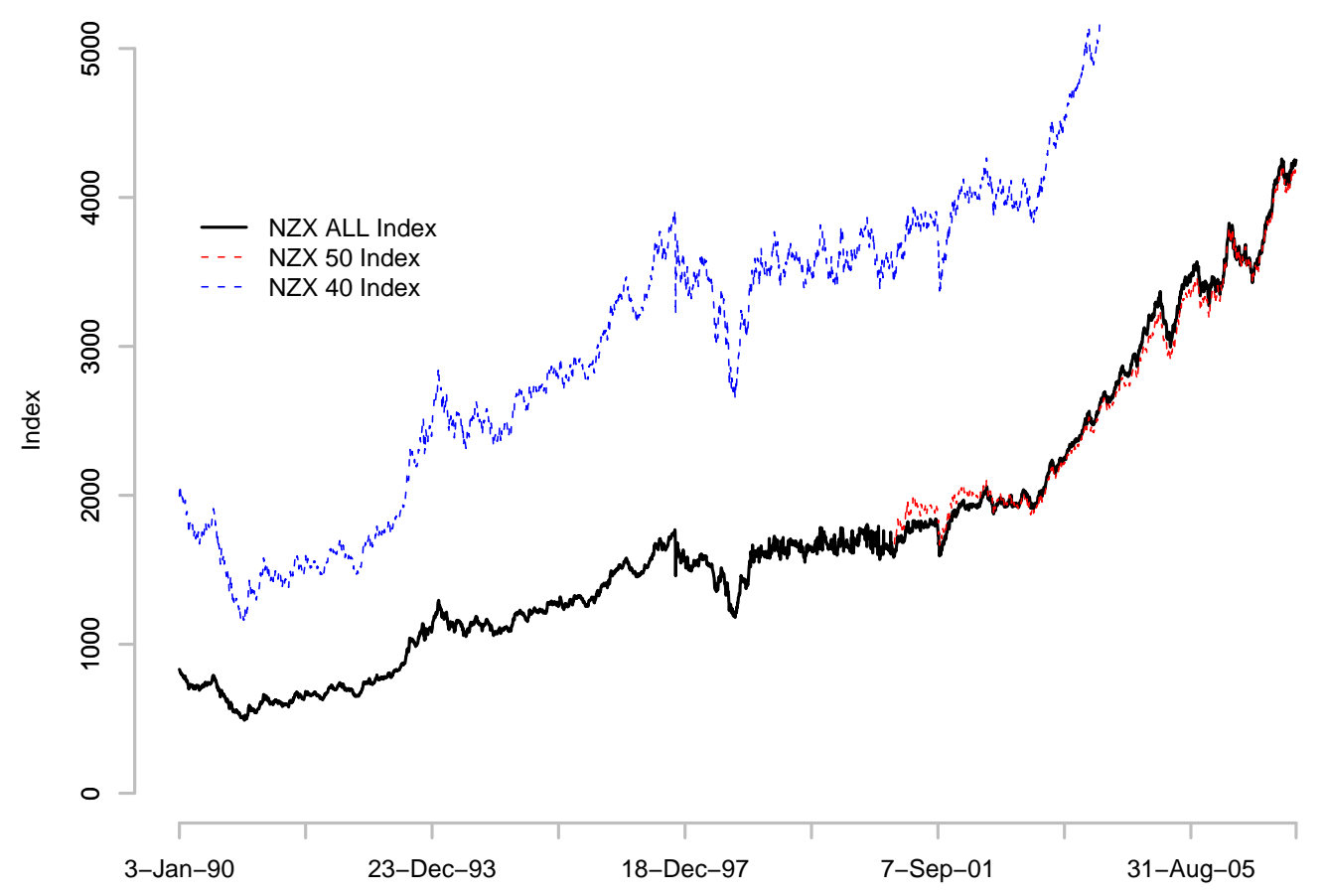

The NZX All Index data is also provided by IRG Ltd, which is on a daily basis from 3-Jan-1990 to 29-Dec-2006. Monthly and weekly returns on the NZX All Index are calculated in the same way as for calculating stock returns (3.2). The NZSE-40, NZX-50 and NZX All Index are plotted in Figure 3.1. The solid black curve shows the NZX All Index which is also the only index to cover the entire period from 1990 to 2006. The NZX All Index grew gradually before 2002, and followed by a rapid growth from 2002 onwards.

The 10 year government bond yield is used as a proxy for the risk free rate, which is obtained from the Reserve Bank of New Zealand. The raw 
data is provided in two formats. One is the annualized yield in monthly frequency from Jan-1990 to Dec-2006, while the other is in daily frequency from 03-Jan-1990 to 29-Dec-2006. To obtain monthly yields, the equation below is applied to the yield data in the monthly frequency.

$$
R_{f, t}^{m}=\left(1+R_{f, t}^{y}\right)^{1 / 12}-1
$$

where $R_{f, t}^{m}$ is the monthly yield at the month $t$ and $R_{f, t}^{y}$ is the annal yield at the same month.

The yield data in the daily frequency is used to obtain the weekly yield. Annual returns on the last day of each week are picked, and weekly returns are calculated using the following equation

$$
R_{f, t}^{w}=\left(1+R_{f, t}^{y}\right)^{1 / 52}-1
$$

where $R_{f, t}^{w}$ is the weekly yield at the week $t$ and $R_{f, t}^{y}$ is the annal yield at the same week.

The bond yield is different from the return on that bond in the sense that the yield is the rate of return for holding a bond to the maturity while the return is what has been realized after selling the bond. Therefore, an alternative way of obtaining a proxy for the risk free rate is to calculate the one-period (monthly) return on the bond. As the coupon payment for the 10 year government bond is on the annual basis, the capital gain rate can be a good approximation of the one-period return (which it will be unless coupons are paid monthly).

In order to calculate the monthly capital gain return on the 10 year government bond, the bond price at each month has to be obtained. Without 
introducing large distortions, it is not inappropriate to assume that the 10 year government bond is a perpetuity. Then, the bond price at the month $t$ can be calculated by

$$
P_{t}=\frac{A}{r_{t}},
$$

where $A$ is the coupon payment and $r_{t}$ is the yield at the month $t$. Then, the monthly capital gain return of a bond being purchased at the month $t-1$ and sold at $t$ can then be calculated by

$$
\begin{aligned}
R_{f, t} & =\frac{P_{t}-P_{t-1}}{P_{t-1}} \\
& =\frac{\frac{A}{r_{t}}-\frac{A}{r_{t-1}}}{\frac{A}{r_{t-1}}} \\
& =\frac{r_{t-1}}{r_{t}}-1,
\end{aligned}
$$

Figure 3.2 plots two proxies for the risk free rate. The solid black curve is the 10-year government bond yield (LHS) while the gray curve is the approximate annualized monthly capital gain returns on the bond (RHS). Because of the simplifying perpetuity assumption for deriving the capital gain return, a small change in the yield will result in large variations in the capital gain returns.

Table 3.3 provides summary statistics of proxies for the annual market portfolio returns , 10-year government bond yield $\left(R_{f 1}\right)$ and annualized monthly capital gain returns $\left(R_{f 2}\right)$. The bond yield decreases gradually from 1990 to 2006 with an average of $7.34 \%$ while the return on the bond has a lower average of $5.38 \%$. On the other hand, the return on the NZX All Index varies strongly. Tax-adjusted excess returns on the market portfolio were positive and significant in more recent years (2001 to 2006) 
Figure 3.2: The 10-year government bond yield and the approximate monthly capital gain returns on the bond from 1990 to 2006 at the monthly frequency

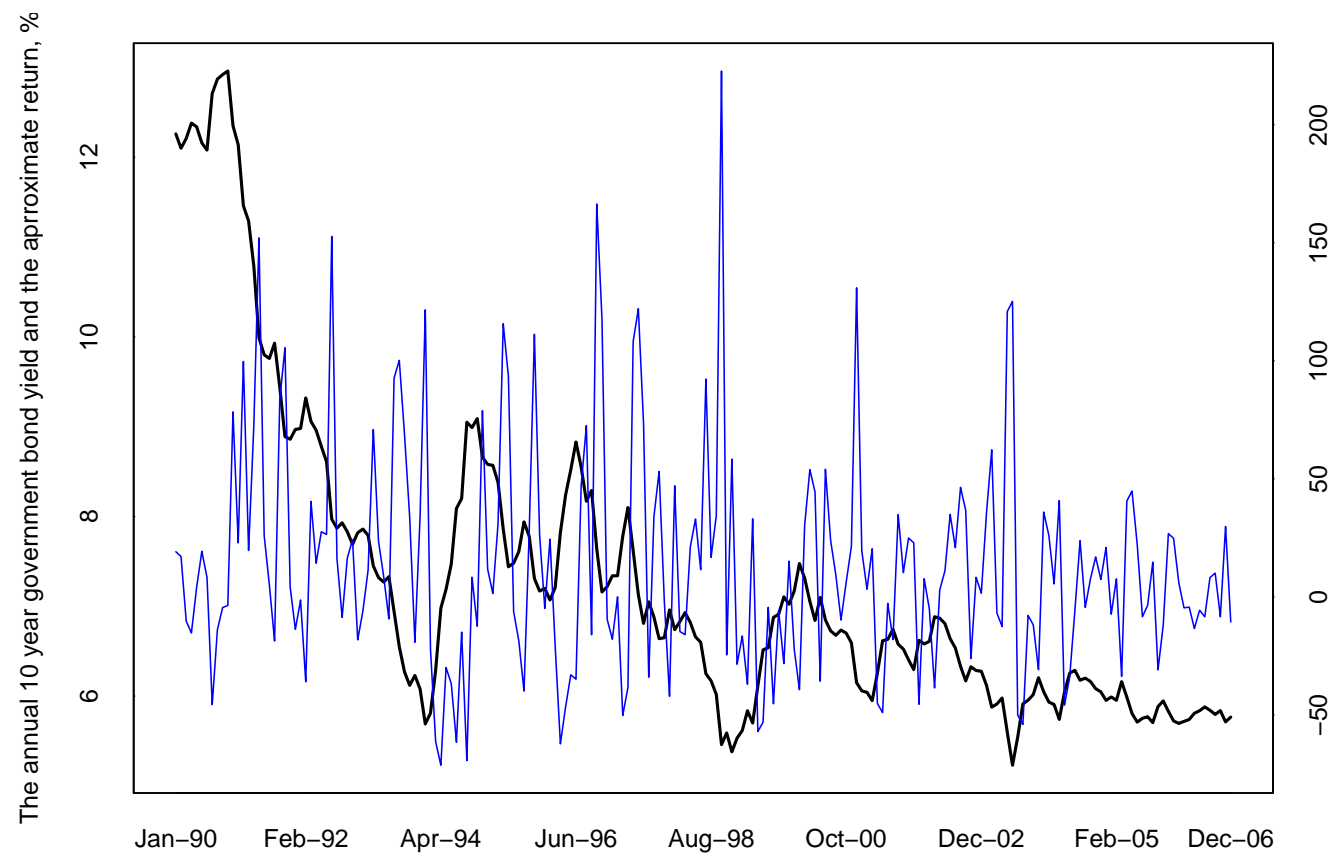

which signifies the recent bull market. On average, the tax-adjusted excess return on the market portfolio calculated using $R_{f 1}\left(\tilde{R}_{m 1}=R_{m, t}-\right.$ $R_{f 1, t-1}\left(1-T_{I}\right)^{2}$ where $T_{I}$ is set equal to $\left.33 \%\right)$ equals $6.3 \%$ per year and $\tilde{R}_{m 2}$ $\left(\tilde{R}_{m 2}={ }_{m, t}-R_{f 2, t}\left(1-T_{I}\right)\right)$ averages to $7.6 \%$.

${ }^{2}$ When calculating the excess returns using the yield data, I have to shift it one period backward. That is because: the yield is forward looking (e.g., $R_{f, t}$ covers the period from $t$ to $t+1)$; on the other hand, the way of calculating the return for securities $\left(R_{i, t}\right)$ makes it to cover the period from $t-1$ to $t$; therefore, in order to match the period, $R_{m, t}-R_{f 1, t-1}\left(1-T_{I}\right)$ is used. 


\section{Table 3.3: Summary statistics of proxies for $R_{m}$ and $R_{f}$}

This table shows the summary statistics of proxies for the risk free rate and the return on the market portfolio. $R_{f 1}$ and $R_{f 2}$ denote the two proxies for the risk free rate, which are the 10-year government bond yield and the annualized monthly capital gain returns on the bond. $R_{m}$ denotes the proxy for the return on the market portfolio return.

$$
\begin{gathered}
\tilde{R}_{m 1}=R_{m, t}-R_{f 1, t-1}\left(1-T_{I}\right) \\
\tilde{R}_{m 2}=R_{m, t}-R_{f 2, t}\left(1-T_{I}\right)
\end{gathered}
$$

$T_{I}$ is the average (across equity investors) of their marginal tax rates on ordinary income, whose value is assumed to be $33 \%$ in order to be in accordance with the Commission's reports.

\begin{tabular}{rlllllllll}
\hline \multicolumn{7}{c}{$R_{f 1}$} & \multicolumn{7}{c}{$R_{f 2}$} & & \\
\cline { 2 - 6 } & Mean & Std & Mean & Std & Mean & Std & $\tilde{R}_{m 1}$ & $\tilde{R}_{m 2}$ \\
\hline 1990 & $12.45 \%$ & $0.33 \%$ & $1.03 \%$ & $8.09 \%$ & $-37.12 \%$ & $18.82 \%$ & $-45.46 \%$ & $-37.81 \%$ \\
1991 & $10.11 \%$ & $1.08 \%$ & $38.39 \%$ & $10.92 \%$ & $32 \%$ & $15.17 \%$ & $25.23 \%$ & $6.27 \%$ \\
1992 & $8.4 \%$ & $0.6 \%$ & $15.2 \%$ & $9.82 \%$ & $15.5 \%$ & $20.57 \%$ & $9.87 \%$ & $5.32 \%$ \\
1993 & $6.93 \%$ & $0.66 \%$ & $29.07 \%$ & $8.92 \%$ & $53.98 \%$ & $18.67 \%$ & $49.33 \%$ & $34.5 \%$ \\
1994 & $7.63 \%$ & $1.25 \%$ & $-28.63 \%$ & $18.47 \%$ & $-5.45 \%$ & $18.35 \%$ & $-10.56 \%$ & $13.73 \%$ \\
1995 & $7.78 \%$ & $0.51 \%$ & $20.98 \%$ & $11.49 \%$ & $20.14 \%$ & $10.02 \%$ & $14.93 \%$ & $6.08 \%$ \\
1996 & $7.89 \%$ & $0.62 \%$ & $1.07 \%$ & $17.15 \%$ & $19.23 \%$ & $10.31 \%$ & $13.94 \%$ & $18.51 \%$ \\
1997 & $7.19 \%$ & $0.46 \%$ & $4.81 \%$ & $15.06 \%$ & $3.89 \%$ & $14.32 \%$ & $-0.93 \%$ & $0.67 \%$ \\
1998 & $6.29 \%$ & $0.57 \%$ & $30.16 \%$ & $11.89 \%$ & $-0.41 \%$ & $25.08 \%$ & $-4.62 \%$ & $-20.62 \%$ \\
1999 & $6.41 \%$ & $0.62 \%$ & $-24.64 \%$ & $9.69 \%$ & $18.38 \%$ & $16.14 \%$ & $14.09 \%$ & $34.89 \%$ \\
2000 & $6.85 \%$ & $0.35 \%$ & $17.24 \%$ & $10.92 \%$ & $-8.57 \%$ & $11.08 \%$ & $-13.16 \%$ & $-20.12 \%$ \\
2001 & $6.39 \%$ & $0.27 \%$ & $-6.68 \%$ & $10.18 \%$ & $18.18 \%$ & $16.55 \%$ & $13.9 \%$ & $22.66 \%$ \\
2002 & $6.53 \%$ & $0.25 \%$ & $5.74 \%$ & $7.2 \%$ & $4.68 \%$ & $10.16 \%$ & $0.31 \%$ & $0.84 \%$ \\
2003 & $5.87 \%$ & $0.28 \%$ & $4.85 \%$ & $15.04 \%$ & $27.01 \%$ & $9.42 \%$ & $23.08 \%$ & $23.76 \%$ \\
2004 & $6.07 \%$ & $0.16 \%$ & $1.91 \%$ & $7.9 \%$ & $28.55 \%$ & $9.48 \%$ & $24.49 \%$ & $27.27 \%$ \\
2005 & $5.88 \%$ & $0.14 \%$ & $2.34 \%$ & $7.3 \%$ & $9.65 \%$ & $11.81 \%$ & $5.72 \%$ & $8.08 \%$ \\
2006 & $5.78 \%$ & $0.06 \%$ & $1.17 \%$ & $3.82 \%$ & $19.59 \%$ & $12.89 \%$ & $15.72 \%$ & $18.81 \%$ \\
\hline Average & $7.32 \%$ & $1.77 \%$ & $5.38 \%$ & $12.01 \%$ & $11.2 \%$ & $15.67 \%$ & $6.3 \%$ & $7.6 \%$ \\
\hline
\end{tabular}




\subsection{Market capitalization data}

The market capitalization data is needed when calculating portfolio returns (value weighting stock returns). The data is provided in the monthly frequency by IRG Ltd, which covers all ordinary stocks (listed and delisted) from Jan-1990 to Dec-2006. To obtain the weekly data, it is assumed that market capitalization for a stock is constant within a given month; then, breaking each month into a certain number of trading days in accordance with the date of stock returns; finally, choosing market values on the last day of each week to form the weekly market capitalization data.

Another feature of the New Zealand Stock Exchange is that large companies dominate the market, which is illustrated in Table 3.4. Each cell of the table represents a percentage of the total market value dominated by a given percentage of largest companies listed on the New Zealand Stock Market in a certain year. It shows that $5 \%$ of companies take up approximately 53\% of the market on average from 1990 to 2006. Although the percentage of the market dominated by large companies has dropped in more recent years, there is still approximately $90 \%$ of the market that are dominated by only 30\% of trading companies each year from 1990 to 2006.

Because of two features of the New Zealand Stock Exchange - the small number of stocks and the dominance of large companies - forming portfolios on a value-weighted base, instead of on an equally-weighted base, is required. Portfolio returns, calculated by equally weighted averaging stock returns, tend to bias towards stock returns with small market capitalization, which will result in portfolio betas to be bias towards small-cap- 
stock betas especially when the proxy of the market portfolio is a valueweighted index. Such bias will refrain from the precise estimation of portfolio betas (the independent variable in the FM cross sectional regression), and hence the empirical CAPM estimates. 


\section{Table 3.4: Market capitalization data: large companies dom- inate the New Zealand Stock Exchange}

In this table, each cell represents a percentage of the total market value dominated by a given percentage of the largest companies listed on the New Zealand Stock Market at a certain year. It is calculated by adding up the market capitalization of a certain percentage (5\%, etc) of the largest companies in a certain year (1990 to 2006), then dividing it by the sum of the market capitalization of all companies. For example, $70.7 \%$ in the first cell suggests that $5 \%$ of the largest companies accounts for $70.7 \%$ of the market value in the year 1990.

\begin{tabular}{ccccccc}
\hline & \multicolumn{5}{c}{ Percentage of the company } \\
\cline { 2 - 7 } $5 \%$ & $10 \%$ & $15 \%$ & $20 \%$ & $25 \%$ & $30 \%$ \\
\hline 1990 & $70.7 \%$ & $82.9 \%$ & $87.6 \%$ & $90.9 \%$ & $92.7 \%$ & $94.4 \%$ \\
1991 & $74.3 \%$ & $83.2 \%$ & $88.1 \%$ & $90.7 \%$ & $92.7 \%$ & $94.2 \%$ \\
1992 & $65.9 \%$ & $76.1 \%$ & $82.1 \%$ & $86.4 \%$ & $89.3 \%$ & $91.4 \%$ \\
1993 & $55.4 \%$ & $68.3 \%$ & $77.6 \%$ & $83 \%$ & $87.5 \%$ & $90.5 \%$ \\
1994 & $51.2 \%$ & $66.8 \%$ & $75.9 \%$ & $82 \%$ & $86.4 \%$ & $89.6 \%$ \\
1995 & $50.7 \%$ & $65.5 \%$ & $75.8 \%$ & $81.7 \%$ & $86.7 \%$ & $89.7 \%$ \\
1996 & $48.4 \%$ & $64.4 \%$ & $74.5 \%$ & $81.2 \%$ & $86 \%$ & $89.3 \%$ \\
1997 & $47.7 \%$ & $63 \%$ & $73.6 \%$ & $80.1 \%$ & $85.7 \%$ & $89 \%$ \\
1998 & $49.1 \%$ & $64 \%$ & $74.3 \%$ & $80.7 \%$ & $86.3 \%$ & $89.4 \%$ \\
1999 & $46.2 \%$ & $62.5 \%$ & $72.5 \%$ & $79.8 \%$ & $84.6 \%$ & $88.3 \%$ \\
2000 & $47 \%$ & $64 \%$ & $74.6 \%$ & $81.1 \%$ & $85.7 \%$ & $89.1 \%$ \\
2001 & $47.5 \%$ & $64.2 \%$ & $74 \%$ & $80.2 \%$ & $85.6 \%$ & $88.9 \%$ \\
2002 & $46.1 \%$ & $64.5 \%$ & $74.1 \%$ & $80.5 \%$ & $85.3 \%$ & $88.9 \%$ \\
2003 & $49 \%$ & $64.9 \%$ & $75 \%$ & $80.7 \%$ & $85.6 \%$ & $88.8 \%$ \\
2004 & $49.4 \%$ & $65.9 \%$ & $75.8 \%$ & $81.9 \%$ & $86.3 \%$ & $89.6 \%$ \\
2005 & $49 \%$ & $67.2 \%$ & $75.2 \%$ & $81.6 \%$ & $86.5 \%$ & $89.4 \%$ \\
2006 & $49 \%$ & $66.3 \%$ & $75.8 \%$ & $82 \%$ & $86.5 \%$ & $89.7 \%$ \\
\hline Average & $52.7 \%$ & $67.9 \%$ & $76.8 \%$ & $82.6 \%$ & $87 \%$ & $90 \%$ \\
\hline
\end{tabular}




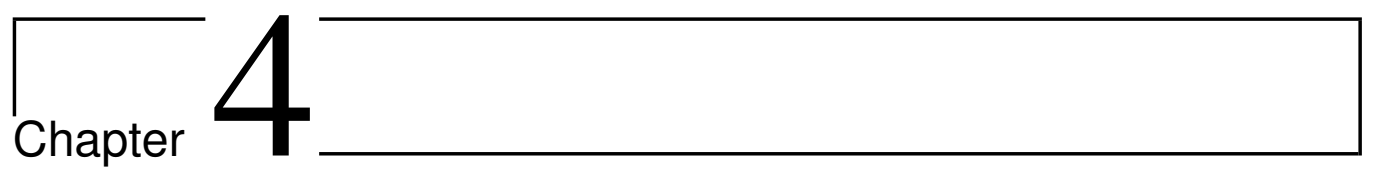

\section{Estimation Results}

This chapter provides all estimation results of the empirical CAPM. As there are two proxies derived for the risk free rate in Chapter 3, we choose to present results estimated using the 10-year government bond yield as the risk free rate in this chapter while all other key results estimated using the capital gain rate as the risk free rate are presented in the Appendix (There are no significant changes in the final estimates of the empirical CAPM).

\subsection{Estimation results: the FM method with the stock betas (SB) as the independent variable (FM SB)}

As described in Chapter 2, stock betas are firstly estimated. Table 4.1 presents the summary statistics of stock beta estimates in each period. The first column shows all estimation periods. The second column presents 
the number of stocks whose beta is estimated and following columns provide the summary statistics. Stock betas are estimated using both OLS and SW methods. As using the SW method does not alter results significantly, they are placed in the Appendix (Table 7.1).

One way to check if stock betas are appropriately estimated is to examine whether the value-weighted stock beta is (approximately) equal to 1 . As the market portfolio is proxied by the NZX All Index and a large part of the index consists of the selected stocks for a given period, a value weighted stock beta should be approximately equal to one. That is:

$$
\bar{\beta}^{V}=\sum_{i=1}^{N} w_{i} \hat{\beta}_{i} \approx 1,
$$

where $w_{i}=\frac{M V_{i}}{M V_{1}+M V_{2}+\cdots+M V_{N}} ; M V_{i}$ denotes the market capitalization of stock $i$, which is calculated by averaging the market capitalization for each stock over the beta-estimation period; $N$ is the total number of stocks to form portfolios and $\hat{\beta}_{i}$ is the estimated beta of stock $i$. For example, for the period of 1990 to 1992, stock betas are estimated. Then, for each stock I take the average of their market capitalization from 1990 to 1992, and divide them by the sum of all stocks' average market capitalization to yield $w_{i}$. By applying (4.1), the value-weighted stock beta is computed. Table 4.1 shows that value-weighted stock betas are approximately equal to 1 for all beta estimation periods, which reflects the reliability of the quality of stock betas. 


\section{Table 4.1: Stock betas estimated using the OLS method with monthly data}

This table shows stock beta estimates. Stocks are selected based on 2 criteria: 1.) a selected stock must have at least two latest years of returns available (out of 3 years of beta estimation period) in order to estimate stock betas. 2.) a selected stock must also have all returns available in the following year in order to perform the cross-sectional regression. The second column shows the number of stocks meeting both conditions. Following columns present the summary statistics of estimated stock betas. The last column shows the value-weight stock betas for each estimation period, which is calculated by taking the average of market capitalization of each stock at each period (90-92, 91-93 etc), dividing it by the sum of all stocks' average market capitalization at the same period to yield $w_{i}$, and finally applying Equation (4.1).

\begin{tabular}{lccccc}
\hline & No. of stocks & Min & Median & Max & Mean $^{V}$ \\
\hline $1990-1992$ & 86 & -1.31 & 0.75 & 3.65 & 0.99 \\
$1991-1993$ & 90 & -1.29 & 0.70 & 4.29 & 0.98 \\
$1992-1994$ & 99 & -0.87 & 0.78 & 3.59 & 1.02 \\
$1993-1995$ & 104 & -0.15 & 0.81 & 3.70 & 1.00 \\
$1994-1996$ & 112 & -0.75 & 0.85 & 2.78 & 1.03 \\
$1995-1997$ & 110 & -0.49 & 0.89 & 5.80 & 1.05 \\
$1996-1998$ & 107 & -0.03 & 0.83 & 3.28 & 1.06 \\
$1997-1999$ & 113 & -0.77 & 0.75 & 3.10 & 0.97 \\
$1998-2000$ & 104 & -0.83 & 0.68 & 2.71 & 0.92 \\
$1999-2001$ & 105 & -0.57 & 0.61 & 2.63 & 0.98 \\
$2000-2002$ & 116 & -2.68 & 0.64 & 3.81 & 1.00 \\
$2001-2003$ & 119 & -2.59 & 0.72 & 4.74 & 1.00 \\
$2002-2004$ & 114 & -1.49 & 0.69 & 3.56 & 0.96 \\
$2003-2005$ & 113 & -2.14 & 0.90 & 3.88 & 1.00 \\
\hline
\end{tabular}


The next step is to estimate $\gamma_{0, t}$ and $\gamma_{1, t}$. As described in Chapter 2, for each month from Jan-93 to Dec-06, tax-adjusted excess stock returns are regressed on their betas estimated using the previous 3-year data, which yields 168 time series estimates of $\gamma_{i, t}$ respectively. Figure 4.1 shows their histograms (Figure 7.1 shows histograms for $\gamma_{0, t}$ and $\gamma_{1, t}$ estimated when the SW method is applied to estimate stock betas). 
Figure 4.1: The Histogram of $\hat{\gamma}_{i, t}$ estimated where the OLS method is used to estimate stock betas

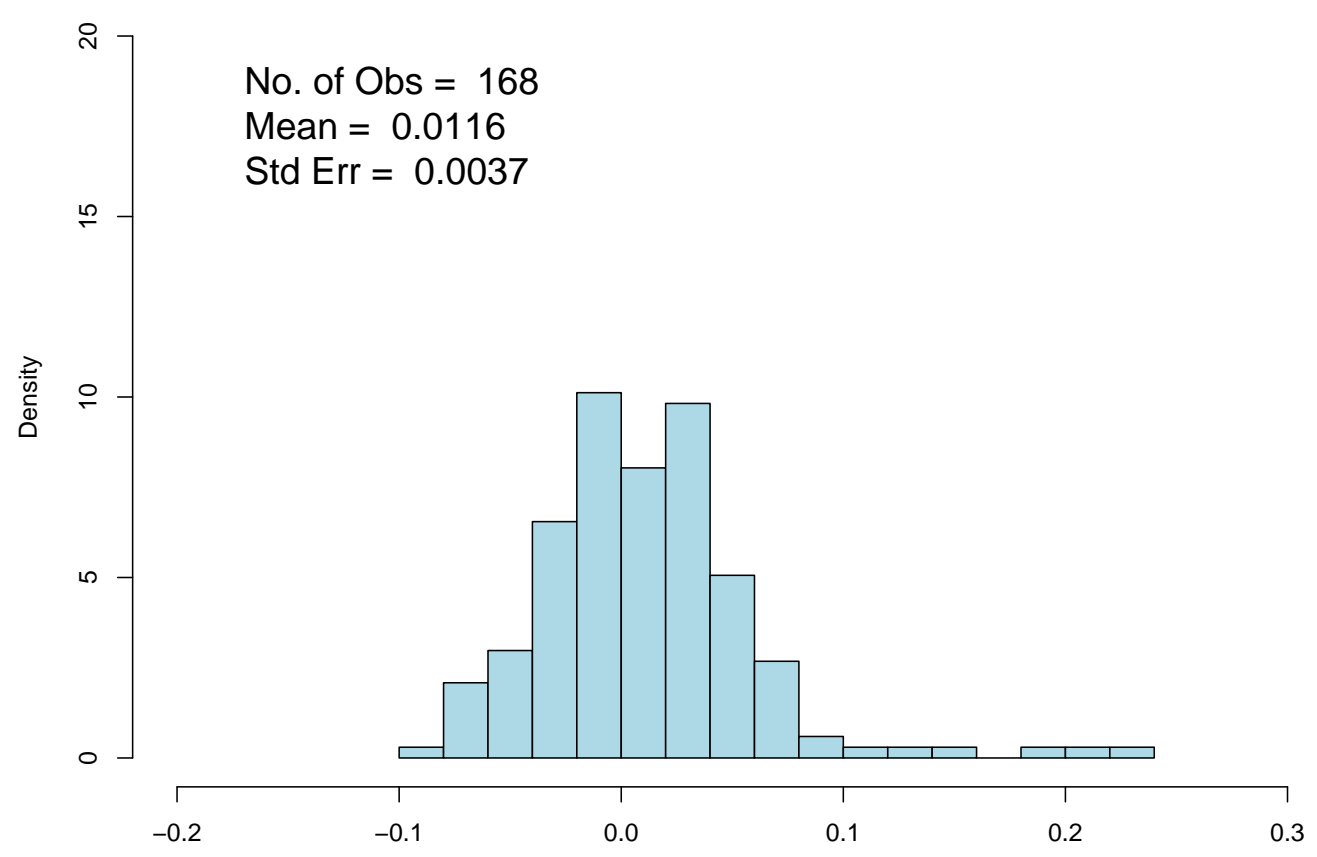

(a) $\gamma_{0, t}$

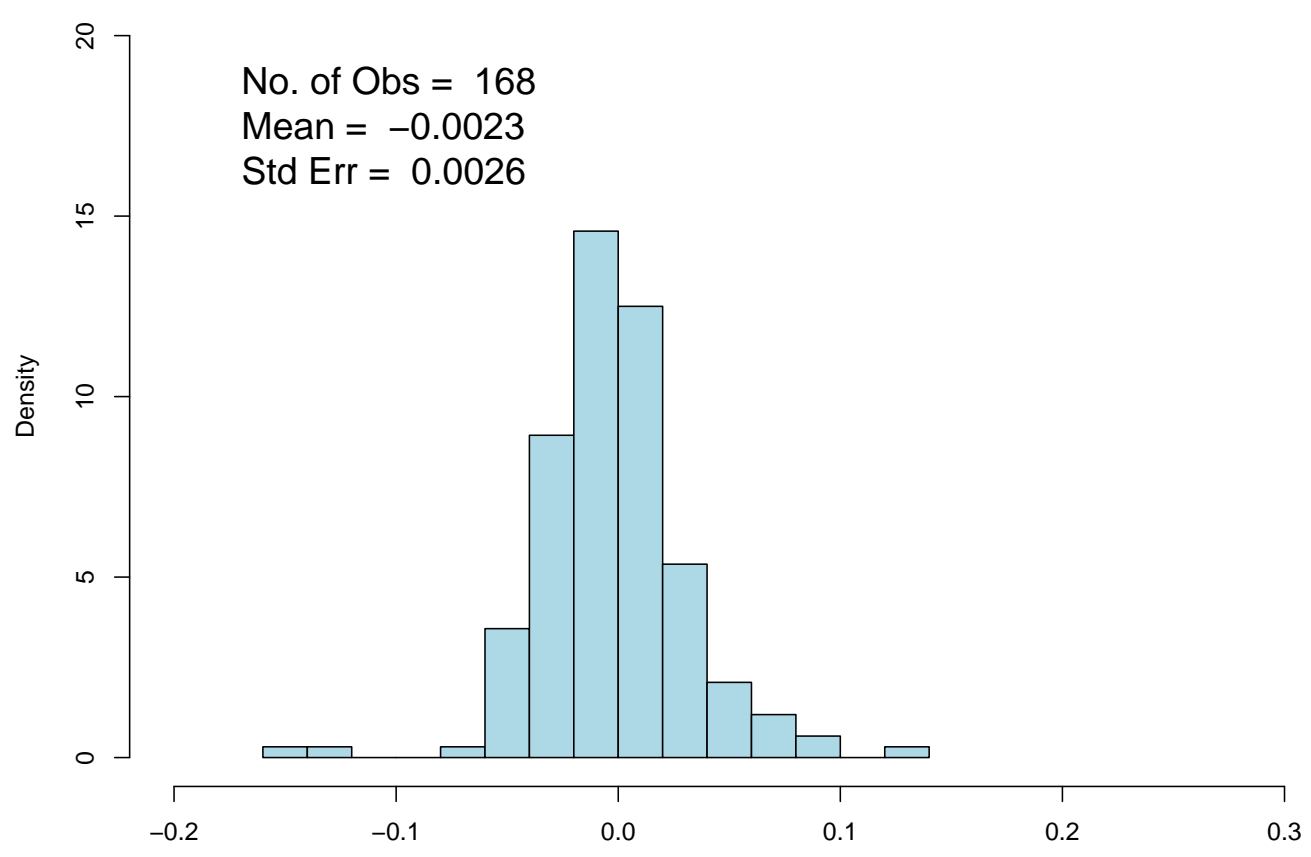

(b) $\gamma_{1, t}$ 
With $\hat{\gamma}_{i, t},(2.2)$ and (2.3) are applied to calculate $\gamma_{i}^{\star}$ and their standard errors respectively. Results are shown in Table 4.2, where "FM SB: OLS" means stock betas used as the independent variable in the FM cross sectional regressions are estimated by the OLS method while "FM SB: SW" means ones are estimated by the SW mehtod. As noted, $\hat{\gamma}_{i}$ and their estimated standard errors, estimated using both methods, are with great similarities, which may contradict to the expectation that the SW model will generate rather different results. The use of monthly data may be the culprit resulting such a contradiction. As the thin trading problem is much alleviated in monthly data, the difference between stock betas estimated from the OLS and SW method may also be narrowed.

To avoid repetition, only one set of $\gamma_{i}^{\star}$ (FM SB: OLS) is used to illustrate how the following results are derived (corresponding results for (FM SB: $\mathrm{SW}$ ) are derived following the same processes). Given the information provided in Table 4.2, the empirical CAPM is then presented by

$$
\tilde{R}_{i}=1.16 \%-0.23 \% \beta_{i}
$$

The standard error of $\tilde{R}_{i}$ is calculated by

$$
\hat{\sigma}\left(\tilde{R}_{i}\right)=\sqrt{(0.37 \%)^{2}+(0.26 \%)^{2} \beta_{i}^{2}+2\left(-3.98 \times 10^{-6}\right) \beta_{i}}
$$

As $\gamma_{i}^{\star}$ are estimated using monthly data, the tax-adjusted excess return and the standard error predicted from the empirical CAPM are also in monthly frequency, which are transferred to the annual frequency to facilitate the comparison with results from the Commission's reports.

For the tax-adjusted excess return, it is compounded up by 12 to yield the 


\section{Table 4.2: The summary of $\gamma_{i}^{\star}-$ FM SB: OLS and SW}

This table shows the summary of $\gamma_{i}^{\star}$ calculated when the independent variable (stock betas) in the cross sectional regressions are estimated using the OLS and SW method. "FM SB: OLS" means stock betas used as the independent variable in the FM cross sectional regressions are estimated by the OLS method while "FM SB: SW" means ones estimated by the SW mehtod. (2.2) and (2.3) are applied to calculated $\gamma_{i}^{\star}$ and their standard errors. The "P-value" are calculated under the alternative hypothesis of $\gamma_{i}^{\star} \neq 0$. The covariance of $\gamma_{i}^{\star}$ is given in this table as well because it will be used in calculating the standard error of the cost of capital in the later chapter. The covariance is calculated by

$$
\operatorname{cov} v\left(\gamma_{0}^{\star}, \gamma_{1}^{\star}\right)=\frac{\operatorname{cov} v\left(\hat{\gamma}_{0, t}, \hat{\gamma}_{1, t}\right)}{168}
$$

\begin{tabular}{ccccc}
\hline \multicolumn{5}{c}{ FM SB: OLS } \\
\hline & $\gamma_{i}^{\star}$ & $\hat{\sigma}\left(\gamma_{i}^{\star}\right)$ & P-value & $c \hat{c o v}\left(\gamma_{0}^{\star}, \gamma_{1}^{\star}\right)$ \\
\cline { 2 - 5 }$\gamma_{0, t}$ & $1.16 \%$ & $0.37 \%$ & 0.002 & $-3.98 \times 10^{-6}$ \\
$\gamma_{1, t}$ & $-0.23 \%$ & $0.26 \%$ & 0.38 & $-3.98 \times 10^{-6}$ \\
\hline \hline
\end{tabular}

FM SB: SW

\begin{tabular}{ccccc}
\hline & $\gamma_{i}^{\star}$ & $\hat{\sigma}\left(\gamma_{i}^{\star}\right)$ & P-value & $c \hat{o} v\left(\gamma_{0}^{\star}, \gamma_{1}^{\star}\right)$ \\
\cline { 2 - 5 }$\gamma_{0, t}$ & $1.20 \%$ & $0.36 \%$ & 0.001 & $-1.88 \times 10^{-6}$ \\
$\gamma_{1, t}$ & $-0.20 \%$ & $0.16 \%$ & 0.21 & $-1.88 \times 10^{-6}$ \\
\hline
\end{tabular}

annual return. That is

$$
\tilde{R}_{i}^{y}=\left(1+\tilde{R}_{i}\right)^{12}-1
$$

where $\tilde{R}_{i}^{y}$ is the estimated annual tax-adjusted excess return for security $i$. The "Delta method"1 (Casella and Berger (2002)) is applied to transfer the

\footnotetext{
${ }^{1}$ Given
}

$$
\sqrt{n}(X-x) \rightarrow N(0, \operatorname{Sd}(X))
$$


monthly standard error to the annual one, which implies

$$
\hat{\sigma}\left(\tilde{R}_{i}^{y}\right) \approx 12 \hat{\sigma}\left(\tilde{R}_{i}\right)
$$

where $\hat{\sigma}\left(\tilde{R}_{i}^{y}\right)$ is the annualized standard error.

In following steps, the 95\% confidence interval for an estimated annual tax-adjusted excess return is calculated by

$$
\begin{aligned}
& \tilde{R}_{i}^{y, \text { lower }}=\tilde{R}_{i}^{y}-1.96 \hat{\sigma}\left(\tilde{R}_{i}^{y}\right) \\
& \tilde{R}_{i}^{y, \text { upper }}=\tilde{R}_{i}^{y}+1.96 \hat{\sigma}\left(\tilde{R}_{i}^{y}\right),
\end{aligned}
$$

where $\tilde{R}_{i}^{y, \text { lower and upper }}$ are the lower and upper bounds for $\tilde{R}_{i}^{y}$ respectively. In order to have a general idea of the difference between the theoretical and empirical CAPM, the latter is used to predict the return for two special securities - the zero systematic risk security and the unit systematic risk security. $\beta_{i}=0$ and 1 are substituted into (4.2) and (4.3) to yield monthly where $\operatorname{Sd}(X))$ is the standard deviation of $X$. The "Delta method" implies

$$
\sqrt{n}(f(X)-f(x)) \rightarrow N\left(0, \operatorname{Sd}(X) f^{\prime}(x)\right)
$$

where $f(.$.$) is a function.$

In this paper,

$$
\sqrt{n}\left(\tilde{R}_{i}-\tilde{r}_{i}\right) \rightarrow N\left(0, \hat{\sigma}\left(\tilde{R}_{i}\right)\right),
$$

where $\tilde{r}_{i}$ is the true value of $\tilde{R}_{i}$. Then,

$$
\sqrt{n}\left(f\left(\tilde{R}_{i}\right)-f\left(\tilde{r}_{i}\right)\right) \rightarrow N\left(0, \hat{\sigma}\left(\tilde{R}_{i}\right) f^{\prime}\left(\tilde{r}_{i}\right)\right),
$$

where $f\left(\tilde{r}_{i}\right)=\left(1+\tilde{r}_{i}\right)^{12}-1$ and $f^{\prime}\left(\tilde{r}_{i}\right)=12\left(1+\tilde{r}_{i}\right)^{11}$. Assuming $\left(1+\tilde{r}_{i}\right)$ is very close to $1, f^{\prime}\left(\tilde{r}_{i}\right) \approx 12$. As noticed, this approximation will understate the annualized standard error. 
estimates

$$
\begin{aligned}
\tilde{R}_{i} \mid\left(\beta_{i}=0\right) & =1.16 \% \\
\hat{\sigma}\left(\tilde{R}_{i}\right) \mid\left(\beta_{i}=0\right) & =0.37 \% \\
\tilde{R}_{i} \mid\left(\beta_{i}=1\right) & =0.93 \% \\
\hat{\sigma}\left(\tilde{R}_{i}\right) \mid\left(\beta_{i}=1\right) & =\sqrt{(0.37 \%)^{2}+(0.26 \%)^{2}+2\left(-3.98 \times 10^{-6}\right)} \\
& =0.36 \%
\end{aligned}
$$

Then, these monthly estimates are transferred to annual estimates applying (4.4) and (4.5)

$$
\begin{aligned}
\tilde{R}_{i}^{y} \mid\left(\beta_{i}=0\right) & =(1+1.16 \%)^{12}-1=14.9 \% \\
\hat{\sigma}\left(\tilde{R}_{i}^{y}\right) \mid\left(\beta_{i}=0\right) & \approx 12 \times 0.37 \%=4.41 \% \\
\tilde{R}_{i}^{y} \mid\left(\beta_{i}=1\right) & =(1+0.93 \%)^{12}-1=11.8 \% \\
\hat{\sigma}\left(\tilde{R}_{i}^{y}\right) \mid\left(\beta_{i}=1\right) & \approx 12 \times 0.36 \%=4.25 \%
\end{aligned}
$$

Finally, the 95\% confidence interval is calculated applying (4.6)

$$
\begin{aligned}
& \tilde{R}_{i}^{y \text {,lower }} \mid\left(\beta_{i}=0\right)=14.9 \%-1.96 \times 4.41 \%=6.23 \% \\
& \tilde{R}_{i}^{y \text {,upper }} \mid\left(\beta_{i}=0\right)=14.9 \%+1.96 \times 4.41 \%=23.5 \% \\
& \tilde{R}_{i}^{y \text { lower }} \mid\left(\beta_{i}=1\right)=11.8 \%-1.96 \times 4.25 \%=3.5 \% \\
& \tilde{R}_{i}^{y \text {,upper }} \mid\left(\beta_{i}=1\right)=11.8 \%+1.96 \times 4.25 \%=20.2 \%
\end{aligned}
$$

Table 4.3 summarizes final outputs from the above processes - annualized tax-adjusted excess returns and 95\% confidence intervals for the zero and unit systematic risk securities. Returns for both securities are predicted with very wide confidence intervals and the security with $\beta_{i}=0$ is predicted to have a greater return than the one with $\beta_{i}=1$. The empirical 
CAPM seems to contradict to the theoretical one (1.3). In order to carry on more sophisticated investigation on both theoretical and empirical CAPM, they are plotted in the same graph.

\section{Table 4.3: The $95 \%$ confidence interval of the estimated an- nual tax-adjusted excess returns for two special securities: $\beta=0$ and $1-$ FM SB: OLS and SW}

This table shows the 95\% confidence interval constructed for the estimated annual taxadjusted excess return of 2 special securities with $\beta=0$ and 1 respectively. As outputs from (4.2) and (4.3) are in monthly frequency, they have to be annualized by applying (4.4) and (4.5). Finally, the 95\% confidence interval is calculated applying (4.6)

\begin{tabular}{ccccc}
\hline \multicolumn{5}{c}{ FM SB: OLS } \\
\hline \multirow{5}{*}{$\beta=0$} & Lower bound & Mean & Upper bound & Std Err \\
\cline { 2 - 5 }$\beta=1$ & $6.23 \%$ & $14.9 \%$ & $23.5 \%$ & $4.41 \%$ \\
\hline \hline \multirow{5}{c}{ FM SB: SW } \\
\hline \multirow{5}{*}{$\beta=0$} & Lower bound & Mean & Upper bound & Std Err \\
\cline { 2 - 5 }$\beta=1$ & $7.02 \%$ & $15.4 \%$ & $23.7 \%$ & $4.27 \%$ \\
\hline
\end{tabular}

The graph is plotted in the space, where the $x$ axis shows the systematic risk ranging from 0 to 1 and the $y$ axis shows the annual tax-adjusted excess return. For each systematic risk from 0 to 1, the corresponding annualized tax-adjusted excess return is calculated by

$$
\tilde{R}_{i}^{y}=\left(1+1.16 \%-0.23 \% \beta_{i}\right)^{12}-1
$$


(4.10) is obtained by substituting (4.2) into (4.4). The $95 \%$ confidence interval is calculated by

$$
\begin{aligned}
\tilde{R}_{i}^{y, \text { lower }}= & \left(\left(1+1.16 \%-0.23 \% \beta_{i}\right)^{12}-1\right) \\
& -1.96 \times 12 \sqrt{(0.37 \%)^{2}+(0.26 \%)^{2} \beta_{i}^{2}+2\left(-3.98 \times 10^{-6}\right) \beta_{i}} \\
\tilde{R}_{i}^{y \text {,upper }}= & \left(\left(1+1.16 \%-0.23 \% \beta_{i}\right)^{12}-1\right) \\
& +1.96 \times 12 \sqrt{(0.37 \%)^{2}+(0.26 \%)^{2} \beta_{i}^{2}+2\left(-3.98 \times 10^{-6}\right) \beta_{i}}
\end{aligned}
$$

(4.11) is obtained by substituting (4.3) and (4.5) into (4.6).

(4.10) and (4.11) are functions of the systematic risk $\left(\beta_{i}\right)$. As the value of $\beta_{i}$ varies from 0 to 1 , the corresponding returns and the confidence interval are produced. (4.10) presents an approximate linear relationship between the annualized return and the systematic risk as the small coefficient value in front of the $\beta_{i}$ will make its square, cube and high power values negligible.

On the other hand, the theoretical form of the CAPM is presented by

$$
\tilde{R}_{i}=\widehat{M R P} \beta_{i},
$$

where $\widehat{M R P}$ is the tax-adjusted market risk premium. In order to plot the theoretical CAPM, $\widehat{M R P}$ is assumed to be $7 \%$, which is taken from one of the Commission's reports (Commerce Commission (2005b)).

Figure (4.2) plots the empirical and the theoretical form of the CAPM. The black line shows annual tax-adjusted excess returns predicted from (4.10) for any given systematic risk from 0 to 1 . The dotted curves are the $95 \%$ confidence intervals calculated from (4.11). The gray line represents the CAPM calculated from (4.12). 
The empirical CAPM is virtually a flat line compared to the theoretical one, and the confidence interval is remarkably wide. When $\beta_{i}=0$, the lower bound of the empirical CAPM's prediction is even higher than the mean value predicted from the theoretical CAPM. Most notably, returns predicted from the empirical CAPM are consistently greater than ones predicted from the theoretical one.

The virtually flat line with the wide confidence interval imply that the empirical relationship between the expected return and the systematic risk in New Zealand might not be what have been stated in the CAPM theory or at least the return is not as responsive to the systematic risk as it is believed be. The significant intercept coefficient of the empirical CAPM suggests that there might be other risks, in addition to the systematic risk, that investors in New Zealand are care about. Therefore, it is possible that the theoretical CAPM may underestimate the cost of equity required by the New Zealand market.

On the other hand, above results may be imprecise or even incorrect due to a flawed estimation method - with estimated stock betas used as the independent variable in the FM cross sectional regression, the error-in-variable problem may refrain from the precise estimation of the empirical CAPM. In order to minimize the error-in-variable problem (hopefully), estimated portfolio betas take over of the role of stock betas since Fama and MacBeth (1973) argued that the former can be more precisely estimated than the latter under certain conditions. Therefore, results estimated using portfolio betas as the independent variable in the FM cross sectional regressions are presented and analyzed in following contents. 
Figure 4.2: The plot of the empirical and theoretical CAPM

- FM SB: OLS and SW

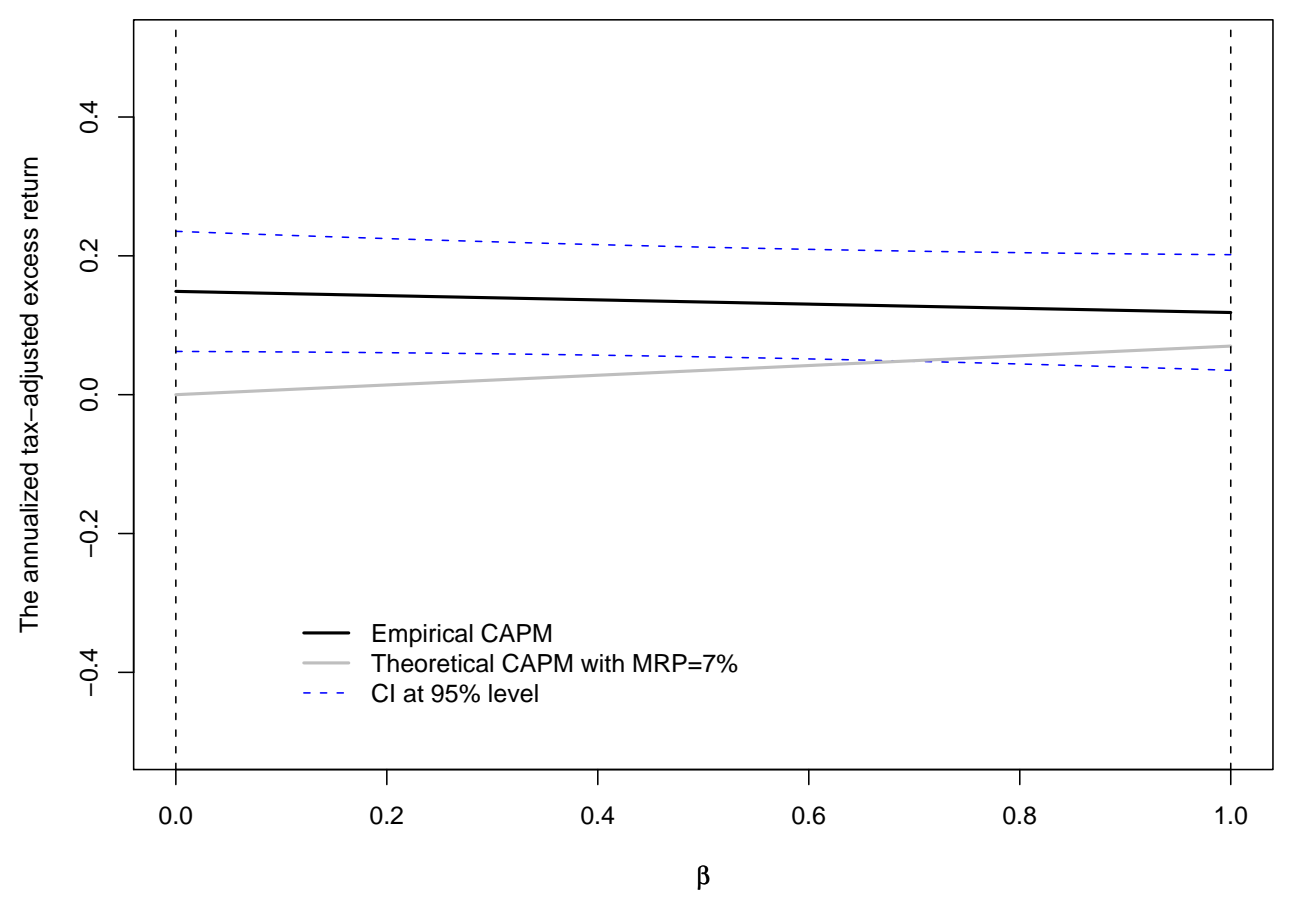

(a) FM SB: OLS

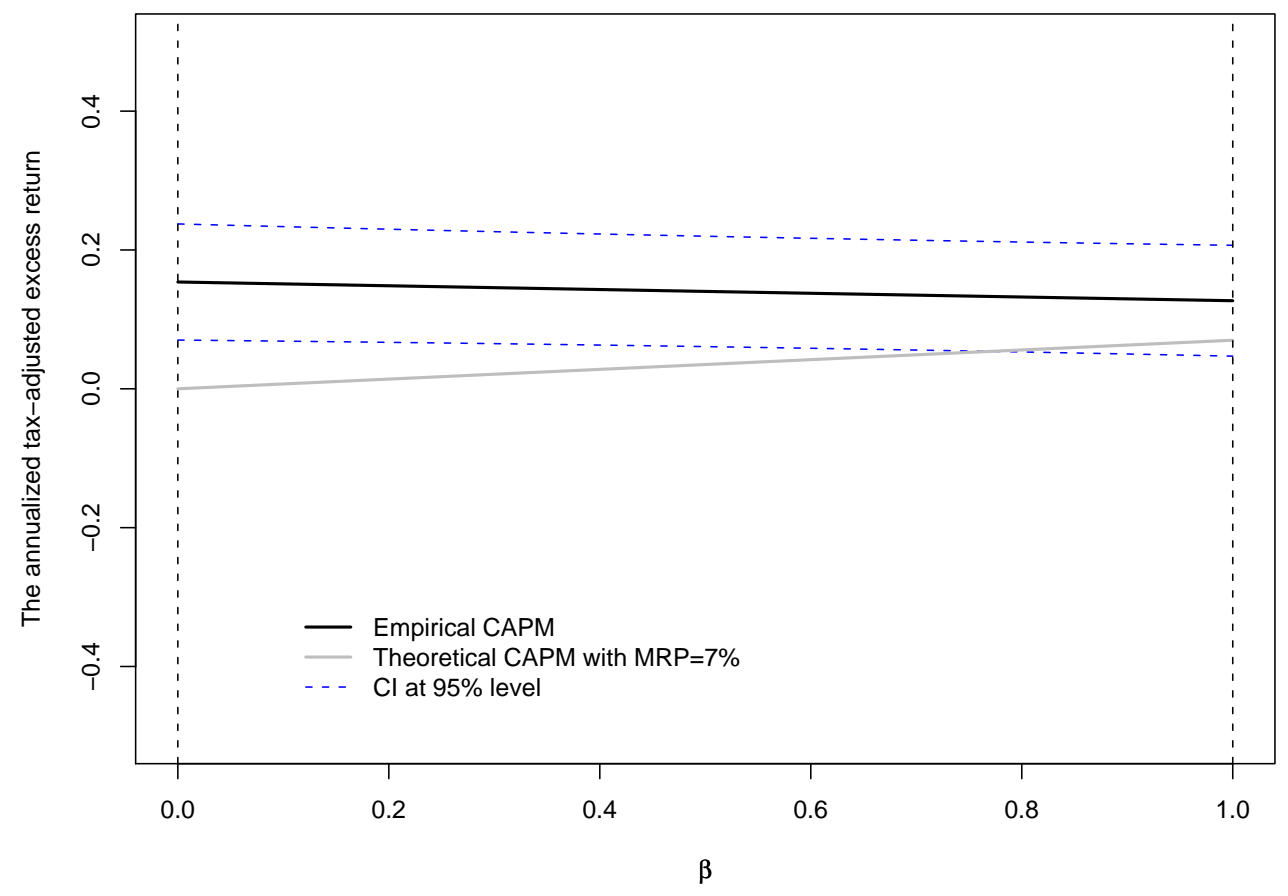

(b) FM SB: SW 


\subsection{Estimation results: the FM method with the portfolio betas (PB) as the independent vari- able (FM PB)}

\subsubsection{The baseline case result: monthly data with the OLS beta-estimation method}

Baseline results are built upon the monthly data, and most importantly, portfolio betas, estimated using the OLS method, are used as the independent variable in the FM cross-sectional regressions.

Stock betas (estimated using the OLS mehtod) have already been estimated and presented in the previous section (Table 4.1). Portfolios are formed and returns are calculated in the way described in Chapter 2, which yield 10 portfolios with returns from Jan-93 to Dec-06. Then, their betas are estimated using the OLS method.

The summary statistics of 10 portfolios betas are presented in Table 4.4 (As $\hat{\alpha}$ are so insignificant, they are scaled up by multiplying 100 to be visible in 3 decimal places). Notably, $\hat{\alpha}$ are positive for all portfolios, which suggests that the CAPM may understate expected returns for all securities from Jan90 to Dec-06. Although, only two $\hat{\alpha}$ are significant at 5\% level, Black et al. (1972) points out that interpreting t-statistics should be undertaken with caution because of the violation of normality assumptions, and suggested that low t-statistics for $\hat{\alpha}$ can still indicate an alternative form of CAPM or missing independent variables. 


\section{Table 4.4: The summary of portfolio betas estimated using the OLS method}

Portfolio betas are estimated by regressing portfolio returns on market portfolio returns for the entire period - 1993-2006. $\hat{\alpha}$ is the estimated intercept coefficient, which is scaled up by 100 times in order to be visible in 3 decimal places; $\hat{\beta}$ is the estimated slope coefficient. The bracketed numbers are t-statistics of null hypothesis if $\alpha=0$ or $\beta=0$.

\begin{tabular}{ccccccccccc}
\hline & P1 & P2 & P3 & P4 & P5 & P6 & P7 & P8 & P9 & P10 \\
\hline $100 \hat{\alpha}$ & 0.36 & 0.59 & 0.85 & 0.02 & 0.71 & 0.43 & 0.18 & 0.25 & 0.98 & 0.03 \\
& $(0.85)$ & $(1.77)$ & $(2.76)$ & $(0.05)$ & $(1.91)$ & $(1.46)$ & $(0.61)$ & $(0.74)$ & $(2.83)$ & $(0.07)$ \\
$\hat{\beta}$ & 0.69 & 0.59 & 0.55 & 0.91 & 0.85 & 0.95 & 0.94 & 1 & 0.98 & 1.3 \\
& $(6.79)$ & $(7.4)$ & $(7.59)$ & $(10.8)$ & $(9.6)$ & $(13.68)$ & $(13.51)$ & $(12.33)$ & $(11.91)$ & $(12.38)$ \\
\hline
\end{tabular}

The next step is to estimate $\gamma_{i, t}$ following the method described in Chapter 2. Their histograms are presented in Figure (4.3), where compared with Figure (4.1), there are more extreme values in $\hat{\gamma}_{i, t}$ estimated using portfolio betas than using stock betas. 
Figure 4.3: The Histogram of $\hat{\gamma}_{i, t}-$ FM PB: OLS+OLS

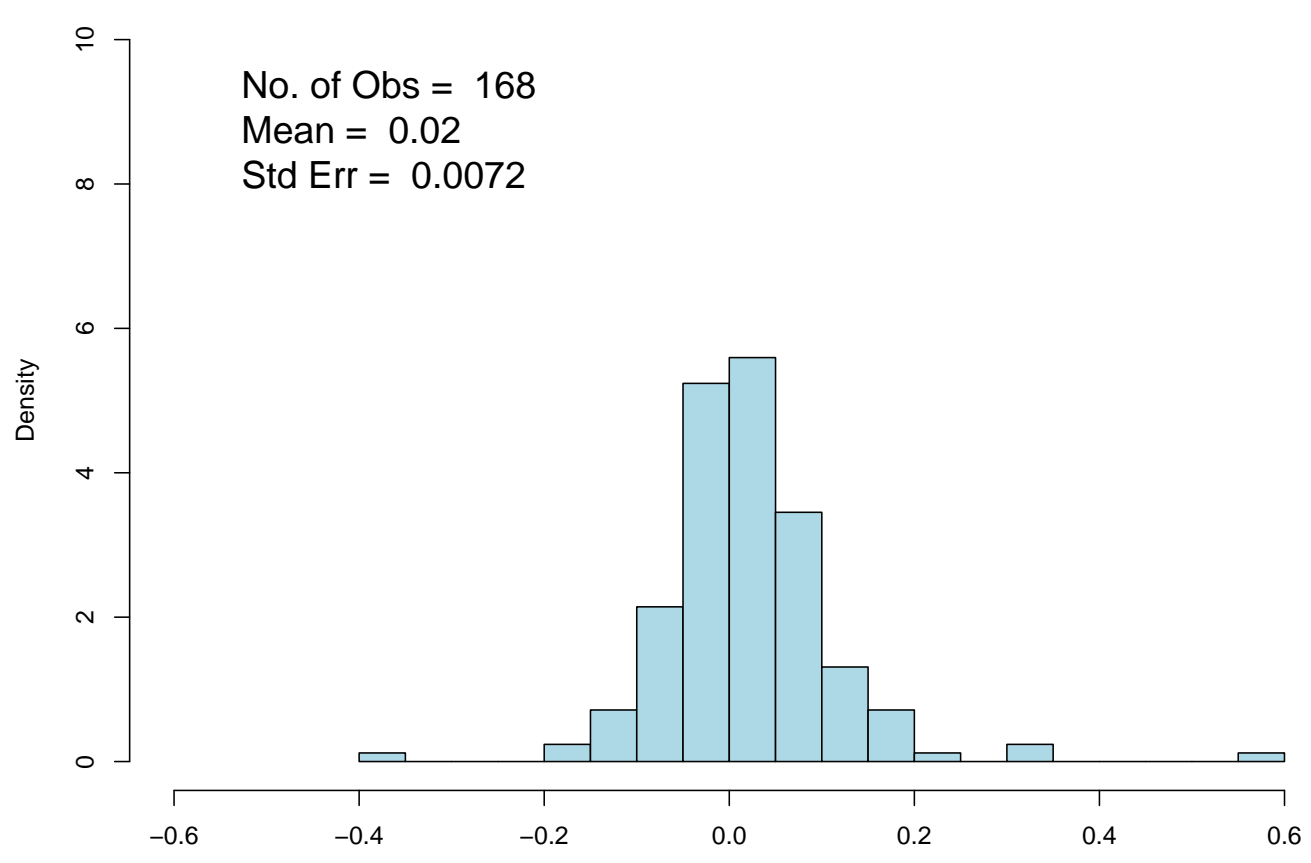

(a) $\gamma_{0, t}$

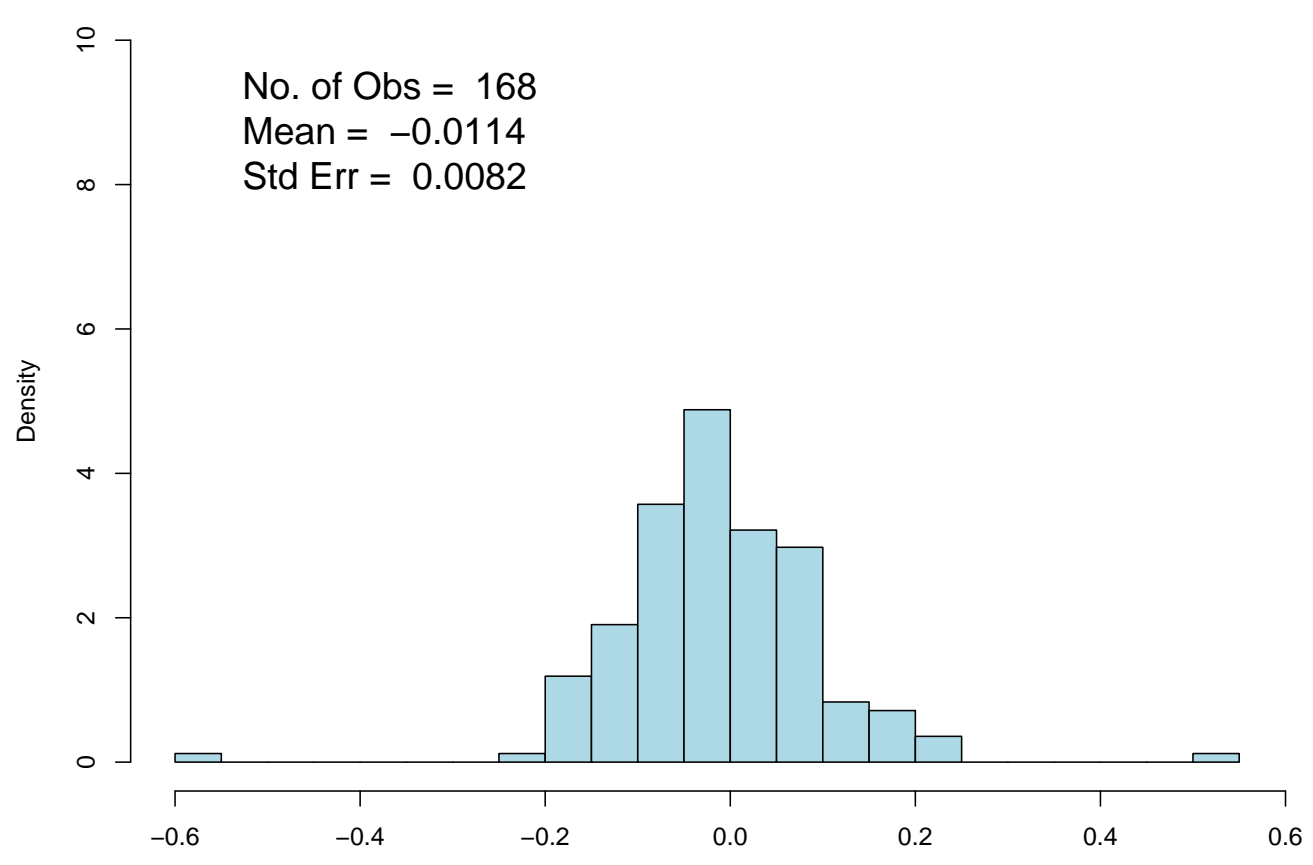

(b) $\gamma_{1, t}$ 
$\gamma_{i}^{\star}$ and $\hat{\sigma}\left(\gamma_{i}^{\star}\right)$ are calculated applying (2.2) and (2.3) respectively. Table 4.5 summarizes key estimates. There is a feature worth noting from the table, which is that $\gamma_{i}^{\star}$ estimated using portfolio betas have larger standard errors than ones estimated using the stock betas. This feature may signal that using stock betas as the independent variable is superior to using the portfolio betas. The sign and the statistical significance of $\gamma_{i}^{\star}$ are exactly the same in both cases.

\section{Table 4.5: The summary of $\gamma_{i}^{\star}$ - FM PB: OLS+OLS}

This table summarizes key estimates of $\gamma_{i}^{\star}$. "FM PB: OLS+OLS" means that 1.) portfolios betas are used as the independent variable in the FM cross sectional regressions and 2.) stock betas are estimated using the OLS method, and ranked to form 10 portfolios, whose betas are then estimated using the OLS method. (2.2) and (2.3) are applied to calculate $\gamma_{i}^{\star}$ and their standard errors respectively. The "P-value" are calculated under the alternative hypothesis of $\gamma_{i}^{\star} \neq 0$. The covariance of $\gamma_{i}^{\star}$ is given in this table as well because it will be useful in calculating the standard error of the cost of capital in the later chapter. The covariance is calculated by

\begin{tabular}{ccccc}
\multicolumn{5}{c}{$c \hat{o} v\left(\gamma_{0}^{\star}, \gamma_{1}^{\star}\right)=\frac{\operatorname{cov}\left(\hat{\gamma}_{0, t}, \hat{\gamma}_{1, t}\right)}{168}$} \\
\hline & $\gamma_{i}^{\star}$ & $\hat{\sigma}\left(\gamma_{i}^{\star}\right)$ & P-value & $\operatorname{cov} v\left(\gamma_{0}^{\star}, \gamma_{1}^{\star}\right)$ \\
\cline { 2 - 5 }$\gamma_{0}$ & $2.0 \%$ & $0.72 \%$ & 0.005 & $-5.26 \times 10^{-5}$ \\
$\gamma_{1}$ & $-1.14 \%$ & $0.82 \%$ & 0.16 & $-5.26 \times 10^{-5}$ \\
\hline
\end{tabular}

Using the information provided in Table 4.5, the empirical CAPM is then presented as

$$
\tilde{R}_{i}=2.0 \%-1.14 \% \beta_{i}
$$


The standard error of $\tilde{R}_{i}$ is calculated by

$$
\hat{\sigma}\left(\tilde{R}_{i}\right)=\sqrt{(0.72 \%)^{2}+(0.82 \%)^{2} \beta_{i}^{2}+2\left(-5.26 \times 10^{-5}\right) \beta_{i}}
$$

Once again, the newly estimated empirical CAPM is used to predict returns for two special securities - the zero systematic risk security and the unit systematic risk one. $\beta_{i}=0$ and 1 are substituted into (4.13) and (4.14) to yield monthly estimates

$$
\begin{aligned}
\tilde{R}_{i} \mid\left(\beta_{i}=0\right) & =2.0 \% \\
\hat{\sigma}\left(\tilde{R}_{i}\right) \mid\left(\beta_{i}=0\right) & =0.72 \% \\
\tilde{R}_{i} \mid\left(\beta_{i}=1\right) & =0.86 \% \\
\hat{\sigma}\left(\tilde{R}_{i}\right) \mid\left(\beta_{i}=1\right) & =\sqrt{(0.72 \%)^{2}+(0.82 \%)^{2}+2\left(-5.26 \times 10^{-5}\right)} \\
& =0.37 \%
\end{aligned}
$$

Then, these monthly estimates are transferred to annual ones applying (4.4) and (4.5)

$$
\begin{aligned}
\tilde{R}_{i}^{y} \mid\left(\beta_{i}=0\right) & =(1+2.0 \%)^{12}-1=26.8 \% \\
\hat{\sigma}\left(\tilde{R}_{i}^{y}\right) \mid\left(\beta_{i}=0\right) & \approx 12 \times 0.72 \%=8.66 \% \\
\tilde{R}_{i}^{y} \mid\left(\beta_{i}=1\right) & =(1+0.67 \%)^{12}-1=10.8 \% \\
\hat{\sigma}\left(\tilde{R}_{i}^{y}\right) \mid\left(\beta_{i}=1\right) & \approx 12 \times 0.37 \%=4.53 \%
\end{aligned}
$$

Finally, the $95 \%$ confidence interval is constructed by applying (4.6)

$$
\begin{aligned}
& \tilde{R}_{i}^{y, \text { lower }} \mid\left(\beta_{i}=0\right)=26.8 \%-1.96 \times 8.66 \%=9.86 \% \\
& \tilde{R}_{i}^{y \text {,upper }} \mid\left(\beta_{i}=0\right)=26.8 \%+1.96 \times 8.66 \%=43.8 \% \\
& \tilde{R}_{i}^{y \text { lower }} \mid\left(\beta_{i}=1\right)=8.3 \%-1.96 \times 4.7 \%=1.97 \% \\
& \tilde{R}_{i}^{y \text {,upper }} \mid\left(\beta_{i}=1\right)=8.3 \%+1.96 \times 4.7 \%=19.7 \%
\end{aligned}
$$


Table 4.6 summarizes annualized tax-adjusted excess returns and the $95 \%$ confidence interval for the zero and unit systematic risk securities. Compared with previous estimates (Table 4.3), returns for both securities are predicted with even wider confidence interval when portfolio betas are used as the independent variable in the FM cross sectional regressions. Moreover, the security with $\beta_{i}=0$ is predicted of much greater return than the one with $\beta_{i}=1$ ( $26.8 \%$ and $\left.10.8 \%\right)$.

\section{Table 4.6: The $95 \%$ confidence interval of the estimated an- nual tax-adjusted excess returns for two special securities: $\beta=0$ and 1 - FM PB: OLS+OLS}

This table shows the $95 \%$ confidence interval constructed for the estimated annual taxadjusted excess returns of 2 special securities with $\beta=0$ and 1 respectively.

\begin{tabular}{ccccc}
\hline & Lower bound & Mean & Upper bound & Std Err \\
\cline { 2 - 5 }$\beta=0$ & $9.86 \%$ & $26.8 \%$ & $43.8 \%$ & $8.66 \%$ \\
$\beta=1$ & $1.97 \%$ & $10.8 \%$ & $19.7 \%$ & $4.53 \%$ \\
\hline
\end{tabular}

The empirical and theoretical forms of the CAPM again are plotted. The empirical CAPM is constructed following the way described in the previous section. For each systematic risk ranging from 0 to 1 , the corresponding annualized tax-adjusted excess return is calculated by

$$
\tilde{R}_{i}^{y}=\left(1+2.0 \%-1.14 \% \beta_{i}\right)^{12}-1
$$


The $95 \%$ confidence interval is calculated by

$$
\begin{aligned}
\tilde{R}_{i}^{y, \text { lower }}= & \left(\left(1+2.0 \%-1.14 \% \beta_{i}\right)^{12}-1\right) \\
& -1.96 \times 12 \sqrt{(0.72 \%)^{2}+(0.82 \%)^{2} \beta_{i}^{2}+2\left(-5.26 \times 10^{-5}\right) \beta_{i}} \\
\tilde{R}_{i}^{y, \text { upper }}= & \left(\left(1+2.0 \%-1.14 \% \beta_{i}\right)^{12}-1\right) \\
& +1.96 \times 12 \sqrt{(0.72 \%)^{2}+(0.82 \%)^{2} \beta_{i}^{2}+2\left(-5.26 \times 10^{-5}\right) \beta_{i}}
\end{aligned}
$$

The theoretical form of the CAPM remains the same, where $\widehat{M R P}$ is again assumed to be $7 \%$.

Figure 4.4: The plot of the empirical and theoretical CAPM

\section{- FM PB: OLS+OLS}

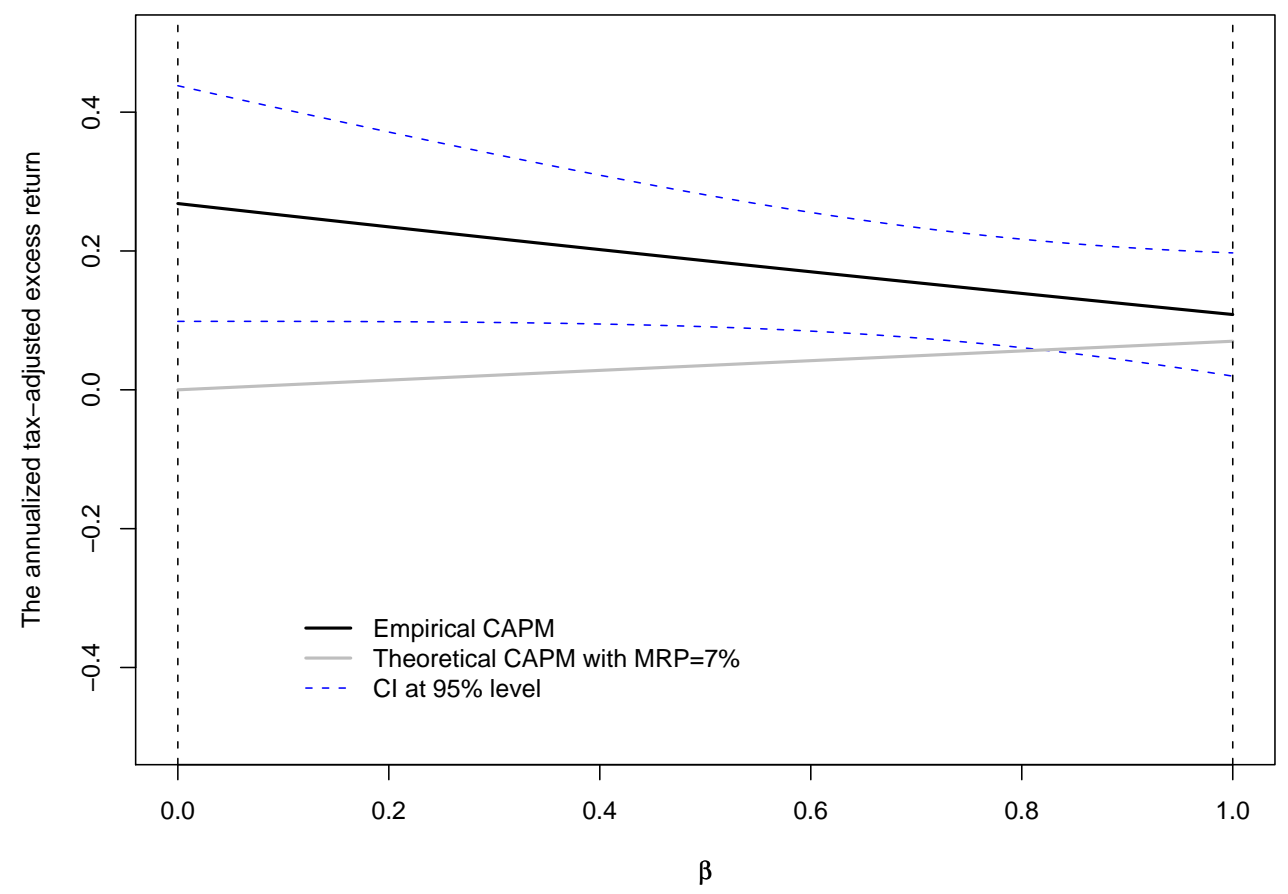

Results shown in Figure 4.4 and 4.2 share great similarities. The empirical 
CAPM is always downward sloping with the wide-open confidence interval, which may suggest the ambiguous empirical relationship between the expected return and the systematic risk in New Zealand. The significantly positive return on the zero-beta security may indicate the possibility of the existence of risks that investors may require extra returns on, but being omitted by the theoretical CAPM.

The greater width of the confidence intervals shown in Figure 4.4 (v.s Figure 4.2) may cast doubts on the selected estimation methodology. The reason for using portfolio betas is to improve the precision of the independent variable, which may lead to less standard error in $\gamma_{i}^{\star}$. However, it appears that using the stock betas as the independent variable may be a better choice, which may be due to two reasons.

The first reason is that the precision of estimated portfolio betas may not be better than that of estimated stock betas. As stated in Fama and MacBeth (1973), one condition that portfolio betas can be more precisely estimated is that errors in stock beta estimates should be significantly less than perfectly positively correlated, or in other words, the portfolio is well diversified. However, given the small size of the New Zealand Stock Market, this condition may not be achieved. If that is the case, then using stock beta estimates as the independent variable in the cross-sectional regressions is indeed a better choice.

The second reason is that methods for forming portfolios and estimating betas may worsen, instead of improving, the precision of portfolio beta estimates. As discussed in Chapter 2, the OLS estimator of a security's beta tends to bias downward when that security is infrequently traded. Given 
the thin trading problem inhabited in the stock return data (Table 3.2), the OLS may not be the ideal method to estimate stock and portfolio betas. If that is the case, the precision of $\gamma_{i}^{\star}$ may be improved if using a better beta estimation method - the SW model.

Therefore, in the following section, I will adopt a different method to estimate stock and portfolio betas - the SW method (Scholes and Williams (1977)) - to take care of the thin trading problem. In addition, all analyses are carried on the weekly data. Reasons for doing so are two-folds. Firstly, it may be a chance to improve the precision of $\gamma_{i}^{\star}$ (less standard errors). Second, it offers an opportunity to perform robustness check on existing results.

\subsubsection{Robust check I: monthly data with the SW beta-estimation method}

The OLS method may not be sufficient for consistently estimating stock and portfolio betas because of the thin trading problem inhabited in the stock return data in New Zealand (Scholes and Williams (1977), Cohen et al. (1983) and Bartholdy and Riding (1994)). The SW model is therefore adopted to overcome this problem.

More specifically, the detailed methodology described in Chapter 2 remains except for switching the OLS to SW method. The SW method will be applied to estimate stock betas. Then, the SW method is applied again to estimate portfolio betas. As thin trading problem is largely alleviated in portfolio returns, the OLS method is applied to estimate portfolio betas as 
well.

Stock and portfolio beta estimates are presented in Table 7.1 and 7.2 in the Appendix. These tables show that the SW and OLS method produce very similar beta estimates, which may be due to the use of the monthly data (the alleviated thin trading problem).

In order to facilitate the comparison, Table 4.7 summarizes all $\gamma_{i}^{\star}$ estimated using FM SB: OLS and SW, and FM PB: OLS+OLS, SW+SW and SW+OLS, where OLS+OLS, SW+SW and SW+OLS represent combinations of method. The first method is the method used to estimate stock betas while the second is for estimating portfolio betas.

As noted, the change in the beta-estimation method from the OLS to the SW model does not alter $\gamma_{i}^{\star}$ significantly. Results from OLS+OLS and SW+OLS are nearly identical. The only "outlier" seems to be the SW+SW method, where the $\gamma_{1}^{\star}$ is positive but still insignificant, and the $\gamma_{0}^{\star}$ is insignificant. The table also illustrate that the standard error of $\gamma_{i}^{\star}$ is much smaller when stock betas are used as the independent variable, which may confirm our guess that using portfolio beta as the independent variable in the FM cross sectional regressions may not be suitable for studies using the New Zealand stock data because of the limited number of firms. (Table 7.5 shows the same results with the capital gain returns as the proxy for the risk free rate. It appears that the change of the proxy for the risk free rate does not alter the final results critically.) 


\section{Table 4.7: The summary of $\gamma_{i}^{\star}-$ FM SB: OLS and SW; FM PB: OLS+OLS, SW+SW and SW+OLS}

The table presents all $\gamma_{i}^{\star}$. Results for FM SB: OLS and SW, and FM PB: OLS+OLS are obtained from Table 4.2 and 4.5 respectively. OLS+OLS, SW+SW and SW+OLS represent combinations of method. The first method is the method used to estimate stock betas while the second is for estimating portfolio betas. Results from the OLS+OLS combination are the baseline results while ones from the SW+SW and SW+OLS combinations are for the robustness check.

\begin{tabular}{|c|c|c|c|c|}
\hline \multicolumn{5}{|c|}{ FM SB: OLS } \\
\hline & $\gamma_{i}^{\star}$ & $\hat{\sigma}\left(\gamma_{i}^{\star}\right)$ & P-value & $\operatorname{cov} v\left(\gamma_{0}^{\star}, \gamma_{1}^{\star}\right)$ \\
\hline$\gamma_{0, t}$ & $1.16 \%$ & $0.37 \%$ & 0.002 & $-3.98 \times 10^{-6}$ \\
\hline$\gamma_{1, t}$ & $-0.23 \%$ & $0.26 \%$ & 0.38 & $-3.98 \times 10^{-6}$ \\
\hline \multicolumn{5}{|c|}{ FM SB: SW } \\
\hline & $\gamma_{i}^{\star}$ & $\hat{\sigma}\left(\gamma_{i}^{\star}\right)$ & P-value & $\operatorname{cô} v\left(\gamma_{0}^{\star}, \gamma_{1}^{\star}\right)$ \\
\hline$\gamma_{0, t}$ & $1.20 \%$ & $0.36 \%$ & 0.001 & $-1.88 \times 10^{-6}$ \\
\hline$\gamma_{1, t}$ & $-0.20 \%$ & $0.16 \%$ & 0.21 & $-1.88 \times 10^{-6}$ \\
\hline \multicolumn{5}{|c|}{ FM PB: OLS+OLS } \\
\hline & $\gamma_{i}^{\star}$ & $\hat{\sigma}\left(\gamma_{i}^{\star}\right)$ & P-value & $\operatorname{cov} v\left(\gamma_{0}^{\star}, \gamma_{1}^{\star}\right)$ \\
\hline$\gamma_{0}$ & $2.0 \%$ & $0.72 \%$ & 0.005 & $-5.26 \times 10^{-5}$ \\
\hline$\gamma_{1}$ & $-1.14 \%$ & $0.82 \%$ & 0.16 & $-5.26 \times 10^{-5}$ \\
\hline \multicolumn{5}{|c|}{ FM PB: SW+SW } \\
\hline & $\gamma_{i}^{\star}$ & $\hat{\sigma}\left(\gamma_{i}^{\star}\right)$ & P-value & $c \hat{o} v\left(\gamma_{0}^{\star}, \gamma_{1}^{\star}\right)$ \\
\hline$\gamma_{0, t}$ & $0.72 \%$ & $0.73 \%$ & 0.32 & $-4.1 \times 10^{-5}$ \\
\hline$\gamma_{1, t}$ & $0.30 \%$ & $0.64 \%$ & 0.64 & $-4.1 \times 10^{-5}$ \\
\hline \multicolumn{5}{|c|}{ FM PB: SW+OLS } \\
\hline & $\gamma_{i}^{\star}$ & $\hat{\sigma}\left(\gamma_{i}^{\star}\right)$ & P-value & $\operatorname{cô} v\left(\gamma_{0}^{\star}, \gamma_{1}^{\star}\right)$ \\
\hline$\gamma_{0, t}$ & $1.8 \%$ & $0.81 \%$ & 0.026 & $-6.34 \times 10^{-5}$ \\
\hline$\gamma_{1, t}$ & $-0.84 \%$ & $0.86 \%$ & 0.33 & $-6.34 \times 10^{-5}$ \\
\hline
\end{tabular}


To avoid repetition, only one set of estimation results of $\gamma_{i}^{\star}(\mathrm{FM}$ PB: SW+SW) is used to show how to derive following results (results for (FM SB: SW+OLS) are derived following the same processes). The newly estimated empirical CAPM is expressed by

$$
\tilde{R}_{i}=0.72 \%+0.3 \% \beta_{i}
$$

The standard error of $\tilde{R}_{i}$ is given by

$$
\hat{\sigma}\left(\tilde{R}_{i}\right)=\sqrt{(0.73 \%)^{2}+(0.64 \%)^{2} \beta_{i}^{2}+2\left(-4.1 \times 10^{-5}\right) \beta_{i}}
$$

$\beta_{i}=0$ and 1 are substituted into (4.20) and (4.21) to yield monthly estimates

$$
\begin{aligned}
\tilde{R}_{i} \mid\left(\beta_{i}=0\right) & =0.72 \% \\
\hat{\sigma}\left(\tilde{R}_{i}\right) \mid\left(\beta_{i}=0\right) & =0.73 \% \\
\tilde{R}_{i} \mid\left(\beta_{i}=1\right) & =1.02 \% \\
\hat{\sigma}\left(\tilde{R}_{i}\right) \mid\left(\beta_{i}=1\right) & =\sqrt{(0.73 \%)^{2}+(0.64 \%)^{2}+2\left(-4.1 \times 10^{-5}\right)} \\
& =0.35 \%
\end{aligned}
$$

Then, these monthly estimates are transferred to annual estimates applying (4.4) and (4.5)

$$
\begin{aligned}
\tilde{R}_{i}^{y} \mid\left(\beta_{i}=0\right) & =(1+0.73 \%)^{12}-1=8.92 \% \\
\hat{\sigma}\left(\tilde{R}_{i}^{y}\right) \mid\left(\beta_{i}=0\right) & \approx 12 \times 0.73 \%=8.73 \% \\
\tilde{R}_{i}^{y} \mid\left(\beta_{i}=1\right) & =(1+1.02 \%)^{12}-1=12.9 \% \\
\hat{\sigma}\left(\tilde{R}_{i}^{y}\right) \mid\left(\beta_{i}=1\right) & \approx 12 \times 0.35 \%=4.08 \%
\end{aligned}
$$


Finally, the $95 \%$ confidence interval is calculated applying (4.6)

$$
\begin{aligned}
& \tilde{R}_{i}^{y, \text { lower }} \mid\left(\beta_{i}=0\right)=8.92 \%-1.96 \times 8.73 \%=-8.19 \% \\
& \tilde{R}_{i}^{y \text {,upper }} \mid\left(\beta_{i}=0\right)=8.92 \%+1.96 \times 8.73 \%=26.0 \% \\
& \tilde{R}_{i}^{y \text { lower }} \mid\left(\beta_{i}=1\right)=12.9 \%-1.96 \times 3.5 \%=4.93 \% \\
& \tilde{R}_{i}^{y, \text { upper }} \mid\left(\beta_{i}=1\right)=12.9 \%+1.96 \times 3.5 \%=20.9 \%
\end{aligned}
$$




\section{Table 4.8: The $95 \%$ confidence interval of the estimated an-} nual tax-adjusted excess returns for two special securities: $\beta=0$ and $1-$ a summary

Results for FM SB: OLS and SW, and FM PB: OLS+OLS are obtained from Table 4.2 and 4.5 respectively. This table shows the $95 \%$ confidence interval constructed for the estimated annual tax-adjusted excess returns of 2 special securities with $\beta=0$ and 1 respectively. All results presented in this table are either drawn from previous results or newly estimated

\begin{tabular}{lcccc}
\hline$\beta=0$ & \multicolumn{5}{l}{} \\
\hline & Lower bound & Mean & Upper bound & Std Err \\
\cline { 2 - 5 } FM SB: OLS & $6.23 \%$ & $14.9 \%$ & $23.5 \%$ & $4.41 \%$ \\
FM SB: SW & $7.02 \%$ & $15.4 \%$ & $23.7 \%$ & $4.27 \%$ \\
FM PB: OLS+OLS & $9.86 \%$ & $26.8 \%$ & $43.8 \%$ & $8.66 \%$ \\
FM PB: SW+SW & $-8.19 \%$ & $8.92 \%$ & $26.0 \%$ & $8.73 \%$ \\
FM PB: SW+OLS & $4.15 \%$ & $23.2 \%$ & $42.3 \%$ & $9.73 \%$ \\
\hline \hline \multirow{2}{*}{$\beta=1$} & & & & \\
\hline & Lower bound & Mean & Upper bound & Std Err \\
\cline { 2 - 6 } FM SB: OLS & $3.5 \%$ & $11.8 \%$ & $20.2 \%$ & $4.25 \%$ \\
FM SB: SW & $4.71 \%$ & $12.7 \%$ & $20.7 \%$ & $4.10 \%$ \\
FM PB: OLS+OLS & $1.97 \%$ & $10.8 \%$ & $19.7 \%$ & $4.53 \%$ \\
FM PB: SW+SW & $4.93 \%$ & $12.9 \%$ & $20.9 \%$ & $4.08 \%$ \\
FM PB: SW+OLS & $3.08 \%$ & $11.6 \%$ & $20.0 \%$ & $4.34 \%$ \\
\hline
\end{tabular}


Table 4.8 summarizes all predicted returns and their $95 \%$ confidence intervals for the special case (beta $=0$ and 1 ) using all the empirical form of the CAPMs. It appears that there are large systematic errors around the empirical CAPMs. For example, the range of the return of the zero beta security can be from $-9.6 \%$ (FM PB: SW+SW) to $39.8 \%$ (FM PB: OLS+OLS) whereas the range of the return of the unit beta security are from $-0.86 \%$ (FM PB: OLS+OLS) to $20.9 \%$ (FM PB: SW+SW). Moreover, the mean value of predicted returns of zero beta security are, in most cases, greater than those of unit beta security. This table casts doubts on whether a security's beta is the risk, and the only risk, that the market is priced. (Table 7.6 shows the same results with the capital gain returns as the proxy for the risk free rate.)

The empirical and theoretical forms of CAPM are plotted in Figure 4.5. For a given beta, the return estimated using the empirical form is calculated by

$$
\tilde{R}_{i}^{y}=\left(1+0.72 \%+0.3 \% \beta_{i}\right)^{12}-1
$$

The $95 \%$ confidence interval is calculated by

$$
\begin{aligned}
\tilde{R}_{i}^{y, \text { lower }}= & \left(\left(1+0.72 \%+0.3 \% \beta_{i}\right)^{12}-1\right) \\
& -1.96 \times 12 \sqrt{(0.73 \%)^{2}+(0.64 \%)^{2} \beta_{i}^{2}+2\left(-4.1 \times 10^{-5}\right) \beta_{i}} \\
\tilde{R}_{i}^{y, \text { upper }}= & \left(\left(1+0.72 \%+0.3 \% \beta_{i}\right)^{12}-1\right) \\
& +1.96 \times 12 \sqrt{(0.73 \%)^{2}+(0.64 \%)^{2} \beta_{i}^{2}+2\left(-4.1 \times 10^{-5}\right) \beta_{i}}
\end{aligned}
$$

The theoretical CAPM remains the same, where $\widehat{M R P}$ is again assumed to be $7 \%$.

Compared with previous results (Figure 4.2 and 4.4), this figure also shows 
that the theoretical CAPM consistently understates the expected return of any securities with beta ranging from 0 to 1 . By using the monthly data, features illustrated from the empirical CAPM estimated using different methods are remarkably consistent. For example, they all have poor predictability because of the ambiguous empirical risk-return relationship, and they all require extra amount of returns for a given beta (ranging from 0 to 1) compared with the theoretical CAPM. In the next section, I will check if these features still hold when the weekly data are used. (Figure 7.2 shows the same results with the capital gain returns as the proxy for the risk free rate. It appears that the change of the proxy for the risk free rate does not alter final results critically.) 
Figure 4.5: The plot of the empirical and theoretical forms of the CAPM - FM PB: SW+SW and SW+OLS

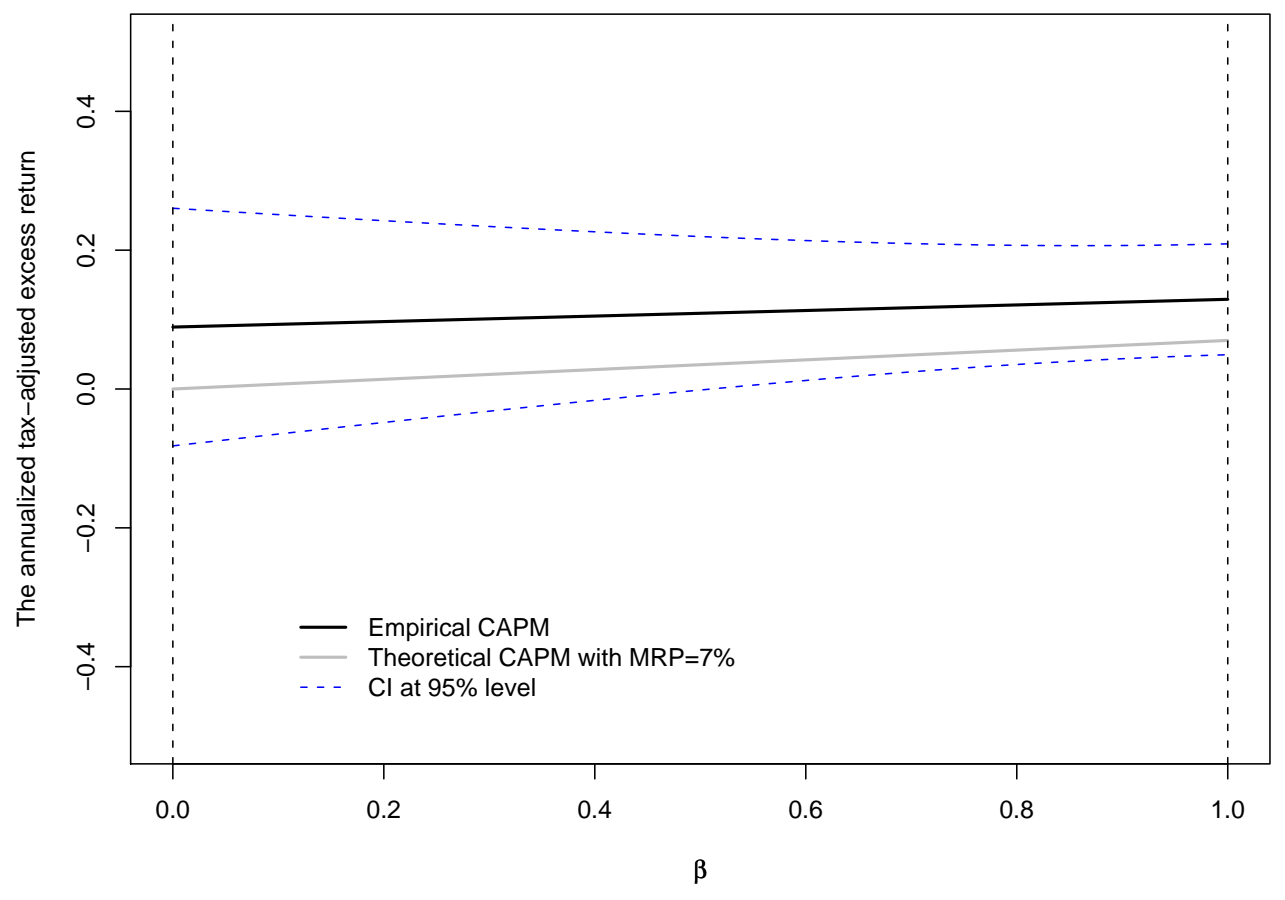

(a) FM PB: SW+SW

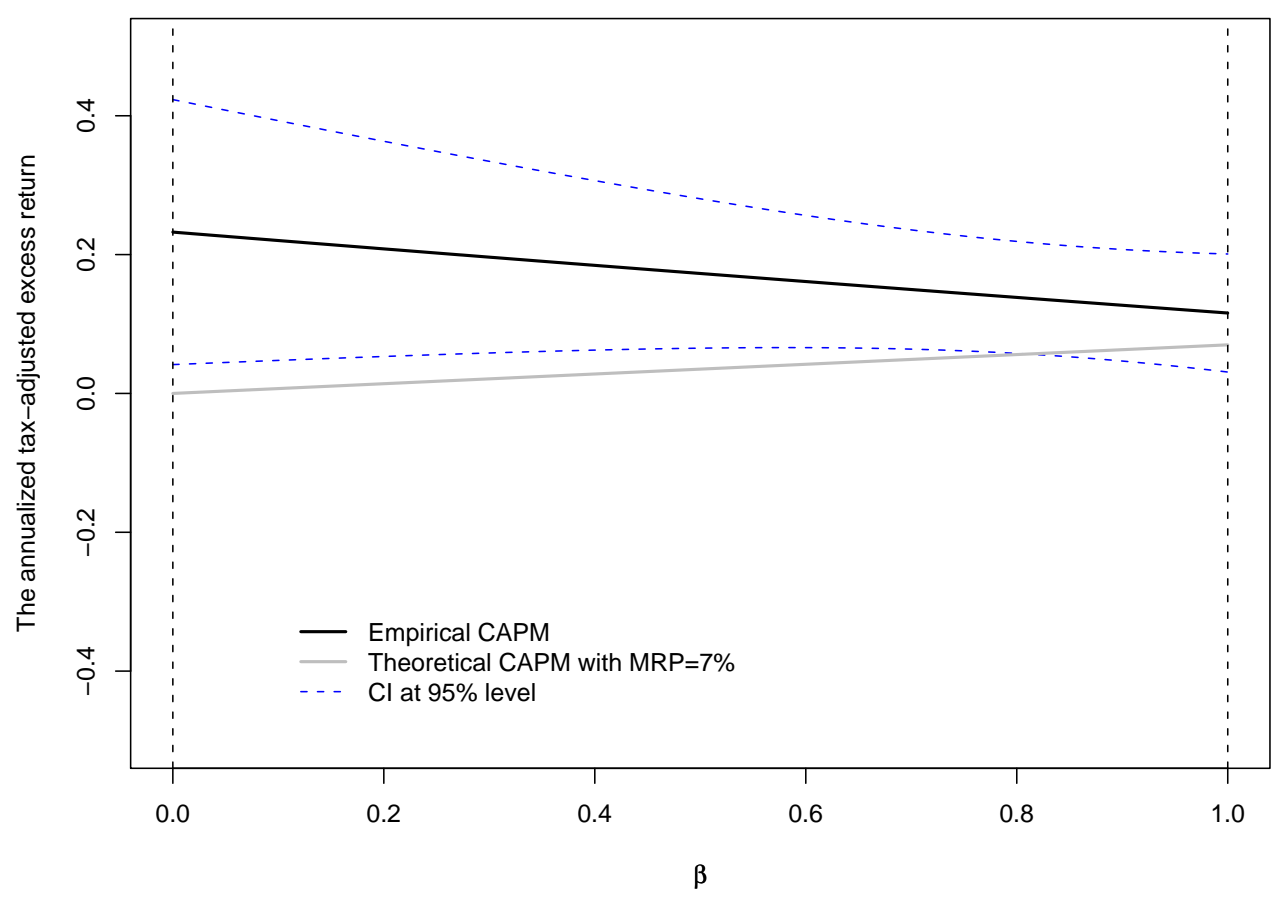

(b) FM PB: SW+OLS 


\subsubsection{Robust check II: the FM method with portfolio betas as the independent variable with the weekly data}

In this section, whether results estimated using the monthly data will still hold on the weekly data is examined. As the CAPM theory does not specify any length of data period (annual, month, week or day), the difference in data frequency should not alter estimation results critically. Although the study by Handa et al. (1993) reported that the choice of return measurement interval has an effect on the risk-return relationship, their conclusions were based on the monthly and annual data from New York Stock Exchange-American Stock Exchange, which cannot be generalised to our study - weekly data from New Zealand Stock Exchange.

\section{Methodology for the weekly data}

Any technical issues discussed in Chapter 2 for monthly data (the FM method with portfolio betas used as the independent variable) are applied to weekly data except for some changes in the choice of stock beta estimation period.

The preliminary step is to estimate stock betas using one year stock returns. More specifically, for the first year period (1-week-90 to 52-week90), we select stocks with returns available at least in the latest 30 weeks (23-week-90 to 52-week-90) and all returns available in the next year (1week-91 to 52-week-91). After selecting stocks, all available returns from 1-week-90 to 52-week-90 are used to estimate stock betas.

The next step is to form 10 portfolios in the way was that described Chap- 
ter 2. Portfolio returns in the next period (1-week-91 to 52-week-91) are computed by value weighting stock returns at the same period.

By repeating the above process except for moving one year forward, portfolio returns from 1-week-92 to 52-week-92 are calculated. That is: for the period of 1-week-91 to 52-week-91, stocks - with returns at least available from 23-week-91 to 52-week-91 and all returns available for 1-week92 to 52-week-92 - are selected; then, using all available stock returns from 1-week-91 to 52-week-91 to estimate stock betas; 10 portfolios are formed and returns from 1-week-92 to 52-week-92 are calculated using value-weighting stock returns from the same period. By repeating the process, portfolio returns from 1-week-91 to 52-week-06 are computed. Finally, 10 portfolio betas are estimated by regressing all portfolio returns from 1-week-91 to 52-week-06 on returns of the market portfolio from the same period.

Again, it is assumed that stocks in each portfolio have their betas equal to the portfolio beta which they belong to. For each week, stock returns are regressed on stock betas. There are in total 832 regressions (16 years $\times 52$ weeks) performed from 1-week-91 to 52-week-06, which yield time series estimates of $\gamma_{i, t}$. Finally, $\gamma_{i}^{\star}$ are calculated by

$$
\gamma_{i}^{\star}=\frac{1}{832} \sum_{t=1 \text {-week-91 }}^{52 \text {-week-06 }} \hat{\gamma}_{i, t},
$$

and their variances are calculated by

$$
\hat{\sigma}^{2}\left(\gamma_{i}^{\star}\right)=\frac{1}{832(832-1)} \sum_{t=1 \text {-week-91 }}^{52 \text {-week-06 }}\left(\hat{\gamma}_{i, t}-\gamma_{i}^{\star}\right)^{2}
$$


As $\gamma_{i}^{\star}$ are estimated using the weekly data, the tax-adjusted excess return and the standard error predicted from the empirical CAPM are also in weekly frequency. They have to be transferred to the annual outputs for facilitating the comparison with results using the monthly data.

For the tax-adjusted excess return, it is compounded up by 52 (assuming there are always 52 weeks in a year) to yield annual outputs. That is

$$
\tilde{R}_{i}^{y}=\left(1+\tilde{R}_{i}\right)^{52}-1,
$$

where $\tilde{R}_{i}^{y}$ is the estimated annual tax-adjusted excess return for security $i$. The "Delta method" is applied to transfer the weekly standard error to the annual one, which implies

$$
\hat{\sigma}\left(\tilde{R}_{i}^{y}\right) \approx 52 \hat{\sigma}\left(\tilde{R}_{i}\right),
$$

where $\hat{\sigma}\left(\tilde{R}_{i}^{y}\right)$ is the annualized standard error.

\section{Estimation results from the weekly data}

Stock and portfolio beta estimates are shown in Table 7.3 and 7.4, which are consistent with their counterparts - ones estimated using monthly estimates.

Table 4.9 summarizes $\gamma_{i}^{\star}$ estimated from different combinations of the method with the weekly data. One important feature of the this table is that results from "OLS+OLS" and "SW+OLS" combinations are almost identical, which is also shown in Table (4.7). By using weekly data, all $\gamma_{1}^{\star}$ are negative which is different from the monthly data case, where the "SW+SW" produces a positive value. However, no $\gamma_{1}^{\star}$ is statistically significant at the 
5\% level. Although results from this table and Table (4.7) cannot be compared directly because of different data frequencies used, both tables give the impression that $\gamma_{i}^{\star}$ are robust to different data frequencies.

\section{Table 4.9: The summary of $\gamma_{i}^{\star}-$ FM PB: OLS+OLS, SW+SW and SW+OLS (weekly data)}

The table presents all $\gamma_{i}^{\star}$ estimated from the different combinations of the method with the weekly data. In this table, "OLS+OLS", "SW+SW" and "SW+OLS" represent the method combinations. The first method is the method used to estimate stock betas while the second is used to estimate portfolio betas.

FM PB: OLS+OLS

\begin{tabular}{ccccc}
\hline & $\gamma_{i}^{\star}$ & $\hat{\sigma}\left(\gamma_{i}^{\star}\right)$ & P-value & $c \hat{o} v\left(\gamma_{0}^{\star}, \gamma_{1}^{\star}\right)$ \\
\cline { 2 - 5 }$\gamma_{0, t}$ & $0.20 \%$ & $0.097 \%$ & 0.04 & $-1.44 \times 10^{-6}$ \\
$\gamma_{1, t}$ & $-0.26 \%$ & $0.17 \%$ & 0.13 & $-1.44 \times 10^{-6}$ \\
\hline \hline
\end{tabular}

FM PB: SW+SW

\begin{tabular}{ccccc}
\hline & $\gamma_{i}^{\star}$ & $\hat{\sigma}\left(\gamma_{i}^{\star}\right)$ & P-value & $c \hat{o} v\left(\gamma_{0}^{\star}, \gamma_{1}^{\star}\right)$ \\
\cline { 2 - 5 }$\gamma_{0, t}$ & $0.06 \%$ & $0.125 \%$ & 0.63 & $-1.2 \times 10^{-6}$ \\
$\gamma_{1, t}$ & $-0.008 \%$ & $0.114 \%$ & 0.94 & $-1.2 \times 10^{-6}$ \\
\hline \hline
\end{tabular}

FM PB: SW+OLS

\begin{tabular}{ccccc} 
& $\gamma_{i}^{\star}$ & $\hat{\sigma}\left(\gamma_{i}^{\star}\right)$ & P-value & $c \hat{c o v}\left(\gamma_{0}^{\star}, \gamma_{1}^{\star}\right)$ \\
\cline { 2 - 5 }$\gamma_{0, t}$ & $0.22 \%$ & $0.121 \%$ & 0.07 & $-2.0 \times 10^{-6}$ \\
$\gamma_{1, t}$ & $-0.28 \%$ & $0.187 \%$ & 0.13 & $-2.0 \times 10^{-6}$ \\
\hline
\end{tabular}

Results from "SW+OLS" are omitted for the great similarity to ones from “OLS+OLS". To avoid repeated analyses, I will focus on exploring results 
from "OLS+OLS" and any coming exploration and explanation on the results from "SW+SW" are executed following the same process.

The estimated empirical CAPM is expressed by

$$
\tilde{R}_{i}=0.2 \%-0.26 \% \beta_{i}
$$

The standard error of $\tilde{R}_{i}$ is given by

$$
\hat{\sigma}\left(\tilde{R}_{i}\right)=\sqrt{(0.097 \%)^{2}+(0.17 \%)^{2} \beta_{i}^{2}+2\left(-1.44 \times 10^{-6}\right) \beta_{i}}
$$

$\beta_{i}=0$ and 1 are substituted into (4.31) and (4.32) to yield weekly estimates

$$
\begin{aligned}
\tilde{R}_{i} \mid\left(\beta_{i}=0\right) & =0.2 \% \\
\hat{\sigma}\left(\tilde{R}_{i}\right) \mid\left(\beta_{i}=0\right) & =0.097 \% \\
\tilde{R}_{i} \mid\left(\beta_{i}=1\right) & =-0.06 \% \\
\hat{\sigma}\left(\tilde{R}_{i}\right) \mid\left(\beta_{i}=1\right) & =\sqrt{(0.097 \%)^{2}+(0.17 \%)^{2}+2\left(-1.44 \times 10^{-6}\right)} \\
& =0.098 \%
\end{aligned}
$$

Then, these weekly estimates are transferred to the annual estimates applying (4.29) and (4.30)

$$
\begin{aligned}
\tilde{R}_{i}^{y} \mid\left(\beta_{i}=0\right) & =(1+0.2 \%)^{52}-1=10.9 \% \\
\hat{\sigma}\left(\tilde{R}_{i}^{y}\right) \mid\left(\beta_{i}=0\right) & \approx 52 \times 0.097 \%=3.1 \% \\
\tilde{R}_{i}^{y} \mid\left(\beta_{i}=1\right) & =(1-0.06 \%)^{52}-1=-3.3 \% \\
\hat{\sigma}\left(\tilde{R}_{i}^{y}\right) \mid\left(\beta_{i}=1\right) & \approx 52 \times 0.0098 \%=5.2 \%
\end{aligned}
$$


Finally, the $95 \%$ confidence interval is calculated applying (4.6)

$$
\begin{aligned}
& \tilde{R}_{i}^{y, \text { lower }} \mid\left(\beta_{i}=0\right)=10.9 \%-1.96 \times 3.1 \%=4.7 \% \\
& \tilde{R}_{i}^{y, \text { upper }} \mid\left(\beta_{i}=0\right)=10.9 \%+1.96 \times 3.1 \%=17 \% \\
& \tilde{R}_{i}^{y, \text { lower }} \mid\left(\beta_{i}=1\right)=-3.3 \%-1.96 \times 5.2 \%=-13.5 \% \\
& \tilde{R}_{i}^{y, \text { upper }} \mid\left(\beta_{i}=1\right)=-3.3 \%+1.96 \times 5.2 \%=6.9 \%
\end{aligned}
$$

Table 4.10: The $95 \%$ confidence interval of estimated annual tax-adjusted excess returns for two special securities: $\beta=0$ and 1 - a summary (weekly data)

This table shows the $95 \%$ confidence interval constructed for estimated annual taxadjusted excess returns of 2 special securities with $\beta=0$ and 1 .

\begin{tabular}{lcccc}
\hline \multirow{2}{*}{$\beta=0$} & & & & \\
\hline & Lower bound & Mean & Upper bound & Std Err \\
\cline { 2 - 5 } FM PB: OLS+OLS & $4.7 \%$ & $10.9 \%$ & $17.0 \%$ & $4.7 \%$ \\
FM PB: SW+SW & $-3.9 \%$ & $3.0 \%$ & $9.9 \%$ & $3.5 \%$ \\
\hline \hline$\beta=1$ & & & & \\
\hline & Lower bound & Mean & Upper bound & Std Err \\
\cline { 2 - 5 } FM PB: OLS+OLS & $-13.5 \%$ & $-3.3 \%$ & $6.9 \%$ & $5.2 \%$ \\
FM PB: SW+SW & $-7.0 \%$ & $2.5 \%$ & $12.1 \%$ & $4.9 \%$ \\
\hline
\end{tabular}

The most noticeable feature is that annualized standard errors are much less than results shown in Table 4.8 (from monthly data), which may not suggest that the empirical CAPM estimated from the weekly data gener- 
ate more accurate predictions. That is because 1.) assuming $\left(1+\tilde{r}_{i}\right)^{51}=0$ (where $\tilde{r}_{i}$ is the true weekly tax-adjusted excess return for security $i$ ) in the implementation of the "Delta method" may severely underestimate the annualized the standard error; 2 .) the weekly data have large manipulation errors as all raw data come in either monthly or daily frequencies.

The empirical and theoretical CAPM are plotted in Figure 4.6. For a given beta, the estimated return predicted using the empirical CAPM is calculated by

$$
\tilde{R}_{i}^{y}=\left(1+0.2 \%-0.26 \% \beta_{i}\right)^{52}-1
$$

The $95 \%$ confidence interval is calculated by

$$
\begin{aligned}
\tilde{R}_{i}^{y \text { lower }}= & \left(\left(1+0.2 \%-0.26 \% \beta_{i}\right)^{52}-1\right) \\
& -1.96 \times 52 \sqrt{(0.097 \%)^{2}+(0.17 \%)^{2} \beta_{i}^{2}+2\left(-1.44 \times 10^{-6}\right) \beta_{i}} \\
\tilde{R}_{i}^{y, \text { upper }}= & \left(\left(1+0.2 \%-0.26 \% \beta_{i}\right)^{52}-1\right) \\
& +1.96 \times 52 \sqrt{(0.097 \%)^{2}+(0.17 \%)^{2} \beta_{i}^{2}+2\left(-1.44 \times 10^{-5}\right) \beta_{i}}
\end{aligned}
$$

The theoretical form remains the same, where $\widehat{M R P}$ is again assumed to be $7 \%$.

Compared this figure with previous ones from the monthly data, the empirical CAPMs estimated from weekly data also show the same feature an almost flat line with the wide confidence intervals. There may be some subtle differences in some return estimates, however, this is nothing significant. Therefore, results from the robustness check demonstrate that the estimation of the empirical form of the CAPM is robust to different betaestimation methods and data frequencies (weekly and monthly). 
Figure 4.6: The plot of the empirical and theoretical CAPM - a summary (weekly data)

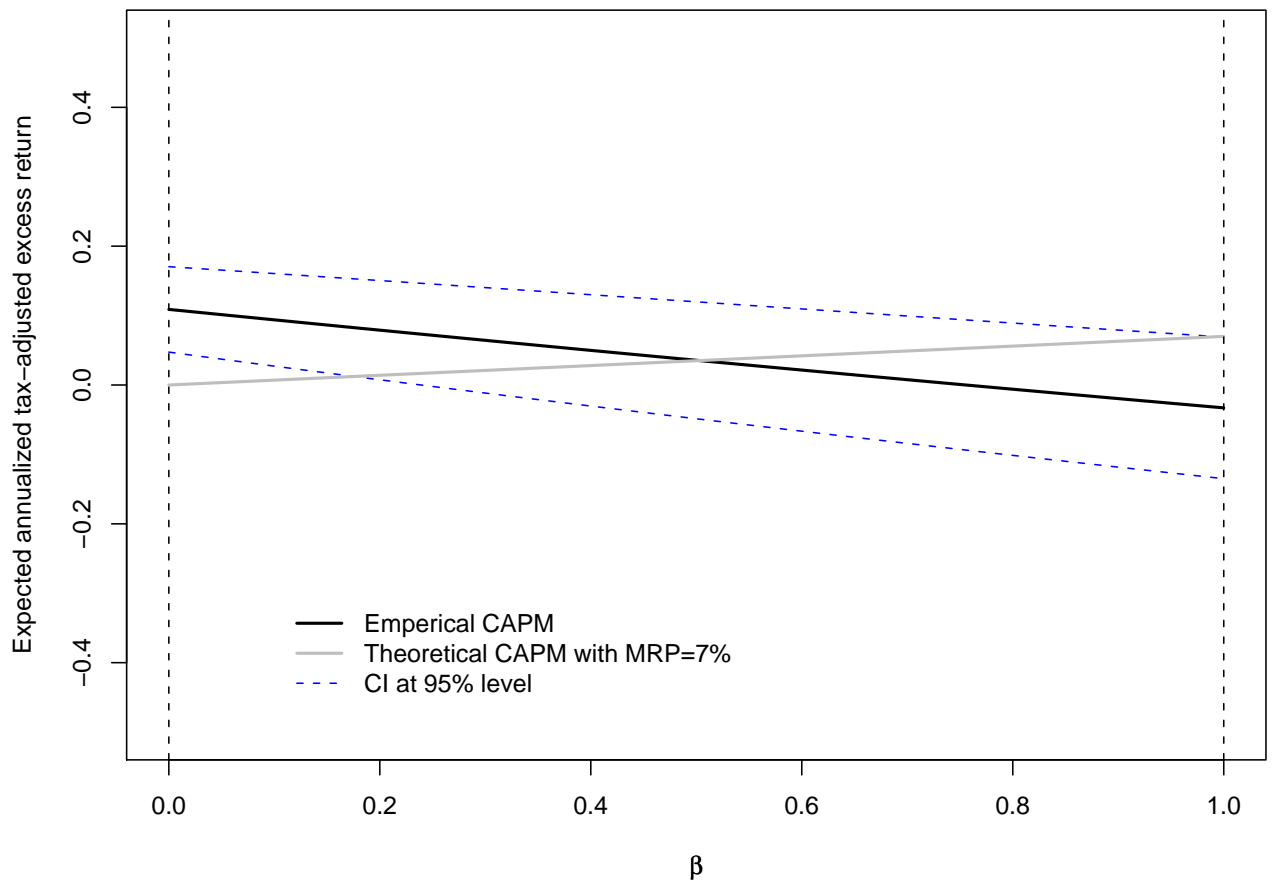

(a) FM PB: OLS+OLS

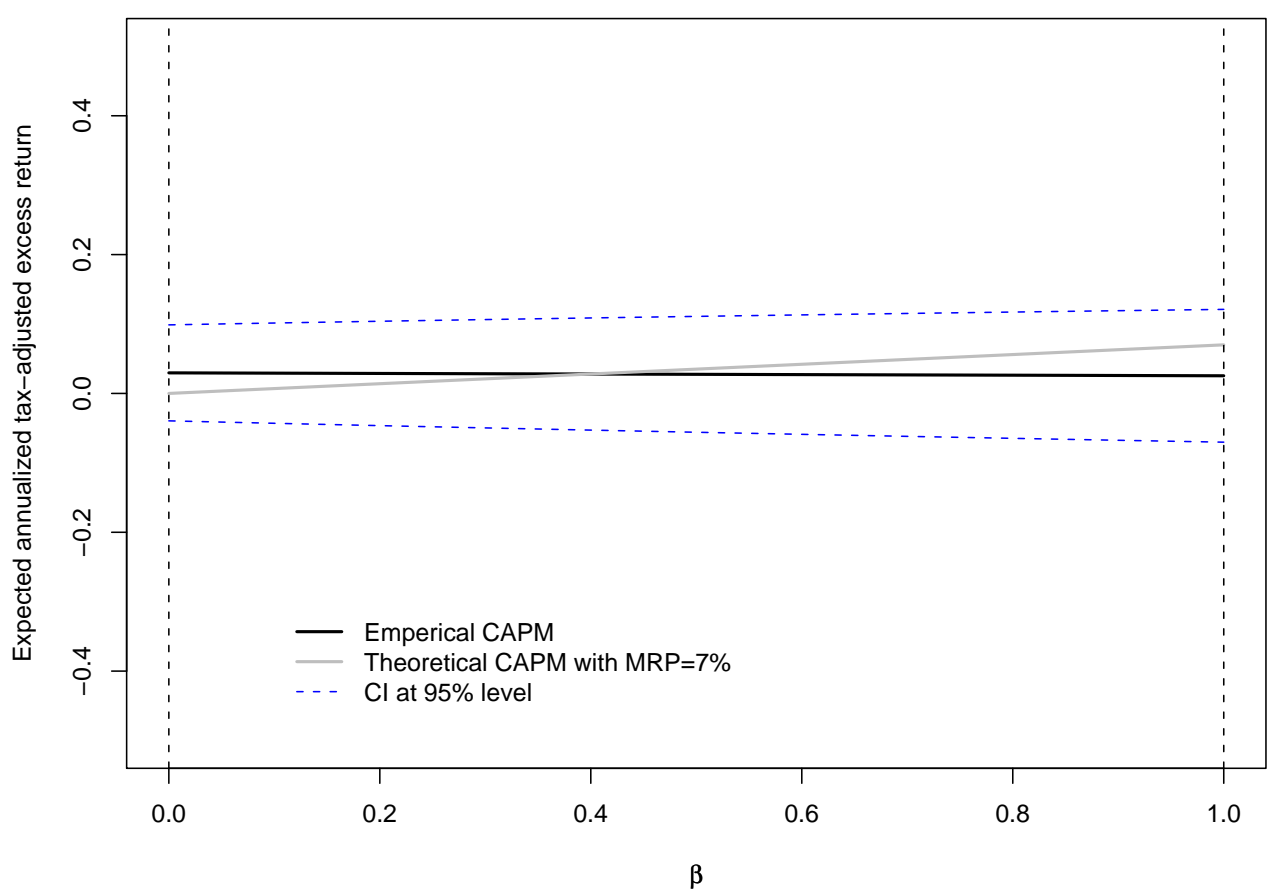

(b) FM PB: SW+SW 


\subsection{A discussion on all estimation results}

This chapter provides the estimation results of the empirical CAPM using different beta-estimation methods with both monthly and weekly data. Table 4.11 summarizes all methods and data used for the estimation of the empirical CAPM. The empirical CAPM, using the FM method with stock betas as the independent variable and the monthly data, is first estimated. Results show that the empirical CAPM is virtually a flat line with wide confidence intervals, which predicts returns (with beta ranging 0 to 1) being consistently greater than ones predicted from the theoretical CAPM. Under the belief that using portfolio betas can improve the precision of the independent variable and hence $\gamma_{i}^{\star}$, the baseline method (FM PB: OLS+OLS) was executed. The newly estimated empirical CAPM illustrates same features except for an increase in the standard error of $\gamma_{i}^{\star}$. Discussed previously, this situation may be resulted from using portfolio betas at the independent variable as they may have not been more precisely estimated than individual stock betas due to the small number of firms. 


\section{Table 4.11: The summary of all methodologies and data used for estimating the empirical CAPM}

\begin{tabular}{|c|c|}
\hline \multicolumn{2}{|r|}{ Monthly Data } \\
\hline Method & Descriptions \\
\hline \multirow[t]{2}{*}{ FM SB: OLS } & Using stock betas as the independent variable \\
\hline & Stock betas are estimated using the OLS method \\
\hline \multirow[t]{2}{*}{ FM SB: SW } & Using stock betas as the independent variable \\
\hline & Stock betas are estimated using the SW method \\
\hline \multirow[t]{3}{*}{ FM PB: OLS+OLS } & Using portfolio betas as the independent variable \\
\hline & OLS+OLS - the OLS method for estimating \\
\hline & stock and portfolio betas \\
\hline \multirow[t]{3}{*}{ FM PB: SW+SW } & Using portfolio betas as the independent variable \\
\hline & SW+SW - the SW method for estimating \\
\hline & stock and portfolio betas \\
\hline \multirow[t]{3}{*}{ FM PB: SW+OLS } & Using portfolio betas as the independent variable \\
\hline & SW+OLS - the SW method for estimating \\
\hline & stock and the OLS method for estimating portfolio betas \\
\hline \multicolumn{2}{|r|}{ Weekly Data } \\
\hline Method & Descriptions \\
\hline
\end{tabular}

FM PB: OLS+OLS Using portfolio betas as the independent variable OLS+OLS - the OLS method for estimating stock and portfolio betas

FM PB: SW+SW Using portfolio betas as the independent variable SW+SW - the SW method for estimating stock and portfolio betas

FM PB: SW+OLS Using portfolio betas as the independent variable SW+OLS - the SW method for estimating stock and the OLS method for estimating portfolio betas 
In the robustness check, I kept working on the monthly data with the SW method used for estimating betas. Once again, estimation results are very similar. After switching to the weekly data, there are still no critical changes in the empirical CAPM. However, there is a difference worth noting: the empirical CAPM seems to predict lower returns with lower standard errors for any given beta from 0 to 1 than ones estimated using the monthly data. This may be due to the use some approximations (in the "Delta method") that might artificially underestimate results, and the "bad" nature of the weekly data. As all dataset come in either monthly or daily frequencies, converting those to weekly and then back to annual frequency may generate great manipulation errors. All in all, the robustness check shows that it is highly likely that the empirical CAPM estimates are reliable. In addition, results (Table 7.5 and 7.6; Figure 7.2) presented in the Appendix demonstrates that the empirical CAPM estimates are also robust to the different choices of of proxies of the risk free rate.

Estimation results from all dimensions exhibit similar features of the empirical CAPM - an virtually flat line with wide confidence intervals. This feature may be due to great ambiguities in the empirical relationship between the expected return and the systematic risk in New Zealand. Moreover, most results illustrate that predicted returns are significantly greater than zero given the systematic risk equal to 0 , which may suggest that there might be other risks (in addition to the systematic risk) that are not included in the CAPM, but are required extra returns by the market and investors in New Zealand.

All these features illustrated from the empirical CAPM will naturally cast 
doubts on results from the Commission's reports (Commerce Commission (2005b) and Commerce Commission (2007)), in which they are calculated using the theoretical CAPM (1.3). In order to better understand what the cost of capital are required by the market might actually be, in the next chapter the Commission's analyses are replicated using the empirical CAPM. 


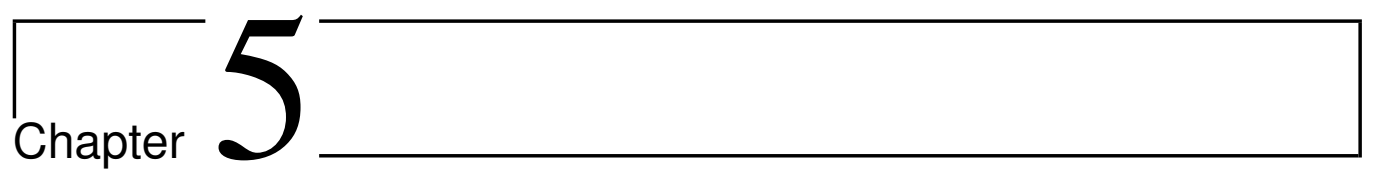

\section{The implication of the empirical}

\section{CAPM}

\subsection{Estimating the WACC using the empirical CAPM}

In contrast to the application of the theoretical CAPM to calculate the WACC, using the empirical CAPM will provide estimates of the cost of equity, and hence the WACC that reflect the expected return on capitals required by the market. In addition, it also gives better estimates of the size of estimation errors than ones reported from the Commission's studies. Following contents explains how to calculate the WACC and its standard error using the empirical CAPM.

As the empirical CAPM estimates are robust to different data frequencies shown in Chapter 4, results estimated using the monthly data are adopted to calculate the WACC because they tend to contain less datamanipulation errors. For example, it is more accurate to transfer daily 
stock returns to monthly returns, than to weekly returns, as the number of days in a month is relatively more stable than one in a week ${ }^{1}$. Hence, I believe that results from the monthly data are more appropriate in the calculation the WACC.

The WACC is formulated as

$$
\mathrm{WACC}=(1-L) R_{e}+L\left(1-T_{c}\right) k_{d},
$$

where $L$ is the financial leverage ratio; $k_{d}$ is the cost of debt; $R_{e}$ is the cost of equity capital and $T_{c}$ is the corporate tax rate.

By assuming every component in (5.1) are estimated without errors except for the cost of equity $-R_{e}$, the estimated WACC can be expressed as

$$
\widehat{\mathrm{WACC}}=(1-L) \hat{R}_{e}+L\left(1-T_{c}\right) k_{d}
$$

and the estimated standard error is presented by

$$
\hat{\sigma}(\widehat{\mathrm{WACC}})=(1-L) \hat{\sigma}\left(\hat{R}_{e}\right)
$$

where $\hat{\sigma}\left(\hat{R}_{e}\right)$ is the standard error of the estimated cost of equity. The $95 \%$ confidence interval for the estimated WACC is calculated by

$$
\begin{aligned}
& \widehat{\mathrm{WACC}}^{\text {lower }}=\widehat{\mathrm{WACC}}-1.96 \hat{\sigma}(\widehat{\mathrm{WACC}}) \\
& \widehat{\mathrm{WACC}}^{\text {upper }}=\widehat{\mathrm{WACC}}+1.96 \hat{\sigma}(\widehat{\mathrm{WACC}})
\end{aligned}
$$

\footnotetext{
${ }^{1}$ There are 5 and 20 trading days in each week and month respectively. Public holidays will have relatively greater marginal effects on the weekly data than on the monthly data
} 


\subsection{Two case studies}

Since the Part 4 of the Commerce Act 1986 (the Act) came to effect on 8 August 2001, the Commission has been required to implement a targeted control regime for the regulated businesses such as electricity line and gas pipeline businesses. The intention of the regime is to promote better quality products with lower prices to benefit consumers. Under the Act, the Commission must set thresholds for the declaration of control of goods and services provided by those businesses, one of which thresholds is the cost of capital that imposes control on the maximum return that can be earned by investors in these businesses. Calculating such a vital threshold has been carefully documented by the Commission in its draft guideline (Commerce Commission (2005a)), which advocates using the capital asset pricing model to estimate the cost of equity that is then incorporated in the calculation of the weighted average cost of capital to determine the maximum return earned by investors.

Two reports, Regulation of Electricity Lines Businesses Target Control Regime Intention to Declare Control Unison Networks Limited (Commerce Commission (2005b)) and Authorisation for the Control of Supply of Natural Gas Distribution Services by Powerco Ltd and Vector Ltd (Commerce Commission (2007)), have been published by the Commission to present how its obligation is fulfilled under the Act, a part of which is to calculate the WACC. Two case studies are then derived from these reports by switching the method for the calculation of the cost of equity from the theoretical CAPM (applied by the Commission) to the empirical CAPM (estimated in this paper). With other parameter values for calculating the WACC remaining 
the same as provided in the Commission's reports, each case study will generate comparable WACC estimate.

Table 5.1 summarizes all information estimated from previous chapter to calculate the cost of equity, where in order to transfer tax-adjusted excess returns to returns, the tax adjusted risk free rate is added back. That is

$$
\hat{R}_{i}^{y}=\tilde{R}_{i}^{y}+R_{f}\left(1-T_{I}\right)
$$

where $\hat{R}_{i}^{y}$ is the estimated annual return for security $i . \hat{\sigma}\left(\hat{R}_{i}^{y}\right)$ is the estimated standard error for the return, which is equal to $\hat{\sigma}\left(\tilde{R}_{i}^{y}\right)$ since $R_{f}$ and $T_{I}$ are assumed to be estimated without errors. 


\section{Table 5.1: The summary of the annual cost of equity and its standard errors esitmated using the empirical CAPM}

This table shows the "annualized" empirical CAPM estimated using different methods with the monthly data. Results shown are all taken from Chapter 4. These empirical CAPMs will predict annual returns (instead of tax-adjusted excess returns), which is achieved by adding back the tax adjusted risk free rate. That is

$$
\hat{R}_{i}^{y}=R_{f}\left(1-T_{I}\right)+\tilde{R}_{i}^{y},
$$

where $\hat{R}_{i}^{y}$ is the estimated annual return for a security $i . \hat{\sigma}\left(\hat{R}_{i}^{y}\right)$ is the estimated standard error for the return, which is equal to $\hat{\sigma}\left(\tilde{R}_{i}^{y}\right)$ since $R_{f}$ and $T_{I}$ are assumed to be estimated without errors.

Method Estimates

FM SB: OLS

$$
\begin{aligned}
& \hat{R}_{i}^{y}=R_{f}\left(1-T_{I}\right)+\left(1+1.16 \%-0.23 \% \beta_{i}\right)^{12}-1 \\
& \hat{\sigma}\left(\hat{R}_{i}^{y}\right)=12 \sqrt{(0.37 \%)^{2}+(0.26 \%)^{2} \beta_{i}^{2}+2\left(-3.98 \times 10^{-6}\right) \beta_{i}}
\end{aligned}
$$

FM SB: SW

$$
\begin{aligned}
& \hat{R}_{i}^{y}=R_{f}\left(1-T_{I}\right)+\left(1+1.20 \%-0.20 \% \beta_{i}\right)^{12}-1 \\
& \hat{\sigma}\left(\hat{R}_{i}^{y}\right)=12 \sqrt{(0.36 \%)^{2}+(0.16 \%)^{2} \beta_{i}^{2}+2\left(-1.88 \times 10^{-6}\right) \beta_{i}}
\end{aligned}
$$

FM PB: OLS+OLS $\quad \hat{R}_{i}^{y}=R_{f}\left(1-T_{I}\right)+\left(1+2.0 \%-1.14 \% \beta_{i}\right)^{12}-1$

$$
\hat{\sigma}\left(\hat{R}_{i}^{y}\right)=12 \sqrt{(0.72 \%)^{2}+(0.82 \%)^{2} \beta_{i}^{2}+2\left(-5.26 \times 10^{-5}\right) \beta_{i}}
$$

FM PB: SW+SW

$$
\begin{aligned}
& \hat{R}_{i}^{y}=R_{f}\left(1-T_{I}\right)+\left(1+0.72 \%+0.3 \% \beta_{i}\right)^{12}-1 \\
& \hat{\sigma}\left(\hat{R}_{i}^{y}\right)=12 \sqrt{(0.73 \%)^{2}+(0.64 \%)^{2} \beta_{i}^{2}+2\left(-4.1 \times 10^{-5}\right) \beta_{i}}
\end{aligned}
$$

FM PB: SW+OLS $\quad \hat{R}_{i}^{y}=R_{f}\left(1-T_{I}\right)+\left(1+1.8 \%-0.84 \% \beta_{i}\right)^{12}-1$

$$
\hat{\sigma}\left(\hat{R}_{i}^{y}\right)=12 \sqrt{(0.81 \%)^{2}+(0.86 \%)^{2} \beta_{i}^{2}+2\left(-6.34 \times 10^{-5}\right) \beta_{i}}
$$


The WACC plays two important roles in the Commission's study on regulating electricity line businesses (Commerce Commission (2005b)). According to the study, the WACC is used to impose the electricity price cap, and for measuring excess profits. The report employs the "Brennan-Lally" version CAPM (1.3) to estimate the cost of equity and the WACC formula (1.1) to calculate the cost of capital for electricity line businesses, where relevant parameter values are listed below

$$
\begin{array}{lll}
L=0.4 & \beta_{e}=0.67 & T_{c}=T_{I}=0.33 \\
R_{f}=0.063 & M P R=0.07 & k_{d}=0.075
\end{array}
$$

where $L$ is the financial leverage ratio; $\beta_{e}$ is the equity beta; $M R P$ is the market risk premium; $T_{c}$ is the corporate tax rate; $R_{f}$ is the risk-free rate and $k_{d}$ is the interest rate on the debt capital. The WACC is reported to be $7.35 \%$ (on page 39 of Commerce Commission $(2005 b))^{2}$.

On the other hand, the WACC calculated using the empirical CAPM is reported in following contents. The cost of equity and its standard error are estimated by substituting $R_{f}, T_{I}$ and $\beta_{e}$ into each equation in Table 5.1. Taking the result from the "FM SB: OLS" as an example, the cost of equity is calculated by

$$
\begin{aligned}
\hat{R}_{e} & =6.3 \%(1-0.33)+(1+1.16 \%-0.23 \% \times 0.67)^{12}-1 \\
& =17.0 \%
\end{aligned}
$$

\footnotetext{
${ }^{2}$ The figure is calculated by applying the CAPM and WACC formula. That is

$$
R_{e}=0.063(1-0.33)+0.07 \times 0.67=0.089
$$$$
\text { WACC }=0.089(1-0.4)+0.073(1-0.33) 0.4=0.0735
$$ 
The standard error is then calculated by

$$
\begin{aligned}
\hat{\sigma}\left(\hat{R}_{e}\right) & =12 \sqrt{(0.37 \%)^{2}+(0.26 \%)^{2} \times 0.67^{2}+2 \times 0.67\left(-3.98 \times 10^{-6}\right)} \\
& =4.1 \%
\end{aligned}
$$

By substituting above estimates into (5.2) and (5.3), the estimated WACC and its standard error are obtained. That is

$$
\begin{aligned}
\widehat{\mathrm{WACC}} & =(1-L) \hat{R}_{e}+L\left(1-T_{c}\right) k_{d} \\
& =(1-0.4) 17 \%+0.4(1-0.33) 7.5 \% \\
& =12.2 \%
\end{aligned}
$$

and

$$
\begin{aligned}
\hat{\sigma}(\widehat{\mathrm{WACC}}) & =(1-L) \hat{\sigma}\left(\hat{R}_{e}\right) \\
& =(1-0.4) 4.1 \% \\
& =2.46 \%
\end{aligned}
$$

The $95 \%$ confidence interval for the WACC estimate is constructed using (5.4). That is

$$
\begin{aligned}
\widehat{\mathrm{WACC}}^{\text {lower }} & =\widehat{\mathrm{WACC}}-1.96 \hat{\sigma}(\widehat{\mathrm{WACC}}) \\
& =12.2 \%-1.96 \times 2.46 \%=7.38 \% \\
\widehat{\mathrm{WACC}}^{\text {upper }} & =\widehat{\mathrm{WACC}}+1.96 \hat{\sigma}(\widehat{\mathrm{WACC}}) \\
& =12.2 \%+1.96 \times 2.46 \%=17.0 \%
\end{aligned}
$$

Table 5.2 summarizes estimated WACCs, the $95 \%$ confidence interval and the standard error. The WACC estimated using the empirical CAPM is approximately $5 \%$ greater than the Commission's estimate $(7.35 \%)$ that 
Table 5.2: The WACC and its $95 \%$ confidence interval for the electricity line business estimated using the empirical CAPM

This table shows the WACC and its 95\% confidence interval estimated using the empirical CAPM.

\begin{tabular}{lcccc}
\hline Estimation methods & Lower bound & Mean & Upper bound & Std Err \\
\hline FM SB: OLS & $7.38 \%$ & $12.2 \%$ & $17.0 \%$ & $2.46 \%$ \\
FM SB: SW & $7.94 \%$ & $12.7 \%$ & $17.4 \%$ & $2.42 \%$ \\
FM PB: OLS+OLS & $9.23 \%$ & $14.1 \%$ & $18.9 \%$ & $2.48 \%$ \\
FM PB: SW+SW & $5.81 \%$ & $11.5 \%$ & $17.2 \%$ & $2.90 \%$ \\
FM PB: SW+OLS & $8.43 \%$ & $13.7 \%$ & $19.0 \%$ & $2.70 \%$ \\
\hline Commission's estimates & & $7.35 \%$ & \\
\hline
\end{tabular}

roughly equal the lower bound of the confidence interval. It may be a sign that the New Zealand market requires more returns to compensate the systematic risk of investing in electricity line businesses than what the Commission has reported. 


\section{Table 5.3: The probability of the underestimation of the Commission's WACC: case study 1}

This table shows the probability of the underestimation of the Commission's WACC. The mean and standard error of the "true" WACC are assumed to be the estimate from this paper. Test statistics, $Z$, is calculated using (5.10). "P-value" is calculated under the alternative hypothesis of $H_{a}:$ WACC $^{c c}<$ WACC. The probability of underestimation is given by $(1-\mathrm{P}$-value $)$

\begin{tabular}{lccccc}
\hline Method & Mean & Std Err & Z & P-value & $\begin{array}{c}\text { Probability } \\
\text { of underestimation }\end{array}$ \\
\hline FM SB: OLS & $12.2 \%$ & $2.46 \%$ & -1.97 & 0.02 & 0.98 \\
FM SB: SW & $12.7 \%$ & $2.42 \%$ & -2.21 & 0.01 & 0.99 \\
FM PB: OLS+OLS & $14.1 \%$ & $2.48 \%$ & -2.72 & 0.01 & 0.99 \\
FM PB: SW+SW & $11.5 \%$ & $2.90 \%$ & -1.43 & 0.08 & 0.92 \\
FM PB: SW+OLS & $13.7 \%$ & $2.70 \%$ & -2.35 & 0.01 & 0.99 \\
\hline
\end{tabular}

There is an interesting question that how certain (or what the probability will be that) the WACC is understated by the Commission await to be answered. By assuming that the WACC distributions estimated from this paper are the true distributions, the probability can be calculated by testing $H_{0}:$ WACC ${ }^{c c}=$ WACC and $H_{a}:$ WACC $^{c c}<$ WACC, where WACC ${ }^{c c}$ is the Commission's value whereas WACC is the true value. The test statistics is

$$
Z=\frac{\mathrm{WACC}^{c c}-\mathrm{WACC}}{\sigma(\mathrm{WACC})},
$$

where WACC and $\sigma(\mathrm{WACC})$ is assumed to be equal to estimates from this 
paper. Then, $(1-\mathrm{P}$-value) from the above test can be interpreted as the probability of the underestimation of the Commission's WACC. As shown in Table 5.3, the null hypothesis of $H_{0}:$ WACC $^{c c}=$ WACC is rejected at the $5 \%$ level, or in other words there is, on average, $95 \%$ chance that the Commission's WACC for electricity line businesses is underestimated.

The second case study is derived from a more recent Commission report (Commerce Commission (2007)) which is on regulating the supply control of the natural gas distribution services by Powerco Ltd and Vector Ltd. The WACC in the study has similar roles compared to the one in electricity line businesses, which is for the price control and the profits assessment. The relevant parameters are given by

$$
\begin{array}{lll}
L=0.4 & \beta_{e}=0.93 & T_{c}=T_{I}=0.33 \\
R_{f}=0.0588 & M R P=0.07 & k_{d}=0.0688
\end{array}
$$

The Commission used the same methodology to calculate the WACC which is reported equal to $8.13 \%{ }^{3}$ and the standard deviation is equal to $1.5 \%$. As noted, the equity beta in this case study is higher than the one in the previous study. Consequently, with other parameter values remaining the same or being similar, applying the theoretical CAPM will yield a higher WACC $(8.13 \%$ v.s. $7.3 \%)$.

On the other hand, will the same situation occur if the empirical CAPM is applied? Table 5.4 summarizes the WACC and its 95\% confidence interval (the methods used are the same as in the first case study with some pa-

\footnotetext{
${ }^{3}$ In the report, it uses the different corporate tax rate and investor tax rate after the $31^{\text {th }}$ Mar 2008. Therefore, it produces two WACC estimates before and after this date. I use the one calculated before the date as our data period is not beyond 2008 .
} 
rameter values changed, e.g, $R_{f}$ and $\left.k_{d}\right)$, and the Commission's estimates.

\section{Table 5.4: The WACC and its $95 \%$ confidence interval for gas pipeline businesses estimated using the empirical CAPM}

This table shows the WACC and its 95\% confidence interval estimated using the empirical CAPM and the Commission's method. Reported from the commission's study, the WACC is equal to $8.13 \%$ and the standard deviation equals $1.5 \%$, which gives a $95 \%$ confidence interval of $5.19 \%(8.13 \%-1.96 \times 1.5 \%)$ and $11.07 \%(8.13 \%+1.96 \times 1.5 \%)$.

\begin{tabular}{lcccc}
\hline Estimation methods & Lower bound & Mean & Upper bound & Std Err \\
\hline FM SB: OLS & $6.52 \%$ & $11.4 \%$ & $16.36 \%$ & $2.51 \%$ \\
FM SB: SW & $7.16 \%$ & $11.9 \%$ & $16.71 \%$ & $2.43 \%$ \\
FM PB: OLS+OLS & $6.36 \%$ & $11.3 \%$ & $16.34 \%$ & $2.55 \%$ \\
FM PB: SW+SW & $6.94 \%$ & $11.8 \%$ & $16.63 \%$ & $2.47 \%$ \\
FM PB: SW+OLS & $6.75 \%$ & $11.6 \%$ & $16.50 \%$ & $2.49 \%$ \\
\hline Commission's estimates & $5.19 \%$ & $8.13 \%$ & $11.07 \%$ & $1.5 \%$ \\
\hline
\end{tabular}

Again, Table 5.4 illustrates that the Commission may underestimate the WACC compared with ones estimated using the empirical CAPM. Overall, the mean value of the WACC is underestimated by approximately $3 \%$. In addition, it seems that the Commission calculated a relatively small standard error (1.5\%) for the WACC estimate, which is, however, not produced from any statistically-sound way. For example, with the standard 
errors being provided for the relevant parameters, the Commission simply aggregates them in line with the CAPM formula to yield the standard error of the cost of equity, which only takes into account of possible errors in the input variables and ignores the potential for specification error in the model.

In contrast, this paper provides a solution for the problem arising from the Commission's method to calculate the standard error. The possible errors arising from the specification in the model are captured in $\gamma_{i}^{\star}$. Furthermore, as the empirical CAPM is estimated from the market data, it automatically incorporates estimation errors from proxies of the risk free rate and the return on the market portfolio respectively. With two sources of error retaining in the WACC estimates, the standard error reported in this paper is consequently larger.

Figure 5.1 shows distributions for all WACC estimates. Knowing the mean and standard deviation, each curve in the graph is plotted assuming the WACC is normally distributed. The distribution of the Commission's WACC is to the left of mine with less spread, which is because the less mean value and the smaller standard error. On the other hand, distributions of WACC estimated using empirical CAPMs are very similar to each other, which signals the robustness of estimation results ${ }^{4}$.

Table (5.5) is constructed in the same way as for the first case study. It

\footnotetext{
${ }^{4}$ All results presented in this chapter are replicated and presented in the Appendix (Table 7.7 and Figure 7.3), where the alternative proxy for the risk free rate, the capital gain return on the bond, is used. It appears that results are robust to the different choice of proxies for the risk free rate as well.
} 
Figure 5.1: The distribution of the WACC calculated using the theoretical and empirical CAPM

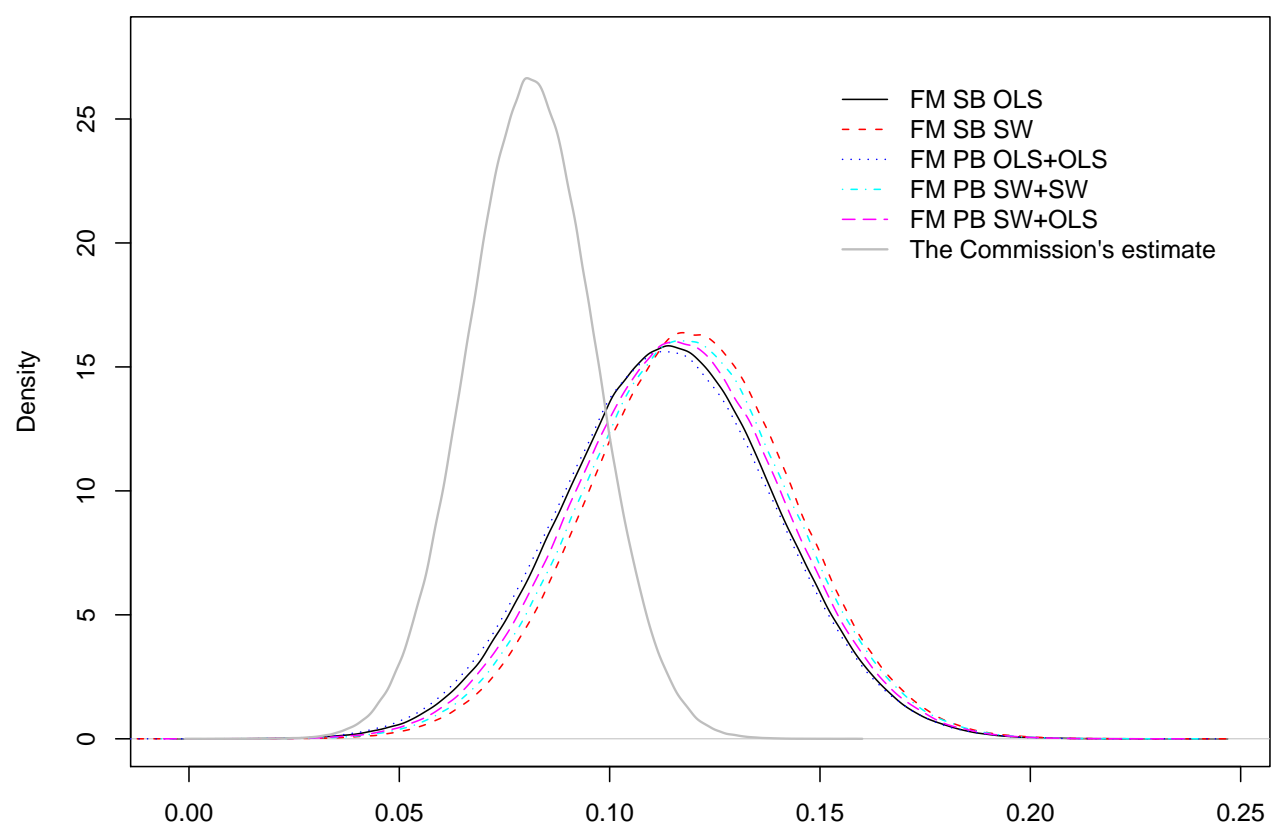

also illustrates that the Commission' WACC for gas pipeline businesses is, highly likely ( $90 \%$ on average), underestimated if assuming the true WACC distribution is equal to what have been estimated in this paper.

These case studies demonstrate that the Commission's WACC estimates may understate the cost of capital required by the New Zealand market (with high probabilities). The WACCs are understated by approximately $5.5 \%$ for electricity line business and 3.5\% for the gas pipeline businesses. Although our estimates have larger standard errors, they are estimated in a statistically-sound way compared to the Commission's estimates. 


\section{Table 5.5: The probability of the underestimation of the Commission's WACC: case study 2}

This table shows the probability of the underestimation of the Commission's WACC. The mean and standard error of the "true" WACC are assumed to be the estimate from this paper. Test statistics, $Z$, is calculated using (5.10). "P-value" is calculated under the alternative hypothesis of $H_{a}$ : WACC ${ }^{c c}<$ WACC. The probability of underestimation is given by $(1-\mathrm{P}$-value $)$

\begin{tabular}{lccccc}
\hline Method & Mean & Std Err & Z & P-value & $\begin{array}{c}\text { Probability } \\
\text { of underestimation }\end{array}$ \\
\hline FM SB: OLS & $11.4 \%$ & $2.51 \%$ & -1.30 & 0.1 & 0.90 \\
FM SB: SW & $11.9 \%$ & $2.43 \%$ & -1.55 & 0.06 & 0.94 \\
FM PB: OLS+OLS & $11.3 \%$ & $2.55 \%$ & -1.24 & 0.11 & 0.89 \\
FM PB: SW+SW & $11.8 \%$ & $2.47 \%$ & -1.48 & 0.07 & 0.93 \\
FM PB: SW+OLS & $11.6 \%$ & $2.49 \%$ & -1.39 & 0.08 & 0.92 \\
\hline
\end{tabular}

Moreover, the estimated empirical CAPMs show that the market is not as responsive to the systematic risk as the CAPM theory states, therefore, using the theoretical model may misinterpret how systematic risks are truly valued by the market. Consequently, the Commission's WACC estimates may not be the true value or an even a good estimate of the true value.

Last but not least, applying either the theoretical or empirical CAPM to calculate the WACC should be viewed with great caution, especially for businesses in regulatory settings. Both forms of CAPM only value sys- 
tematic risks without considering unsystematic risks that are often taken into account by regulated-business-investors. Therefore, applying either the theoretical or empirical CAPM as a part for calculating the WACC may undervalue the cost of capital required by the market and investors in New Zealand. 


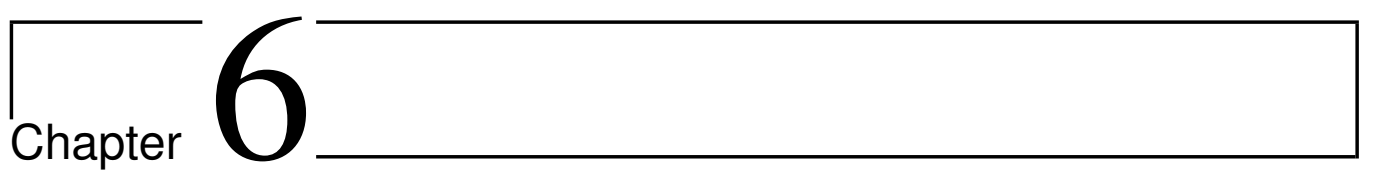

\section{Conclusion}

Outlined in the Commission's draft guideline, the cost of equity, the key component in the calculation of the cost of capital, is estimated using the "strict" version of the capital asset pricing model, whose empirical reliability has been consistently questioned for the past 3 decades. In contrast, I propose to use the empirical CAMP to calculate the cost of equity, which is then used in the calculation of the cost of capital for regulated businesses. I believe there are two advantages for using the empirical CAPM. It provides a point estimate that reflects the expected return required by the market, in addition, it also offers a better estimate of the size of the estimation error of the cost of equity and the cost of capital.

The empirical CAPM is estimated using the framework from Fama and MacBeth (1973) with the latest New Zealand data. In the process of estimating the empirical CAPM, the ordinary least square method was applied to estimate stock and portfolio betas. Scholes and Williams (1977) model was adopted to overcome the thin trading problem. The monthly 
data and the OLS method are used for the baseline case while weekly data and Scholes-William model are applied for a check of robustness.

Results from the baseline case and the robustness check show that the empirical CAPM is virtually a flat line with wide confidence intervals. The cost of equity calculated using the empirical CAPM contains large standard errors, which reflect the great uncertainty in the empirical relationship between the expected return and the systematic risk in New Zealand. The estimated empirical CAPM is applied to calculate the costs of capital for two case studies derived from the Commission's reports on electricity line businesses (Commerce Commission (2005b)) and gas pipeline businesses (Commerce Commission (2007)). It is found that the empiricalCAPM-based-WACC has relatively larger standard errors compared with ones calculated using the theoretical CAPM. This may be because that the Commission does not use any statistically-sound way to estimate its standard errors. The Commission's WACC estimates also tend to underestimate the cost of capital required by the investor compared with estimates from this paper $-7.35 \%$ compared to $12.5 \%$ (on average) for electricity line businesses, and $8.13 \%$ compared to $11.5 \%$ (on average) for gas pipeline businesses.

Caution should be used when applying either model in a regulatory setting. The cost of capital for regulated businesses can directly affect investors' incentives for investment, which can have profound effects on capital investments in New Zealand and national economic growth. Using either the theoretical or empirical CAPM to determine the cost of capital should just be the starting point, not the conclusion for decision makers. 


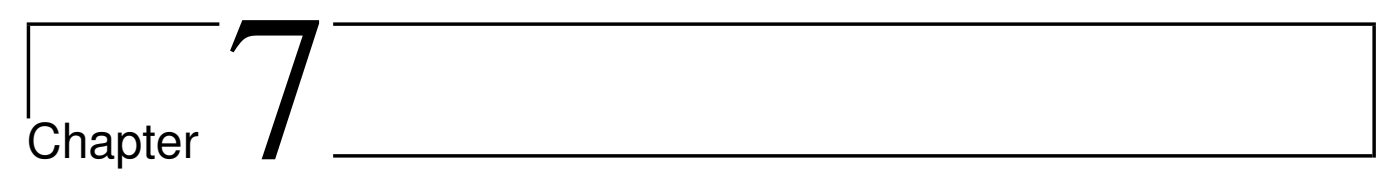

Appendix 


\section{Table 7.1: Stock betas estimated using the SW method with monthly data}

This table shows stock beta estimates. Stocks are selected based on 2 criteria: 1.) a selected stock must have at least two latest years of returns available (out of 3 years of beta estimation period) in order to estimate stock betas. 2.) a selected stock must also have all returns available in the following year in order to perform the cross-sectional regression. The second column shows the number of stocks meeting both conditions. Following columns present the summary statistics of estimated stock betas. The last column shows the value-weight stock betas for each estimation period, which is calculated by taking the average of market capitalization of each stock at each period (90-92, 91-93 etc), dividing it by the sum of all stocks' average market capitalization at the same period to yield $w_{i}$, and finally applying Equation (4.1).

\begin{tabular}{lccccc}
\hline & No. of stocks & Min & Median & Max & Mean $^{V}$ \\
\hline $1990-1992$ & 86 & -1.31 & 0.85 & 3.85 & 1.05 \\
$1991-1993$ & 90 & -10.69 & 0.11 & 12.13 & 0.85 \\
$1992-1994$ & 99 & -2.25 & 0.74 & 7.13 & 1.00 \\
$1993-1995$ & 104 & -1.58 & 1.12 & 6.89 & 1.07 \\
$1994-1996$ & 112 & -2.59 & 0.98 & 4.75 & 1.05 \\
$1995-1997$ & 110 & -2.94 & 1.00 & 9.18 & 1.19 \\
$1996-1998$ & 107 & -1.13 & 1.07 & 5.13 & 1.08 \\
$1997-1999$ & 113 & -1.47 & 0.93 & 4.86 & 0.90 \\
$1998-2000$ & 104 & -2.80 & 1.04 & 3.36 & 0.91 \\
$1999-2001$ & 105 & -5.94 & 0.73 & 6.48 & 1.05 \\
$2000-2002$ & 116 & -3.70 & 0.85 & 4.86 & 0.99 \\
$2001-2003$ & 119 & -6.20 & 0.79 & 6.87 & 1.05 \\
$2002-2004$ & 114 & -4.44 & 1.08 & 9.04 & 0.88 \\
$2003-2005$ & 113 & -2.80 & 1.11 & 5.37 & 1.00 \\
\hline
\end{tabular}


Figure 7.1: The Histogram of $\hat{\gamma}_{i, t}$ estimated where the SW method is used to estimate stock betas

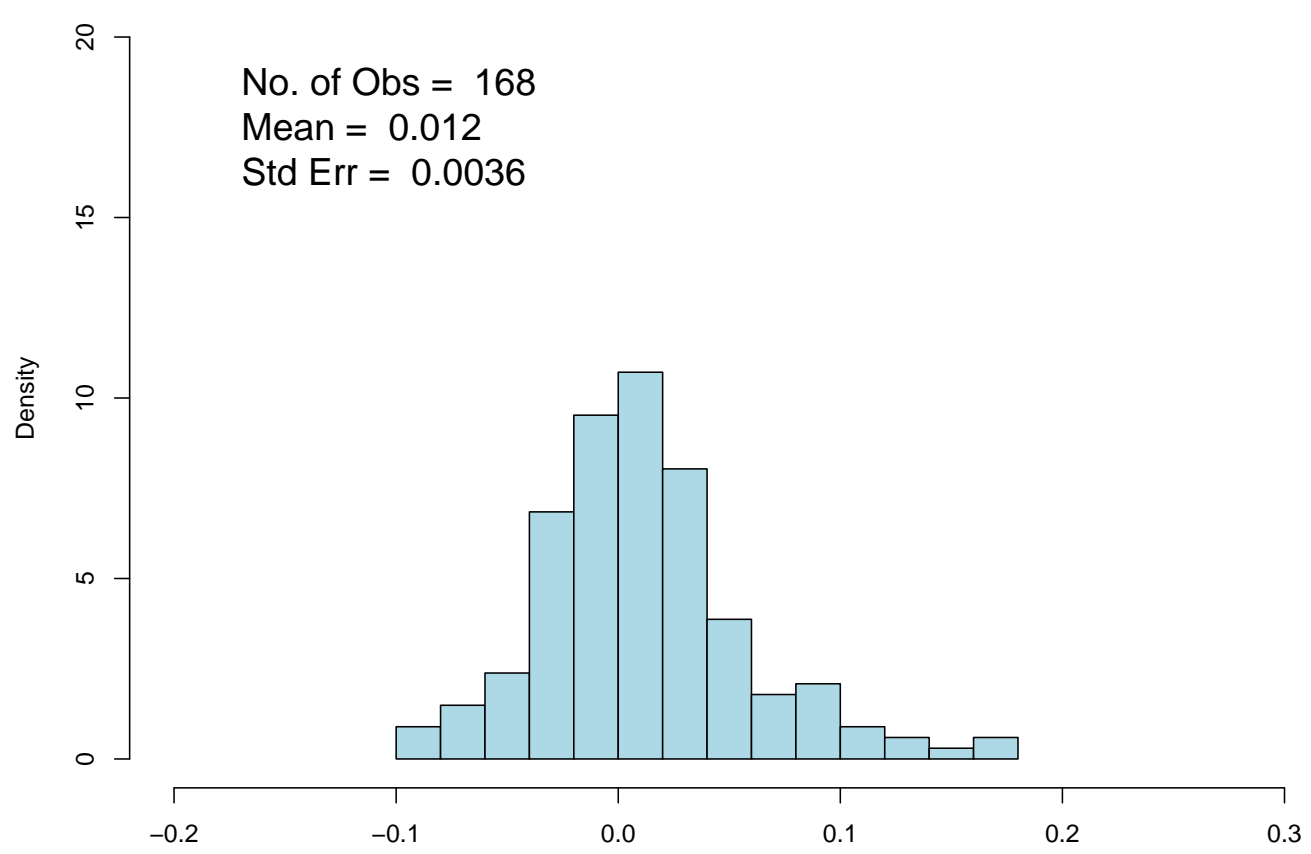

(a) $\gamma_{0, t}$

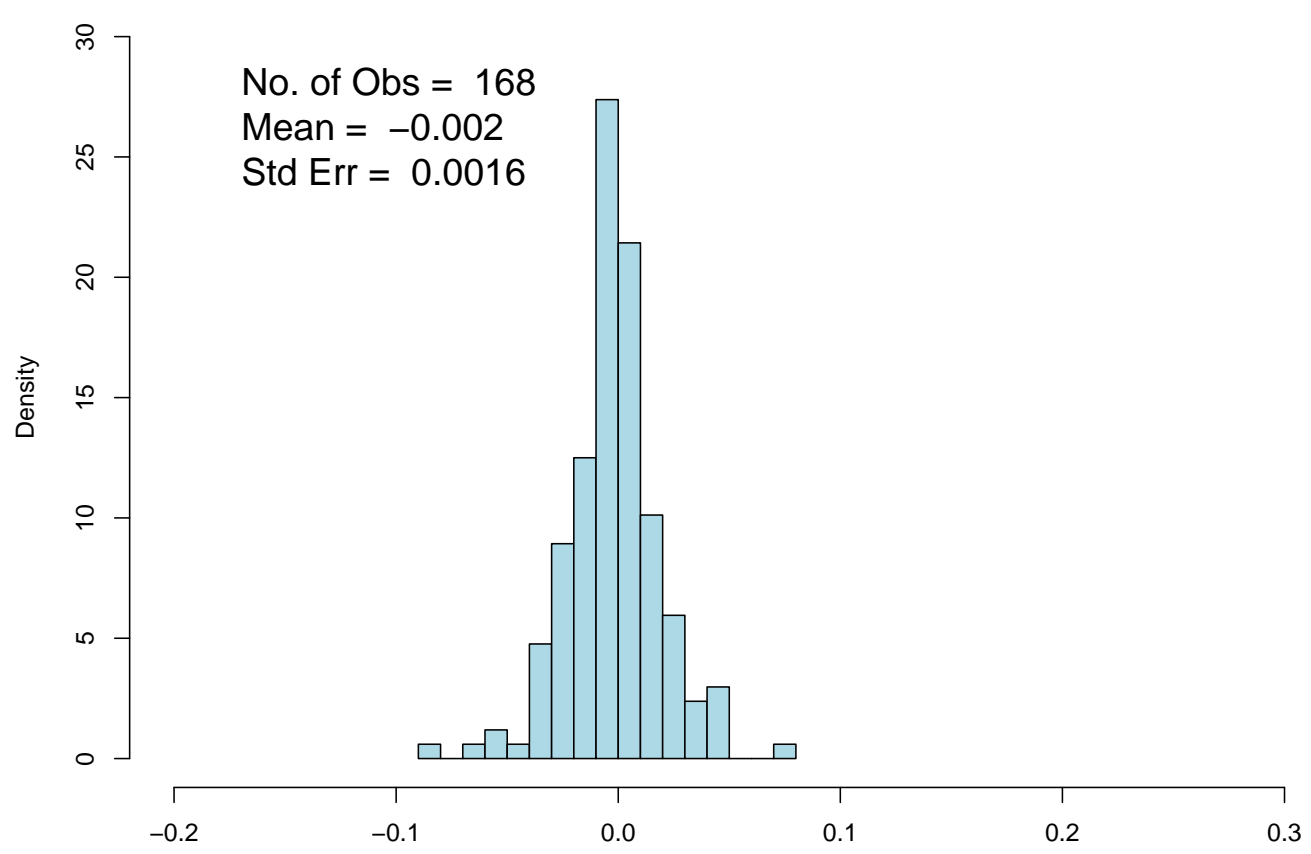

(b) $\gamma_{1, t}$ 


\section{Table 7.2: The summary of portfolio betas estimated using the combination of the SW and OLS method}

Portfolio betas are estimated by regressing portfolio returns on market portfolio returns for the entire period - 1993-2006. $\hat{\alpha}$ is the estimated intercept coefficient, which is scaled up by 100 times in order to be visible in 3 decimal places; $\hat{\beta}$ is the estimated slope coefficient. The bracketed numbers are t-statistics of null hypothesis if $\alpha=0$ or $\beta=0$. "SW+SW" means the SW method is used for estimating stock betas while the same method is used for estimating portfolio betas. "SW+OLS" means the SW method is used for estimating stock betas while the OLS method is used for estimating portfolio betas.

\begin{tabular}{rllllllllll}
\hline \multicolumn{10}{c}{ SW+SW } \\
\hline & P1 & P2 & P3 & P4 & P5 & P6 & P7 & P8 & P9 & P10 \\
\hline $100 \alpha$ & 0.12 & 0.44 & 0.15 & 0.12 & 0.42 & 0.94 & 0.43 & 0.49 & 0.18 & 0.65 \\
& $(0.25)$ & $(1.05)$ & $(0.39)$ & $(0.33)$ & $(1.31)$ & $(1.79)$ & $(1.7)$ & $(1.33)$ & $(0.43)$ & $(0.92)$ \\
$\beta$ & 0.98 & 1.01 & 0.60 & 0.99 & 0.90 & 1.26 & 0.99 & 1.15 & 1.04 & 0.84 \\
& $(8.43)$ & $(10.53)$ & $(6.51)$ & $(12)$ & $(12.57)$ & $(10.28)$ & $(17.27)$ & $(12.67)$ & $(10.33)$ & $(4.71)$ \\
\hline \hline & & & & \multicolumn{1}{c}{ SW+OLS } & & & & \\
\hline $100 \alpha$ & 0.42 & 0.58 & 0.02 & 0.19 & 0.48 & 1.07 & 0.48 & 0.39 & 0.28 & 0.48 \\
& $(0.96)$ & $(1.7)$ & $(0.05)$ & $(0.62)$ & $(1.83)$ & $(2.44)$ & $(2.13)$ & $(1.03)$ & $(0.71)$ & $(0.66)$ \\
$\beta$ & 0.63 & 0.74 & 0.82 & 0.85 & 0.83 & 0.98 & 0.90 & 1.22 & 0.90 & 1.04 \\
& $(6.04)$ & $(9.16)$ & $(9.69)$ & $(11.78)$ & $(13.44)$ & $(9.4)$ & $(16.69)$ & $(13.58)$ & $(9.61)$ & $(6.04)$ \\
\hline
\end{tabular}




\section{Table 7.3: Stock betas estimated using the OLS and SW methods with weekly data}

This table shows the information on the estimation of stock betas. Stocks are selected based on the 2 criteria: 1.) a selected stock must have at least the 30 latest weeks of returns available (out of 1 year of beta estimation period) in order to estimate the stock beta. 2.) a selected stock must also have all returns available in the following year in order to form portfolio returns. The second column shows the number of stocks meeting both conditions. The following columns present the summary statistics of the estimated stock betas. The last column shows the value-weight stock beta for each estimation period, which is calculated by taking the average of market capitalization from each stock in each period (1-week90 to 52-week-90 etc), dividing it by the sum of all stocks' average market capitalization at the same period to yield $w_{i}$ and finally applying Equation (4.1).

\begin{tabular}{lccc}
\hline & & OLS & SW \\
\cline { 3 - 4 } & No. of stocks & Mean $^{V}$ & Mean $^{V}$ \\
\hline 1990 & 82 & 0.98 & 0.91 \\
1991 & 86 & 0.94 & 1.04 \\
1992 & 92 & 1.00 & 0.98 \\
1993 & 102 & 0.95 & 0.96 \\
1994 & 123 & 1.00 & 1.00 \\
1995 & 119 & 0.90 & 0.95 \\
1996 & 120 & 0.97 & 1.03 \\
1997 & 122 & 1.02 & 1.03 \\
1998 & 120 & 0.90 & 0.86 \\
1999 & 122 & 0.91 & 0.98 \\
2000 & 114 & 0.99 & 0.97 \\
2001 & 124 & 0.87 & 0.94 \\
2002 & 126 & 0.99 & 1.01 \\
2003 & 128 & 0.98 & 0.96 \\
2004 & 128 & 0.97 & 1.02 \\
2005 & 131 & 0.93 & 1.03 \\
\hline
\end{tabular}




\section{Table 7.4: The summary of portfolio betas estimated using combinations of the SW and OLS methods with weekly data}

Portfolio betas are estimated by regressing portfolio returns on market portfolio returns for the entire period -1993-2006. $\hat{\alpha}$ is the estimated intercept coefficient, which is scaled up by 100 times in order to be visible in 3 decimal places; $\hat{\beta}$ is the estimated slope coefficient. The bracketed numbers are t-statistics of null hypothesis if $\alpha=0$ or $\beta=0$. "SW+SW" means the SW method is used for estimating stock betas while the same method is used for estimating portfolio betas. "SW+OLS" means the SW method is used for estimating stock betas while the OLS method is used for estimating portfolio betas and so forth.

\begin{tabular}{|c|c|c|c|c|c|c|c|c|c|c|}
\hline \multicolumn{11}{|c|}{ OLS+OLS } \\
\hline & $\mathrm{P} 1$ & $\mathrm{P} 2$ & P3 & $\mathrm{P} 4$ & P5 & P6 & P7 & P8 & P9 & P10 \\
\hline \multirow[t]{2}{*}{$100 \alpha$} & 0.48 & 0.25 & 0.22 & 0.17 & 0.1 & 0.28 & 0.14 & -0.09 & -0.11 & 0.03 \\
\hline & (2.88) & (2.9) & $(2.96)$ & (2.4) & (1.43) & $(3.87)$ & $(1.76)$ & $(-1.25)$ & $(-1.36)$ & $(0.36)$ \\
\hline \multirow[t]{2}{*}{$\beta$} & 0.45 & 0.4 & 0.33 & 0.48 & 0.47 & 0.6 & 0.59 & 0.62 & 0.84 & 0.95 \\
\hline & (5.64) & $(9.97)$ & (9.38) & (14.63) & (14.26) & (17.7) & $(16.17)$ & (18.12) & (22.59) & (21.83) \\
\hline \multicolumn{11}{|c|}{$\mathrm{SW}+\mathrm{SW}$} \\
\hline & P1 & P2 & P3 & P4 & P5 & P6 & P7 & P8 & P9 & P10 \\
\hline \multirow[t]{2}{*}{$100 \alpha$} & 0.12 & 0.17 & 0.17 & 0.16 & 0.04 & 0.07 & -0.07 & -0.09 & 0.05 & 0.12 \\
\hline & $(0.89)$ & (2.17) & (1.69) & (2.23) & $(0.52)$ & (1.26) & $(-0.99)$ & $(-1.25)$ & $(0.63)$ & (1.18) \\
\hline \multirow[t]{2}{*}{$\beta$} & 0.52 & 1.06 & 0.92 & 0.62 & 1.05 & 0.9 & 1.19 & 1.11 & 1.45 & 0.84 \\
\hline & $(7.64)$ & (26.27) & (19.17) & (17.99) & (30.29) & (30.18) & (33.2) & (30.23) & (41.24) & (15.63) \\
\hline \multicolumn{11}{|c|}{ SW+OLS } \\
\hline & P1 & $\mathrm{P} 2$ & P3 & P4 & P5 & P6 & P7 & P8 & P9 & P10 \\
\hline \multirow[t]{2}{*}{$100 \alpha$} & 0.14 & 0.25 & 0.21 & 0.17 & 0.08 & 0.11 & -0.02 & -0.04 & 0.12 & 0.11 \\
\hline & $(1.02)$ & (2.84) & $(2.27)$ & $(2.37)$ & (1.05) & (1.7) & $(-0.26)$ & $(-0.54)$ & $(1.57)$ & $(0.91)$ \\
\hline \multirow[t]{2}{*}{$\beta$} & 0.39 & 0.43 & 0.5 & 0.48 & 0.69 & 0.54 & 0.73 & 0.64 & 0.81 & 0.98 \\
\hline & (6.13) & (10.47) & (11.22) & (14.09) & (19.83) & (17.21) & $(21.26)$ & (18.12) & (23.45) & (17.61) \\
\hline
\end{tabular}




\section{Table 7.5: The summary of $\gamma_{i}^{\star}-$ FM SB: OLS and SW; FM PB: OLS+OLS, SW+SW and SW+OLS (with the alternative risk free rate)}

The table presents all $\gamma_{i}^{\star}$. Results for FM SB: OLS and SW, and FM PB: OLS+OLS are obtained from Table 4.2 and 4.5 respectively. OLS+OLS, SW+SW and SW+OLS represent combinations of method. The first method is the method used to estimate stock betas while the second is for estimating portfolio betas. Results from the OLS+OLS combination are the baseline results while ones from the SW+SW and SW+OLS combinations are for the robustness check.

\begin{tabular}{ccccc}
\hline \multicolumn{6}{l}{ FM SB: OLS } \\
\hline & $\gamma_{i}^{\star}$ & $\hat{\sigma}\left(\gamma_{i}^{\star}\right)$ & P-value & $c \hat{o} v\left(\gamma_{0}^{\star}, \gamma_{1}^{\star}\right)$ \\
\cline { 2 - 5 }$\gamma_{0, t}$ & $1.54 \%$ & $0.37 \%$ & 0 & $-4.96 \times 10^{-6}$ \\
$\gamma_{1, t}$ & $-0.42 \%$ & $0.30 \%$ & 0.16 & $-4.96 \times 10^{-6}$ \\
\hline \hline
\end{tabular}

FM SB: SW

\begin{tabular}{ccccc}
\hline & $\gamma_{i}^{\star}$ & $\hat{\sigma}\left(\gamma_{i}^{\star}\right)$ & P-value & $\operatorname{cô} v\left(\gamma_{0}^{\star}, \gamma_{1}^{\star}\right)$ \\
\cline { 2 - 5 }$\gamma_{0, t}$ & $1.46 \%$ & $0.34 \%$ & 0 & $-2.05 \times 10^{-6}$ \\
$\gamma_{1, t}$ & $-0.20 \%$ & $0.20 \%$ & 0.32 & $-2.05 \times 10^{-6}$ \\
\hline \hline
\end{tabular}

FM PB: OLS+OLS

\begin{tabular}{ccccc}
\hline & $\gamma_{i}^{\star}$ & $\hat{\sigma}\left(\gamma_{i}^{\star}\right)$ & P-value & $\operatorname{cô} v\left(\gamma_{0}^{\star}, \gamma_{1}^{\star}\right)$ \\
\cline { 2 - 5 }$\gamma_{0}$ & $2.66 \%$ & $0.71 \%$ & 0 & $-5.15 \times 10^{-5}$ \\
$\gamma_{1}$ & $-1.71 \%$ & $0.82 \%$ & 0.037 & $-5.14 \times 10^{-5}$ \\
\hline \hline
\end{tabular}

FM PB: SW+SW

\begin{tabular}{ccccc}
\hline & $\gamma_{i}^{\star}$ & $\hat{\sigma}\left(\gamma_{i}^{\star}\right)$ & P-value & $c \hat{c o v}\left(\gamma_{0}^{\star}, \gamma_{1}^{\star}\right)$ \\
\cline { 2 - 5 }$\gamma_{0, t}$ & $1.14 \%$ & $0.74 \%$ & 0.12 & $-5.41 \times 10^{-5}$ \\
$\gamma_{1, t}$ & 0.065 & $0.81 \%$ & 0.94 & $-5.41 \times 10^{-5}$ \\
\hline \hline
\end{tabular}

FM PB: SW+OLS

\begin{tabular}{ccccc}
\hline & $\gamma_{i}^{\star}$ & $\hat{\sigma}\left(\gamma_{i}^{\star}\right)$ & P-value & $\operatorname{cô} v\left(\gamma_{0}^{\star}, \gamma_{1}^{\star}\right)$ \\
\cline { 2 - 5 }$\gamma_{0, t}$ & $1.63 \%$ & $1.01 \%$ & 0.11 & $-1.13 \times 10^{-4}$ \\
$\gamma_{1, t}$ & $-0.49 \%$ & $1.17 \%$ & 0.68 & $-1.13 \times 10^{-4}$ \\
\hline
\end{tabular}


Table 7.6: The $95 \%$ confidence interval of the estimated annual tax-adjusted excess returns for two special securities: $\beta=0$ and $1-$ a summary (with the alternative risk free rate)

This table shows the $95 \%$ confidence interval constructed for the estimated annual taxadjusted excess returns of 2 special securities with $\beta=0$ and 1 respectively. All results presented in this table are either drawn from previous results or newly estimated

\begin{tabular}{lcccc}
\hline$\beta=0$ & & & & \\
\hline & Lower bound & Mean & Upper bound & Std Err \\
\cline { 2 - 5 } FM SB OLS & $11.4 \%$ & $20.2 \%$ & $28.9 \%$ & $4.45 \%$ \\
FM SB SW & $11.0 \%$ & $19.1 \%$ & $27.1 \%$ & $4.09 \%$ \\
FM PB OLS+OLS & $20.4 \%$ & $37.0 \%$ & $53.7 \%$ & $8.5 \%$ \\
FM PB SW+SW & $-2.75 \%$ & $14.6 \%$ & $32.0 \%$ & $8.9 \%$ \\
FM PB SW+OLS & $-2.47 \%$ & $21.5 \%$ & $45.5 \%$ & $12.2 \%$ \\
\hline \hline$\beta=1$ & & & & \\
\hline & Lower bound & Mean & Upper bound & Std Err \\
\cline { 2 - 5 } FM SB OLS & $5.96 \%$ & $14.3 \%$ & $22.7 \%$ & $4.27 \%$ \\
FM SB SW & $8.25 \%$ & $16.2 \%$ & $24.2 \%$ & $4.01 \%$ \\
FM PB: OLS+OLS & $2.95 \%$ & $12.0 \%$ & $21.1 \%$ & $4.63 \%$ \\
FM PB: SW+SW & $7.33 \%$ & $15.5 \%$ & $23.7 \%$ & $4.18 \%$ \\
FM PB: SW+OLS & $5.48 \%$ & $14.7 \%$ & $23.9 \%$ & $4.71 \%$ \\
\hline
\end{tabular}


Figure 7.2: The plot of the empirical and theoretical forms of the CAPM - a summary (with an alternative risk free rate)

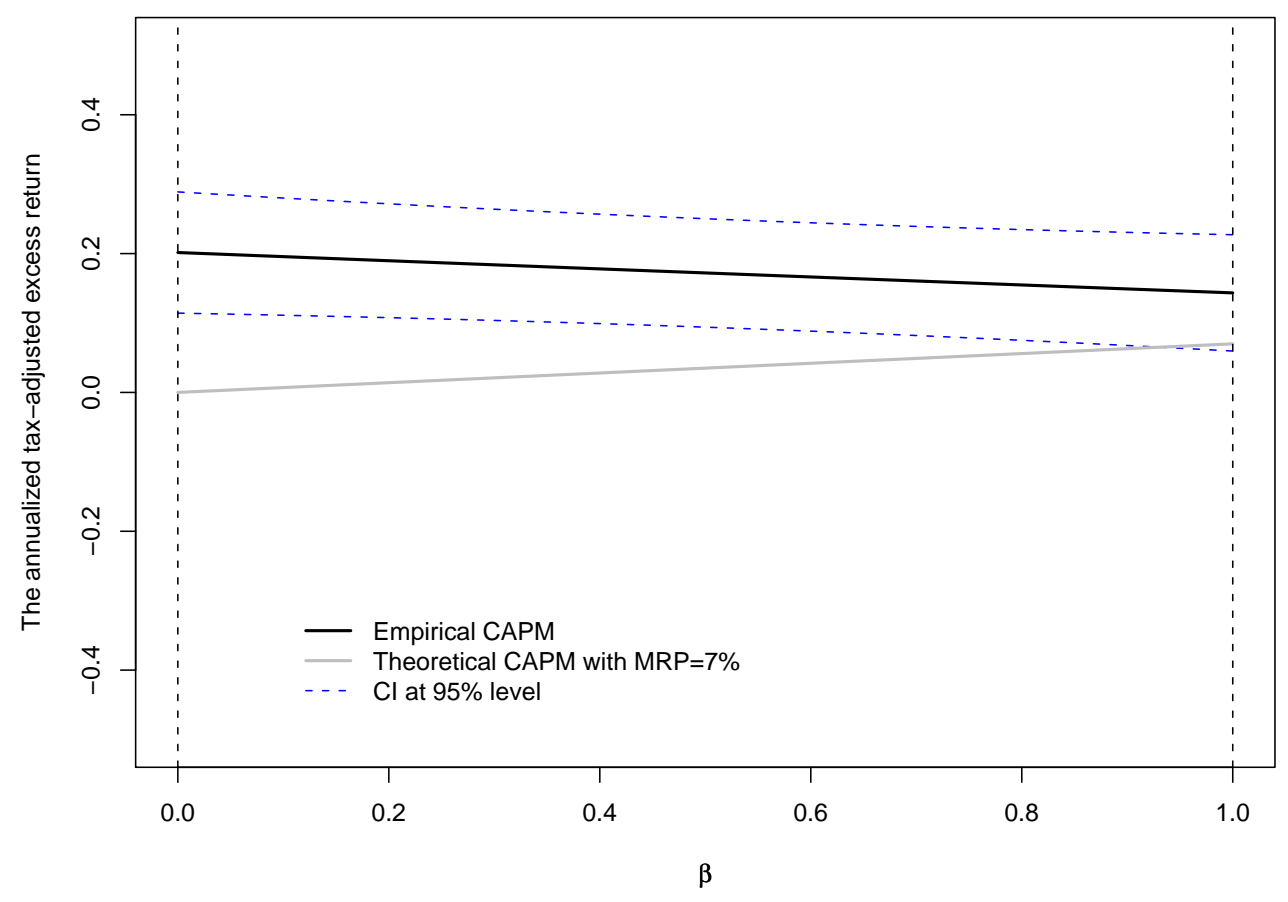

(a) FM SB: OLS

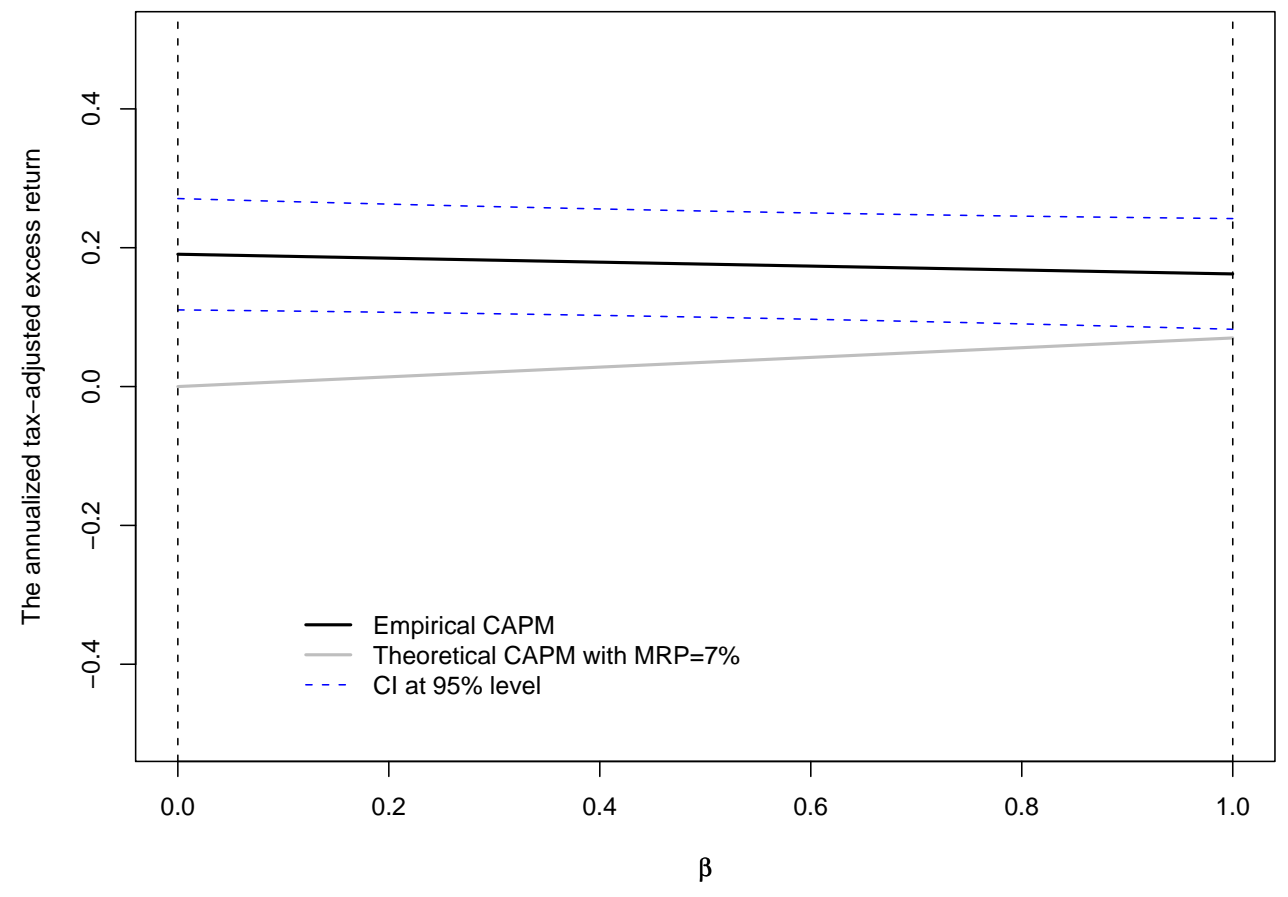

(b) FM SB: SW 


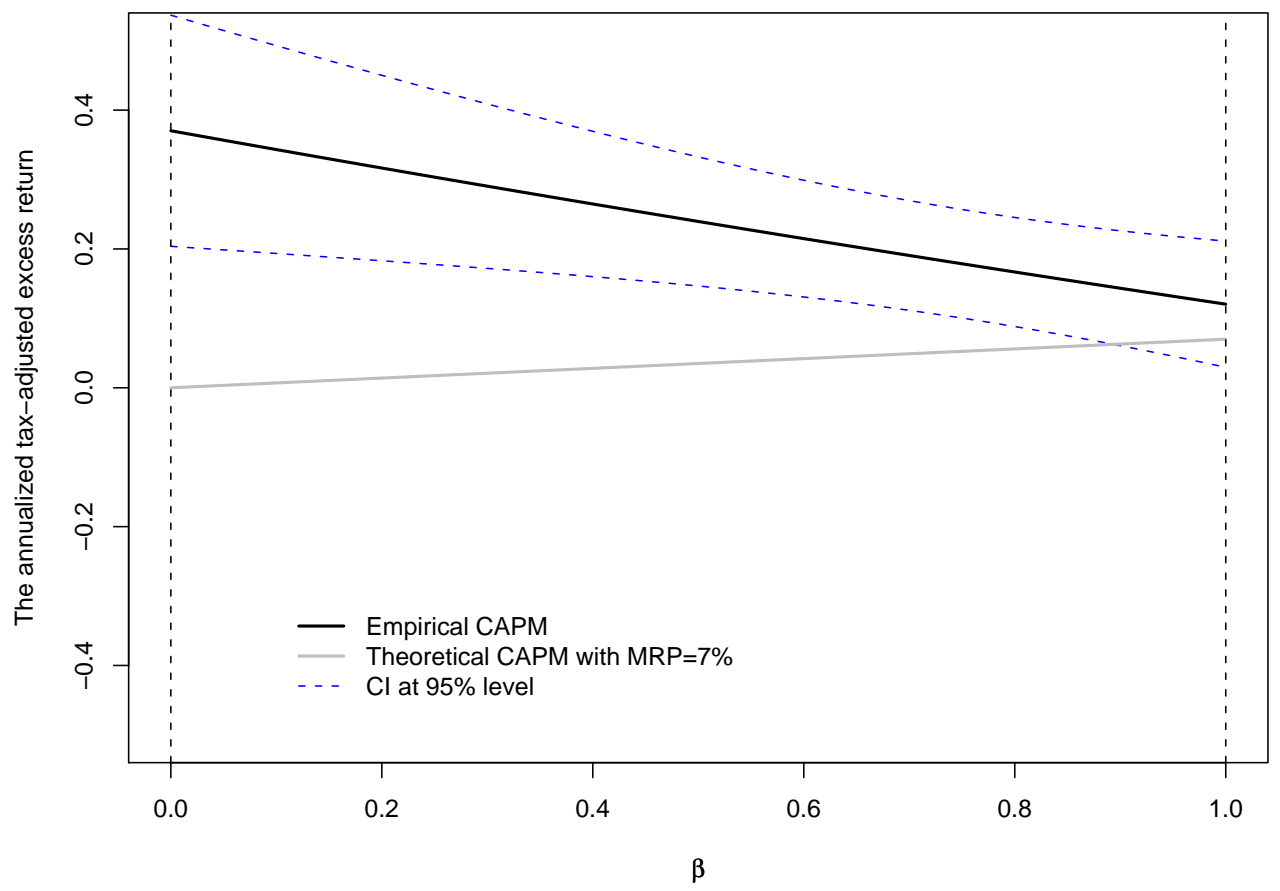

(c) FM PB: OLS+OLS

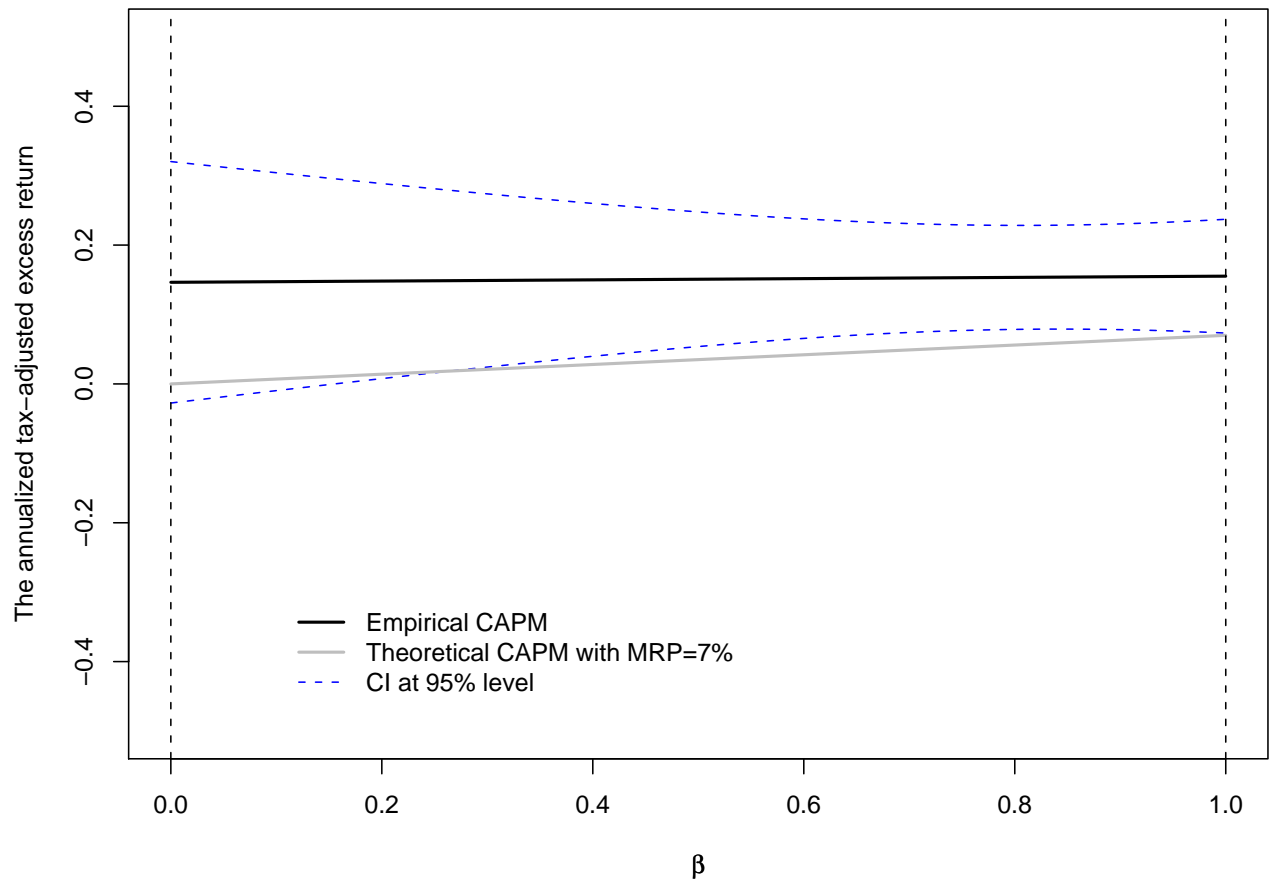

(d) FM PB: SW+SW 


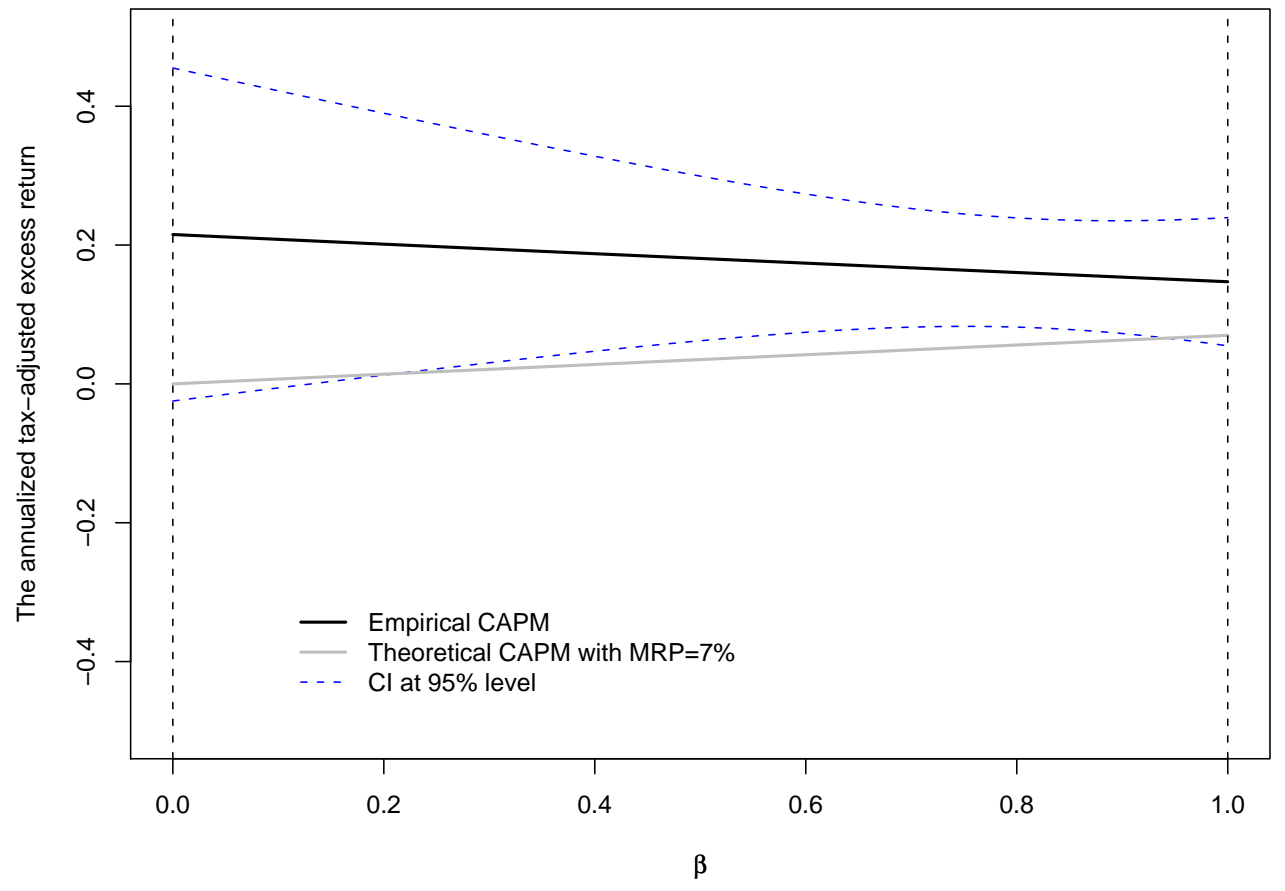

(e) FM PB: SW+OLS 
Table 7.7: The WACC of electricity line businesses and gas pipeline businesses estimated using the empirical CAPM - a summary (with an alternative risk free rate)

This table shows the estimated WACC and its 95\% confidence interval calculated from using the empirical CAPM and the Commission's method. From the commission's study, the WACC is equal to $8.13 \%$ and the standard deviation equals $1.5 \%$, which gives a $95 \%$ confidence interval of $5.19 \%(8.13 \%-1.96 \times 1.5 \%)$ and $11.07 \%(8.13 \%+1.96 \times 1.5 \%)$.

\begin{tabular}{lcccc}
\hline \multicolumn{5}{c}{ Case study I: electricity line businesses } \\
\hline Estimation methods & Lower Bound & Mean & Upper bound & Std Err \\
\hline FM SB OLS & $9.58 \%$ & $14.3 \%$ & $19.0 \%$ & $2.40 \%$ \\
FM SB SW & $10.22 \%$ & $14.8 \%$ & $19.4 \%$ & $2.35 \%$ \\
FM PB (OLS+OLS) & $11.16 \%$ & $16.4 \%$ & $21.2 \%$ & $2.45 \%$ \\
FM PB (SW+SW) & $8.86 \%$ & $13.7 \%$ & $18.5 \%$ & $2.46 \%$ \\
FM PB (SW+OLS) & $9.35 \%$ & $14.7 \%$ & $20.0 \%$ & $2.73 \%$ \\
\hline Commission's estimates & & $7.35 \%$ & \\
\hline \hline & Case study II: pipeline business & \\
\hline Estimation methods & Lower Bound & Mean & Upper bound & Std Err \\
\hline FM SB OLS & $8.12 \%$ & $13.1 \%$ & $17.98 \%$ & $2.51 \%$ \\
FM SB SW & $9.33 \%$ & $14.1 \%$ & $18.79 \%$ & $2.41 \%$ \\
FM PB (OLS+OLS) & $7.31 \%$ & $12.4 \%$ & $17.48 \%$ & $2.60 \%$ \\
FM PB (SW+SW) & $8.84 \%$ & $13.5 \%$ & $18.13 \%$ & $2.37 \%$ \\
FM PB (SW+OLS) & $8.29 \%$ & $13.3 \%$ & $18.34 \%$ & $2.56 \%$ \\
\hline Commission's estimates & $5.19 \%$ & $8.13 \%$ & $11.07 \%$ & $1.5 \%$ \\
\hline
\end{tabular}


Table 7.8: The probability of the underestimation of the Commission's WACC for both studies - a summary (with alternative risk free rate)

This table shows the probabilities of the underestimation of the Commission's WACC. The mean and standard error of the "true" WACC are assumed to be estimates from this paper. Test statistics, $Z$, is calculated from (5.10). "P-value" is calculated under the alternative hypothesis of $H_{a}:$ WACC $^{c c}<$ WACC. The probability of underestimation is given by (1 - P-value $)$

Case study I: electricity line businesses

\begin{tabular}{lccccc}
\hline Method & Mean & Std Err & Z & P-value & $\begin{array}{c}\text { Probability } \\
\text { of underestimation }\end{array}$ \\
\hline FM SB: OLS & $14.3 \%$ & $2.40 \%$ & -2.90 & 0.002 & 0.998 \\
FM SB: SW & $14.8 \%$ & $2.35 \%$ & -3.17 & 0.001 & 0.999 \\
FM PB: OLS+OLS & $16.4 \%$ & $2.45 \%$ & -3.69 & 0.001 & 0.999 \\
FM PB: SW+SW & $13.7 \%$ & $2.46 \%$ & -2.58 & 0.005 & 0.995 \\
FM PB: SW+OLS & $14.7 \%$ & $2.73 \%$ & -2.96 & 0.0041 & 0.996 \\
\hline \hline
\end{tabular}

Case study II: pipeline business

Probability

\begin{tabular}{lccccc} 
Method & Mean & Std Err & Z & P-value & of underestimation \\
\hline FM SB: OLS & $13.1 \%$ & $2.51 \%$ & -1.98 & 0.024 & 0.976 \\
FM SB: SW & $14.1 \%$ & $2.41 \%$ & -2.48 & 0.007 & 0.993 \\
FM PB: OLS+OLS & $12.4 \%$ & $2.60 \%$ & -1.64 & 0.05 & 0.95 \\
FM PB: SW+SW & $13.5 \%$ & $2.37 \%$ & -2.27 & 0.01 & 0.99 \\
FM PB: SW+OLS & $13.3 \%$ & $2.56 \%$ & -2.02 & 0.02 & 0.98 \\
\hline
\end{tabular}


Figure 7.3: The distribution of the WACC calculated using the theoretical and empirical CAPM (with an alternative risk free rate)






\section{Bibliography}

Banz, R. W. (1981). The relationship between return and market value of common stocks. Journal of Financial Economics, 9(1):3-18.

Bartholdy, J., Fox, K., Gilbert, C., Hibbard, R., McNoe, W., Potter, M., Shi, J., and Watt, K. (1996). Estimating beta for new zealand companies. New Zealand Investment Analyst, pages 14-22.

Bartholdy, J. and Riding, A. (1994). Thin trading and the estimation of betas: The efficacy of alternative techniques. Journal of Financial Research, 17/2:241-254.

BASU, S. (1983). The relationship between earnings' yield, market value and return for nyse common stocks: Further evidence. Journal of Financial Economics, 12:129-156.

Black, F., Jensen, M. C., and Scholes, M. (1972). The Capital Asset Pricing Model: Some Empirical Tests. Studies In The Theory Of Capital Markets (Praeger). 
Brennan, M. (1970). Taxes, market valuation and corporate financial policy. National Tax Journal, 23:417-427.

Bryant, P. S. and Eleswarapu, V. R. (1997). Cross-sectional determinants of New Zealand share market returns. Accounting and Finance, 37:181-205.

Casella, G. and Berger, R. L. (2002). Statistical Inference. 2nd edition.

Cliffe, C. and Marsden, A. (1992). The effect of dividend imputation on company financing decisions and the cost of capital in New Zealand. Pacific Accounting Review, 4:1-30.

Cohen, K. J., Hawawini, G. A., Maier, S. F., Schwartz, R. A., and Whitcomb, D. K. (1983). Friction in the trading process and the estimation of systematic risk. Journal of Financial Economics, 12(2):263-278.

Commerce Commission (2005a). Draft guidelines: The Commerce Commission's approach to estimating the cost of capital.

Commerce Commission (2005b). Regulation of electricity lines businesses, targeted control regime, intention to declare control. Technical report, New Zealand Commerce Commission.

Commerce Commission (2007). Authorisation for the control of supply of natural gas distribution services by Powerco Ltd and Vector Ltd. Technical report, New Zealand Commerce Commission.

Dimson, E. (1979). Risk measurement when shares are subject to infrequent trading. Journal of Financial Economics, 7:197-226. 
Fama, E. F. and French, K. R. (1992). The cross-section of expected stock returns. Journal of Finance, 47(2):427-465.

Fama, E. F. and MacBeth, J. D. (1973). Risk, return and equilibrium: Empirical tests. Journal of Political Economy, 81(3):607-636.

Fowler, D. J. and Rorke, C. H. (1983). Risk measurement when shares are subject to infrequent trading: Comment. Journal of Financial Economics, 12:279-283.

Handa, P., Kothari, S. P., and Wasley, C. (1993). Sensitivity of multivariate tests of the capital asset-pricing model to the return measurement interval. Journal of Finance, 48(4):1543-1551.

Jagannathan, R. and Wang, Z. (1996). The conditional capm and the crosssection of expected returns. Journal of Finance, 51(1):3-53.

Kan, R. and Zhang, C. (1999). Two-pass tests of asset pricing models with useless factors. Journal of Finance, LIV(1):203-235.

Lally, M. (1992). The CAPM Under Dividend Imputation. Pacific Accounting Review, 4:31-44.

Lintner, J. (1965). The valuation of risky assets and the selection of risky investments in stock portfolios and capital budgets. Review of Economics and Statistics, 47(1):13-37.

Roll, R. (1977). A critique of the asset pricing theory's tests: On past and potential testability of the theory. Journal of Financial Economics, 4(2):129176. 
Roll, R. and Ross, S. A. (1994). On the cross-sectional relation between expected returns and betas. Journal of Finance, 49(1):101-121.

Scholes, M. and Williams, J. (1977). Estimating betas from nonsynchronous data. Journal of Financial Economics, 5:309-327.

Sharpe, W. F. (1964). Capital asset prices: A theory of market equilibrium under conditions of risk. Journal of Finance, 19(3):425-442. 